\title{
Evaluation and Testing of Metering Pumps for High- Level Nuclear Waste Slurries
}

M. E. Peterson

J. M. Perez, Jr.

H. T. Blair

June 1986

Prepared for the U.S. Department of Energy under Contract DE-AC06-76RLO 1830

Pacific Northwest Laboratory Operated for the U.S. Department of Energy by Battelle Memorial Institute 


\title{
DISCLAIMER
}

This report was prepared as an account of work sponsored by an agency of the United States Government. Neither the United States Government nor any agency thereof, nor any of their employees, makes any warranty, express or implied, or assumes any legal liability or responsibility for the accuracy, completeness, or usefulness of any information, apparatus, product, or process disciosed, or represents that its use would not infringe privately owned rights. Reference herein to any specific commercial product, process, or service by trade name, trademark, manufacturer, or otherwise, does not necessarily constitute or imply its endorsement, recommendation, or favoring by the United States Government or any agency thereof. The views and opinions of authors expressed herein do not necessarily state or reflect those of the United States Government or any agency thereof.

\author{
PACIFIC NORTHWEST LABORATORY \\ operated by \\ BATTELLE \\ for the \\ UNITED STATES DEPARTMENT OF ENERGY \\ under Contract DE-AC06-76RLO 1830
}

\begin{tabular}{|c|c|}
\hline \multicolumn{2}{|c|}{ Printed in the United States of America } \\
\hline \multicolumn{2}{|c|}{$\begin{array}{c}\text { Available from } \\
\end{array}$} \\
\hline \multicolumn{2}{|c|}{ National Technical Information Service } \\
\hline \multirow{2}{*}{\multicolumn{2}{|c|}{$\begin{array}{l}\text { United States Department of Commerce } \\
5285 \text { Port Royal Road }\end{array}$}} \\
\hline & \\
\hline \multicolumn{2}{|c|}{ Springfield, Virginia 22161} \\
\hline \multirow{2}{*}{\multicolumn{2}{|c|}{$\begin{array}{l}\text { NIIS Price Codes } \\
\text { Microfiche A01 }\end{array}$}} \\
\hline & \\
\hline \multicolumn{2}{|c|}{ Printed Copy } \\
\hline & Price \\
\hline Pages & \\
\hline $001-025$ & A02 \\
\hline $026-050$ & $\mathrm{~A} 03$ \\
\hline 051-075 & A04 \\
\hline $076-100$ & A05 \\
\hline $101-125$ & $A 06$ \\
\hline $126-150$ & A07 \\
\hline $151-175$ & $A 08$ \\
\hline $176-200$ & $A 09$ \\
\hline $201-225$ & A010 \\
\hline $226-250$ & A011 \\
\hline $251-275$ & A012 \\
\hline $276-300$ & A013 \\
\hline
\end{tabular}


PNL -5851

UC -70

33679000442121

EVALUATION AND TESTING OF METERING PUMPS

FOR HIGH-LEVEL NUCLEAR WASTE SLURRIES

M. E. Peterson

J. M. Perez, Jr.

H. T. Blair

June 1986

Prepared for

the U.S. Department of Energy

under Contract DE-AC06-76RLO 1830

Pacific Northwest Laboratory

Richland, Washington 99352 


\section{ACKNOWLEDGMENTS}

The authors would like to thank E. J. Eschbach, J. T. Jeffs, and K. D. Muhlstein for their valuable assistance in the design, fabrication, and operation of the test equipment. The success of the test program would not have been possible without their excellent efforts. 


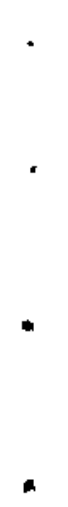

a 


\section{SUMMARY}

Commercial and defense nuclear activities in the United States have produced large volumes of high-level radioactive wastes. These wastes are currently stored as slurries in large underground storage tanks where they are isolated from the environment until a permanent and environmentally acceptable method for permanent storage is developed. The U.S. Department of Energy has programs underway to end this interim storage and achieve final disposal by concentrating and immobilizing these high-level liquid wastes (HLLW) and preparing them for shipment to a federal repository.

The internationally accepted form of immobilized HLLW is borosilicate glass. The process selected in the U.S. for converting the HLLW to glass uses the direct liquid-fed, joule-heated ceramic melter (Brouns 1984). In this vitrification process, HLLW, with much of the nonradioactive salts removed, is blended with glass-forming materials. The resulting slurry is metered into the refractory-lined melting tank. The water is driven off, and the various compounds decompose to form basic oxides that combine to form a homogeneous glass.

The metering pump system that delivers HLLW slurry to a melter is an integral subsystem of the vitrification process. The pump used to feed the slurry to the melter must satisfy many unique requirements because of the chemical, physical, and radiological properties of the slurry. In addition, special design constraints are placed on the pump by the requirement that it be fully capable of remote operation and maintenance.

The process of selecting a pump for this application began with a technical review of pumps typically used for slurry applications. The design and operating characteristics of numerous pumps were evaluated against established criteria. Two pumps, an air-displacement slurry (ADS) pump and an air-lift pump, were selected for further development at the Pacific Northwest Laboratory (PNL). The pump development was conducted under the Nuclear Waste Treatment Program and the Hanford Waste Vitrification Program.

In the development activity, from FY 1983 to FY 1985, the two pumps were subjected to long-term tests using simulated melter feed slurries to evaluate the pumps' performances. Throughout this period, the designs of both pumps 
were modified to better adapt them for this application. Final reference designs were developed for both the air-displacement slurry pump and the air$1 \mathrm{jft}$ pump. Successful operation of the final reference designs has demonstrated the feasibility of both pumps. A fully remote design of the ADS pump has been developed and is currently undergoing testing at the West Valley Demonstration Project (Peterson et al. 1985).

The simulated slurries used in the pump tests have been tailored to produce an acceptable glass product based on site-specific HLLW chemical and phys.ical properties. Slurries prepared to simulate the waste-glass compositions for two different sites were used. One slurry type evolved from glass development for a defense waste currently stored at the Hanford Site in southeast Washington. The second slurry evolved from glass development for a commercial waste currently stored at the West Valley Demonstration Project Site in southwest New York. As development of acceptable glass compositions has continued for each, the slurry compositions have also evolved. At the time of each pump test, the then-current composition was used. While these compositions are no longer considered the reference for these sites, their rheological properties are sufficiently representative of typical HLLW slurries and cover the normal range of both alkaline and acidic mixtures. The slurries tested provided a good demonstration of the pump's ability to perform in this application.

Five designs of the ADS pump were tested and evaluated. The initial four designs proved the operating concept of the ADS pump. Weaknesses in the ADS pump system were identified and eliminated in later designs. The final and reference design was subject to $3700 \mathrm{~h}$ of continuous testing. Flow rates ranging from 10 to $185 \mathrm{~L} / \mathrm{h}$ were achieved; however, flow rates below $20 \mathrm{~L} / \mathrm{h}$ were unstable. The effects of air pressure and cycle time on the pump flow rate were determined. Degradations of the set point flow rate were monitored and consequently signaled the need to water-flush the lines to remove any solid deposits. The slurry flow rate from the pump was found to be only slightly affected by the tank head. Because the chamber was gravity-filled, the pump chamber would not fill with a consistent volume of slurry at low tank heads. 
The flow rate from the pump was found to degrade at heads less than 1.0 psi. Increasing the fill-time compensated for the low tank head, allowing a stable feed rate to be maintained.

After $3700 \mathrm{~h}$ of operation, the pump was disassembled. The major components were examined to determine the corrosion/erosion effects of the slurry on the pump. Wear of the valve, seats, and drive mechanism had occurred; however, wear was not significant and pump operation was not affected. A service life beyond 6 months can be expected for the main pump body, based on the rate of wear that was observed.

The initial design for the air-lift pump was based upon existing published design data, mostly for water and salt solutions. Prior to 1983, work at PNL with air-lift pumps to transfer a slurry that had 40 wt\% solids established the practicality of the pump system. The initial air-lift designs were two-stage pilot-scale pumps designed to lift slurry at rates of 20 to $75 \mathrm{~L} / \mathrm{h}$. These early designs incorporated advances in air-lift design put forth by West German researchers who were also developing the air-lift pump for transferring a slurry to a ceramic melter. Early testing resulted in a number of design changes, particularly in the air injection area, headpot configuration, and second-stage liquid supply line. This test phase also established the importance of adequate flushing capabilities to prevent solids deposition in the air injection points and to allow flushing of the lift lines and headpots themselves.

A full-scale air-lift pump was designed and tested as a final demonstration of the air-lift pump's capabilities. The system demonstrated design rates of 35 to $175 \mathrm{~L} / \mathrm{h}$ and pumped an estimated 125,000 L of slurry during the 1067-h test period. One period of $782 \mathrm{~h}$ of continuous operation was achieved. As testing progressed, preventive maintenance steps were instituted to improve pump performance. On a daily basis the air injection footpieces, headpots, and first-stage demister pad were water-flushed with small amounts of water. In addition, the second-stage lift rate was increased to its maximum of $175 \mathrm{~L} / \mathrm{h}$ for a 5-min period each day as a means of re-entraining any settled solids that might have settled in the second-stage liquid supply line. 
No plugging or other operational problems occurred with the first-stage system. Following institution of the daily flush procedures, only one failure of the second-stage lift occurred. The plug occurred in the second-stage liquid supply line due to settled solids. This plug was easily removed by backflushing the line with water.

Demonstration of the air-lift pump showed that the simplicity of this pump makes it an attractive option for use in radioactive environments. Siurries containing up to 40 wt\% solids were tested and successfully pumped continuously for over a month. It was apparent, however, that adequate flushing capabilities were a necessity, thus somewhat complicating the air-lift pump design for remote use.

The air-displacement slurry pump was operated successfully using both alkaline and acidic slurries. A service life well beyond 6 mo. can be expected. Operation of the air-lift pump was affected by both the type of slurry tested and solids in the slurry. Alkaline slurries caused caking and deposits to form in the air-liquid interface zones. Acidic slurries had poor air-disengaging characteristics in the headpots that led to flooding of the pots with a stable foam. Best results were achieved with a neutral slurry. However, a daily flush procedure was still required to remove solid buildups at the air injection points.

The extensive test program has established that both the air-displacement slurry pump and the air-lift pump can be used in pumping solid-containing slurries at low flow rates. However, the application of the air-lift pump is constrained by the slurry type being considered. In addition, its simple design is complicated by the need for valves and services for periodic flushing and to assure pump-line plugs can be removed. The dir-displacement pump operation is not sensitive to slurry type and has minimal flushing requirements. Therefore, the air-displacement slurry pump is recommended over the air-lift pump for this application. 
CONTENTS

ACKNOWLEDGMENTS $\ldots \ldots \ldots \ldots \ldots \ldots \ldots \ldots \ldots \ldots \ldots \ldots \ldots \ldots \ldots \ldots \ldots \ldots \ldots \ldots \ldots \ldots$

SUMMARY $\ldots \ldots \ldots \ldots \ldots \ldots \ldots \ldots \ldots \ldots \ldots \ldots \ldots \ldots \ldots \ldots \ldots \ldots \ldots \ldots \ldots \ldots \ldots \ldots \ldots$

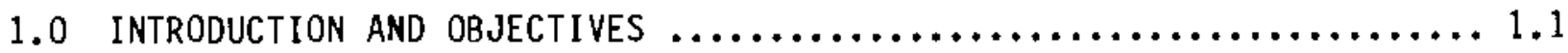

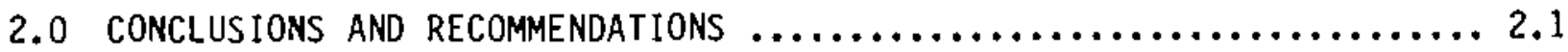

3.0 REQUIREMENTS OF A PUMP FOR THE VITRIFICATION PROCESS $\ldots \ldots \ldots \ldots \ldots \ldots .1$

4.0 THE PUMP SELECTION PROCESS $\ldots \ldots \ldots \ldots \ldots \ldots \ldots \ldots \ldots \ldots \ldots \ldots \ldots \ldots \ldots \ldots \ldots$

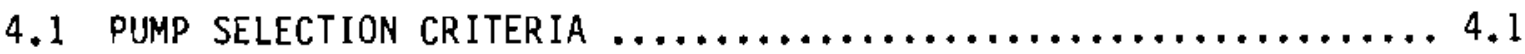

4.2 SURVEY OF AVAILABLE PUMPS $\ldots \ldots \ldots \ldots \ldots \ldots \ldots \ldots \ldots \ldots \ldots \ldots \ldots \ldots \ldots \ldots \ldots \ldots$

4.2 .1 Kinetic Pumps $\ldots \ldots \ldots \ldots \ldots \ldots \ldots \ldots \ldots \ldots \ldots \ldots \ldots \ldots . \ldots \ldots$

4.2.2 Positive Displacement Pumps .................. 4.10

4.3 SELECTION OF CANDIDATE PUMPS $\ldots \ldots \ldots \ldots \ldots \ldots \ldots \ldots \ldots \ldots \ldots \ldots \ldots$

5.0 PREPARATION AND COMPOSITION OF SIMULATED SLURRIES $\ldots \ldots \ldots \ldots \ldots \ldots \ldots .1$

5.1 SIMULATED SLURRIES USED DURING EXPERIMENTS WITH THE AIR-

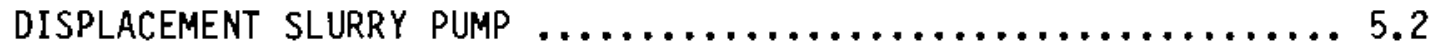

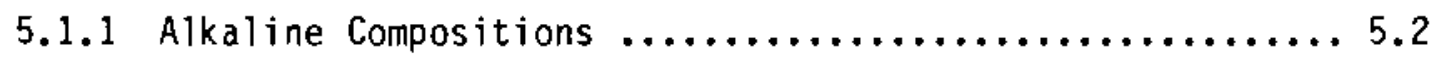

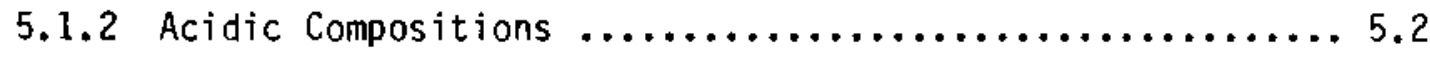

5.2 SIMULATED SLURRIES USED DURING EXPERIMENTS WITH THE AIR-LIFT

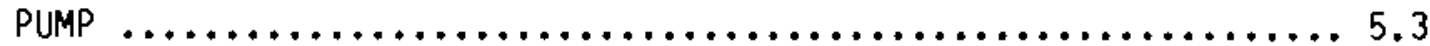

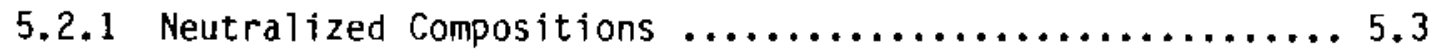

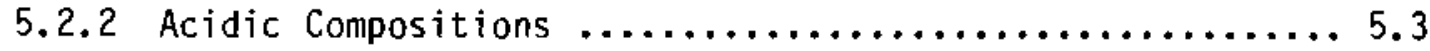

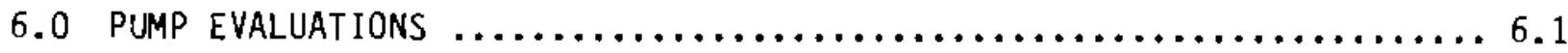

6.1 EXPER IMENTAL PROCEOURES $\ldots \ldots \ldots \ldots \ldots \ldots \ldots \ldots \ldots \ldots \ldots \ldots \ldots \ldots \ldots \ldots \ldots \ldots \ldots \ldots \ldots$

6.2 EXPERIMENTS WITH THE AIR-DISPLACEMENT SLURRY PUMP $\ldots \ldots \ldots \ldots \ldots .6 .3$

6.2 .1 Design Considerations $\ldots \ldots \ldots \ldots \ldots \ldots \ldots \ldots \ldots \ldots \ldots .4$

6.2.2 Experiments with the Initial ADS Pump Designs $\ldots \ldots \ldots \ldots 6.4$ 
6.2.3 Experiments with the Modified ADS Pump Design ........6.15

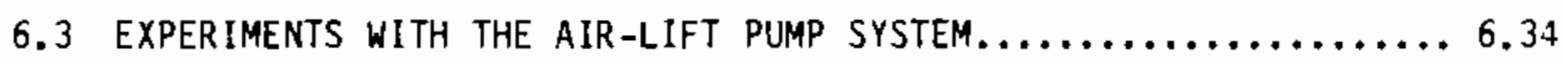

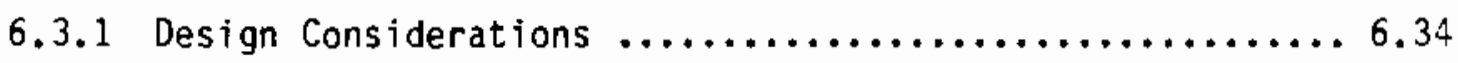

6.3 .2 Initial Testing Experience $\ldots \ldots \ldots \ldots \ldots \ldots \ldots \ldots \ldots \ldots .44$

6.3.3 Fu11-Scale Air-Lift Pump Test Results .............. 6.49

7.0 REFERENCES $\ldots \ldots \ldots \ldots \ldots \ldots \ldots \ldots \ldots \ldots \ldots \ldots \ldots \ldots \ldots \ldots \ldots \ldots \ldots \ldots \ldots$ APPENDIX A: COMPOSITION AND PHYSICAL PROPERTIES OF SIMULATED SLURRIES ... A.I 


\section{FIGURES}

1 Simplified Process Flow Diagram of the Liquid-Fed Ceramic Melter ..... 3.1

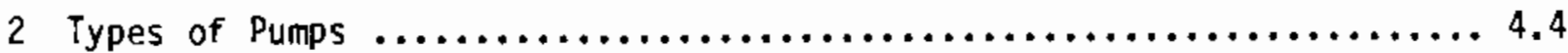

3 Pump Selection Chart ............................... 4.5

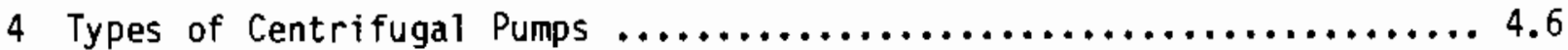

5 Typical Air-Lift Feed System Configuration $\ldots \ldots \ldots \ldots \ldots \ldots \ldots \ldots . \ldots . \ldots$

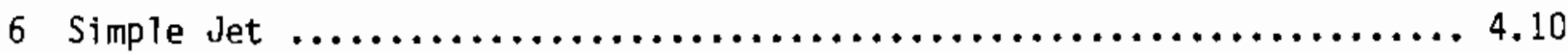

7 Types of Reciprocating Pumps $\ldots \ldots \ldots \ldots \ldots \ldots \ldots \ldots \ldots \ldots \ldots \ldots \ldots \ldots \ldots . \ldots \ldots$

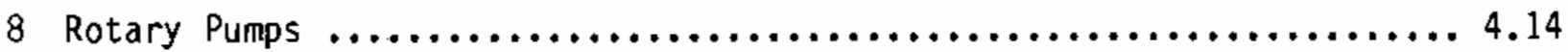

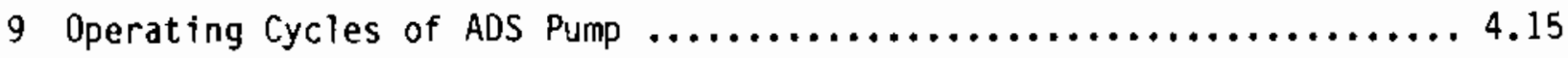

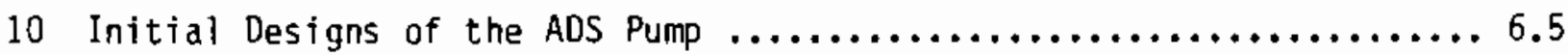

11 Control Schematics for Initial ADS Pump Designs $\ldots \ldots \ldots \ldots \ldots \ldots \ldots . \ldots 6$

12 Effect of Cycle Time on the Flow Pattern of the AirDisplacement Pump .................................... 6.1

13 Effect of Pressure on the Flow Pattern of the Air-Displacement Pump .. 6.12

14 Effect of Cycle Time and Air Pressure on the Flow Rate Using Electric

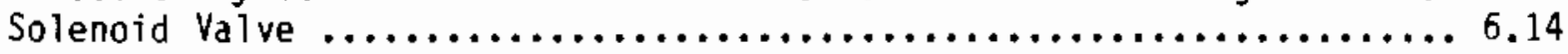

15 Effect of Tank Head on the Pump Output Using the Three-Way Electric

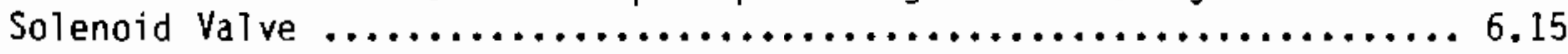

16 Effect of Cycle Time and Air Pressure on the Pump Output .........6.16

17 Modified ADS Pump Design $\ldots \ldots \ldots \ldots \ldots \ldots \ldots \ldots \ldots \ldots \ldots \ldots \ldots \ldots \ldots \ldots \ldots \ldots$

18 Control Schematic for Modified ADS Pump Design .................. 6.19

19 Air Pressure Curves Tested with Modified ADS Pump .............. 6.23

20 Effect of Fill Time on Pump Output Using $\mathrm{H}_{2} \mathrm{O} \ldots \ldots \ldots \ldots \ldots \ldots \ldots \ldots . \ldots \ldots$

21 Effect of Discharge Time on Flow Rate Using $\mathrm{H}_{2} \mathrm{O} \ldots \ldots \ldots \ldots \ldots . \ldots . \ldots . \ldots 6$

22 Effect of Air Pressure on the Pump Flow Rate Using $\mathrm{H}_{2} 0 \ldots \ldots \ldots . \ldots .6$ 
23 Effect of Air Pressure on the Pump Flow Rate Using a Neutralized

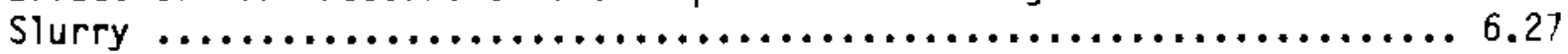

24 Effect of Fill Time on the Flow Rate Using Slurry $\ldots \ldots \ldots \ldots \ldots \ldots, 6.28$

25 Effect of Air Pressure on the Flow Rate Using an Acidic Slurry ...... 6.29

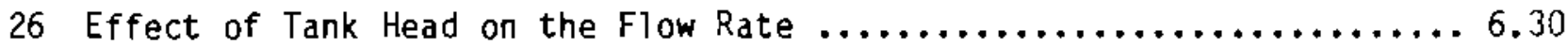

27 ADS Pump Two-Way valve After Testing $\ldots \ldots \ldots \ldots \ldots \ldots \ldots \ldots \ldots \ldots .6 .6 .6 .62$

28 ADS Pump Lower Valve Seating Surface After Testing $\ldots \ldots \ldots \ldots \ldots \ldots .6 .33$

29 Rocker Arm of ADS Pump After Testing $\ldots \ldots \ldots \ldots \ldots \ldots \ldots \ldots \ldots \ldots \ldots .6 .33$

30 Air-Lift Feed System and Process Flowsheet $\ldots \ldots \ldots \ldots \ldots \ldots \ldots \ldots .6 .6 . \ldots$

31 Stage I Air-Lift Footpiece Design ........................... 6.37

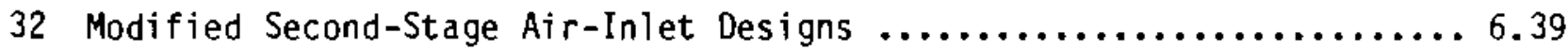

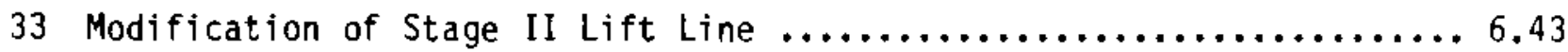

34 Air-Lift Calibration and Test Results of Tests 1, 2, and 3 ....... 6.46

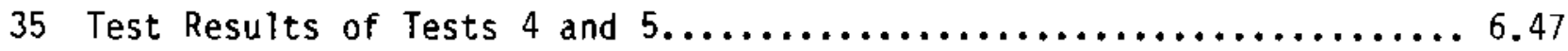

36 Drop in Feed Rate Over Time During Test $7 \ldots \ldots \ldots \ldots \ldots \ldots . \ldots . \ldots .6 .64$

37 Test Results of Test $8 \ldots \ldots \ldots \ldots \ldots \ldots \ldots \ldots \ldots \ldots \ldots \ldots \ldots \ldots \ldots, 6 . \ldots \ldots$

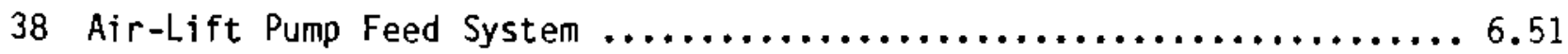

39 First-Stage Slurry Rate Versus Air Rate $\ldots \ldots \ldots \ldots \ldots \ldots \ldots \ldots \ldots .6 .53$

40 Second-Stage Slurry Rate Versus Air Rate at Two Different First-Stage Lift Rates $\ldots \ldots \ldots \ldots \ldots \ldots \ldots \ldots \ldots \ldots \ldots .6 .6 \ldots$ 


\section{TABLES}

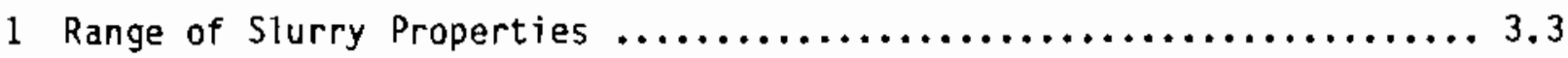

2 Criteria Used in the Evaluation of STurry Pumps $\ldots \ldots \ldots \ldots \ldots \ldots \ldots . \ldots . \ldots$

3 Advantages and Disadvantages of Pumps Considered for the Vitrification Process ................................... 4.17

4 Summary of Initial Pump Designs $\ldots \ldots \ldots \ldots \ldots \ldots \ldots \ldots \ldots \ldots \ldots \ldots \ldots \ldots \ldots \ldots$

5 Weight and Dimensional Changes in ADS Pump Components ............6.31

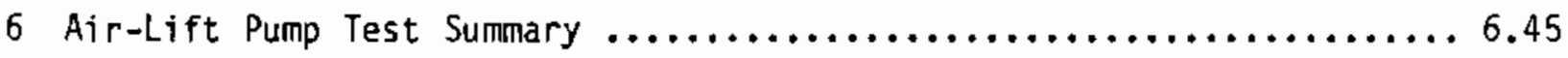




\subsection{INTRODUCTION AND OBJECTIVES}

Commercial and defense nuclear activities in the United States have produced large volumes of high-level radioactive wastes. These wastes are currently stored as slurries in large underground storage tanks where they are isolated from the environment until a permanent and environmentally acceptable method for permanent storage is developed. The U.S. Department of Energy has programs under way to end this interim storage and achieve final disposal by concentrating and immobilizing these high-level liquid wastes (HLLW) and preparing them for shipment to a federal repository.

The internationally accepted form of immobilized HLLW is borosilicate glass. The process selected in the U.S. for converting the HLLW to glass uses a direct liquid-fed, joule-heated ceramic melter (Brouns 1984). In the vitrification process, HLLW, with much of the nonradioactive salts removed, is blended with glass-forming materials. The resulting slurry is metered into the refractory-lined melting tank. There the water is driven off, and the various compounds decompose to form basic oxides that melt into a homogeneous glass.

The pump used to feed the slurry to the melter must satisfy many unique requirements because of the chemical, physical, and radiological properties of the slurry and because of the design constraints of the vitrification process required by the fully remote operation and maintenance. The waste itself is corrosive. It can be either caustic or acidic and often contains fluorides, chlorides, phosphates and sulfates. The caustic wastes will typically contain 20 to 50 vol\% solids as particulates after preparation for vitrification. The glass-forming additives, which can account for make up to $75 \mathrm{wt} \%$ of the total 300 to 500 grams of oxides in a 1 iter of melter feed, also contain insoluble particles of ground glass, silica, or zeolite.

In addition to the chemical and particulate difficulties, radiation doses from the HLLW slurry are calculated at rates of approximately $100 \mathrm{rad} / \mathrm{h}$ alpha, $3.4 \times 10^{5} \mathrm{rad} / \mathrm{h}$ beta and $8.7 \times 10^{5} \mathrm{rad} / \mathrm{h}$ gamma. These radiation levels preclude the use of most types of elastomers, and limit the service life of the remaining elastomers that are commonly incorporated in the design of metering and slurry pumps. 
The full-scale vitrification processes to be used at various sites in the U.S. require controlled delivery of the slurry feed to the melter at rates ranging from $20 \mathrm{~L} / \mathrm{h}$ to $225 \mathrm{~L} / \mathrm{h}$. The pump discharge pressure must be low enough to prevent injection of the slurry into the melt. Thus, the pump must be able to operate at uncommonly low flow rates and be able to deliver slurry at a wide range of flow rates.

The Pacific Northwest Laboratory (PNL) has been developing vitrification technology for the past 20 years. An important part of this development activity has involved the design of a pump to deliver the slurry to the melter. An air-displacement slurry (AOS) pump and an air-lift pump were identified as candidate pumps that warranted evaluation. Therefore, these pumps were subjected to long-term testing using simulated slurries. The specific objectives of the testing were to 1) operate the pumps in long-term tests to determine operating parameters and system reliabitity, 2) identify weaknesses in the pump systems, and 3 ) evaluate the corrosion and erosion of pump components.

The purpose of this report is to document the development of the pumps and present the results of the testing. Section 3.0 of the report presents the requirements of a pump for the vitrification process. Section 4.0 deals with the pump selection process. The process of selecting a pump for this application involved a technical review of pumps currently used in siurry applications. The design and operating characteristics of these pumps were evaluated against established criteria. This evaluation led to the selection of candidate pumps. The simulated slurries used in the pump tests are described in Section 5.0. The experimental procedures used in the evaluations are included in Section 6.1. The results of the long-term testing and evaluation of the ADS and air-lift pumps are given in Sections 6.2 and 6.3 , respectively. 


\subsection{CONCLUSIONS AND RECOMMENOATIONS}

The long-term testing of the ADS pump and the air-lift pump provided quantitative data on the performance of the pumps in simulated slurries. The specific objectives of the evaluation were to 1) operate the pumps in long-term tests to determine operating parameters and system reliability, 2) identify weaknesses in the design of each pump system, and 3) evaluate the corrosion and erosion of pump components.

The designs of both the ADS pump and the air-lift pump were modified to improve their performance with the simulated slurries in the vitrification process. The final reference designs have been successfully demonstrated in long-term tests.

The specific conclusions and recommendations are provided below:

- Based on completion of 1ong-term tests, the ADS pump is preferred over the air-lift pump as the system for the vitrification process.

- The reference ADS pump was successfully operated for $3700 \mathrm{~h}$ using both alkaline and acidic slurries. Stable flow rates of $20-185 \mathrm{~L} / \mathrm{h}$ were achieved.

- The ADS pump operation was not sensitive to slurry type and had minimal water flushing requirements.

- An ADS pump service life beyond 6 mo. was predicted based on corrosion and erosion data.

- The reference air-lift pump was operated for $1067 \mathrm{~h}$ and was able to achieve flow rates of 35 to $175 \mathrm{~L} / \mathrm{h}$.

- The operation of the air-lift pump was affected by both the type of slurry tested and total solids in the slurry. Alkaline siurries caused caking deposits to form which would eventually plug the lines. Acidic slurries had poor air disengaging characteristics in the headpots. The best operation of the air-lift occurred with a neutral slurry composition.

- A daily flush of the air-lift was required to remove solid buildup. 


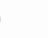

.

•

. 


\subsection{REOUIREMENTS OF A PUMP FOR THE VITRIFICATION PROCESS}

The United States is proceeding with plans to immobilize nuclear highlevel waste by converting it to borosilicate glass and then placing it in a deep geological repository. The process selected for converting the HLLW to glass uses the direct liquid-fed, joule-heated ceramic melter, known as the liquid-fed ceramic melter (LFCM). In the process, HLLW is blended with glassforming materials, and the resulting slurry is metered into the refractory lined melting tank. There the water is driven off, and the various compounds decompose to form basic oxides that melt into a homogeneous glass. A pump is required to deliver the slurry from the mixing tank to the LFCM at the desired processing rates. A process flow diagram is shown in Figure 1.

The vitrification process requires controlled delivery of the slurry feed to the meiter at rates ranging from approximately $20 \mathrm{~L} / \mathrm{h}$ to $200 \mathrm{~L} / \mathrm{h}(0.09 \mathrm{gpm}$ to $0.88 \mathrm{gpm})$. The maximum delivery rates depend on the size of the melter.

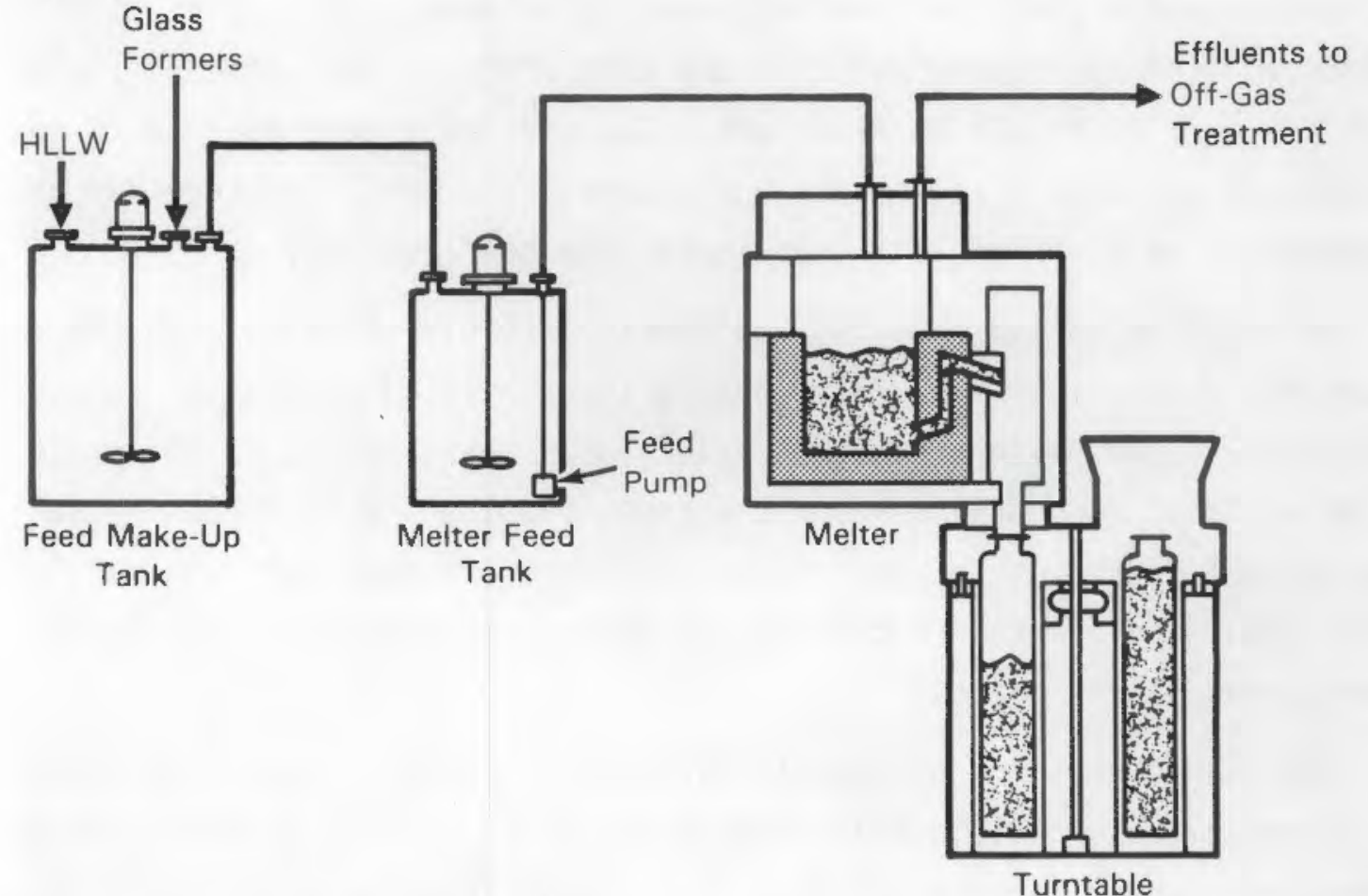

FIGURE 1. Simplified Process Flow Diagram of the Liquid-Fed Ceramic Melter 
The lower flow rates are required during startup periods. The startup flow rates can be a factor of 3 to 5 less than the maximum rate. Thus, the pump must operate over a relatively wide and low flow rate range. In addition, the slurry must be pumped to the meiter at a low pressure so that it will not be injected into the glass melt.

The pump used for the vitrification process must satisfy many unique requirements because of the chemical, physical, and radiological properties of the slurry and because of the design constraints caused by fully remote operation. The waste itself is corrosive. It can either be alkaline or acidic, and often contains fluorides, chlorides, phosphates, and sulfates. The caustic wastes will typically contain 20 to 50 vol\% solids (as particulates) after processing prior to vitrification. The glass-forming additives, which can make up over 75 wt\% of the total solids in the melter feed, also contain insoluble particles of ground glass, silica, or ion exchange material. These particles range in size from $177 \mu \mathrm{m}$ to less than $10 \mu \mathrm{m}$. When the waste and glass formers are combined, the resulting slurry can contain more than 50 vol\% solids. The undissolved solid particles are very erosive to pump parts. They also settle in locations of low slurry velocity and clog orifices and valves. The sediments are very difficult to flush out. Caustic feeds tend to produce salt deposits at air/slurry interfaces which cement the particles together and make the deposits very difficult if not impossible to flush out.

In addition to the chemical and particulate difficulties with the slurry, 1-year-old HLLW mixed with glass formers is calculated to deliver dose rates of approximately $100 \mathrm{rad} / \mathrm{h}$ alpha, $3.4 \times 10^{5} \mathrm{rad} / \mathrm{h}$ beta, and $8.7 \times 10^{5} \mathrm{rad} / \mathrm{h}$ gamma to the parts of a pump submerged in a tank of melter feed. These radiation levels preclude the use of most types of elastomers and limit the service life of the remaining elastomers that are commonly incorporated in the design of metering and slurry pumps.

The characteristics of the slurry to be pumped will depend on the physical, chemical, and radiological properties of the high-level waste and glass formers that are blended to create the slurry. These properties may change as the composition and properties of the high-level waste become more defined and the development of a glass for this application continues. Activities at PNL 
have focused on the development of slurries for two types of high-level waste. One slurry type evolved from glass development for a defense waste currently stored at the Hanford Site in southeast Washington. The second slurry evolved from glass development for a commercial waste currently stored at the West Valley Demonstration Project in southwest New York. These slurry compositions are discussed in Section 5.0.

The process of identifying a pump for this application was initiated based on the range of slurry properties listed in Table 1 . Section 4.0 discusses the pump selection process that was used during this evaluation. Section 4.1 discusses the criteria that were established to evaluate various pump designs. Section 4.2 reviews pumps that are typically used in slurry applications. Section 4.3 discusses the pumps that were selected for additional testing and evaluation.

TABLE 1. Range of Slurry Properties

\begin{tabular}{|c|c|}
\hline Property & Approximate Value or Range \\
\hline Density & $1.2-1.5 \mathrm{~g} / \mathrm{ml}$ \\
\hline Apparent Viscosity & $<50 \mathrm{cP}$ \\
\hline $\mathrm{pH}$ & \\
\hline $\begin{array}{l}\text { Alkaline slurries } \\
\text { Formated slurries } \\
\text { Acidic slurries }\end{array}$ & $\begin{array}{l}8-13 \\
6-8 \\
<1\end{array}$ \\
\hline Temperature & $10-40^{\circ} \mathrm{C}$ \\
\hline Particle Size Distribution & $95 \%$ less than 200 mesh \\
\hline Suspended Solids & $20-50$ vol\% \\
\hline Abrasiveness & Very High \\
\hline Rheological Classification & $\begin{array}{c}\text { Non-Newtonian } \\
\text { (Pseudoplastic, Yield Pseudoplastic }\end{array}$ \\
\hline $\begin{array}{l}\text { Radiation Dose Rate } \\
\text { Alpha } \\
\text { Beta } \\
\text { Gamma }\end{array}$ & $\begin{array}{c}100 \mathrm{rad} / \mathrm{h} \\
3.4 \times 10^{5} \mathrm{rad} / \mathrm{h} \\
8.7 \times 10^{5} \mathrm{rad} / \mathrm{h}\end{array}$ \\
\hline
\end{tabular}





\subsection{THE PUMP SELECTION PROCESS}

The pump selection process integrates the requirements of the application with the operating characteristics of pumps available in the marketplace. The process results in the selection of a pump that will meet the design requirements for the application.

A full understanding of the process, operating requirements, and the physical, chemical, and rheological properties of the fluid is necessary before proceeding with the selection and design of the pumping system. The selection decision should be based on criteria defined in advance. The decision criteria for this evaluation included only non-economic (i.e., technical) considerations (e.g., flow rate, discharge pressure, service life, ease of operation, maintenance requirements, suitability for a radioactive environment, ruggedness, flexibility, etc.).

A discussion of the criteria used in the evaluation of available pumps is provided in Section 4.1. Section 4.2 describes typical pumps used for slurry applications. Section 4.3 discusses the two pump designs that were selected for further evaluation.

\subsection{PUMP SELECTION CRITERIA}

Selection of a pump for the LFCM process is not accomplished by calculation but by the weighing of various features of typical slurry pumps against established criteria. Based on engineering judgment and operating experience at PNL, a 1ist of criteria for the evaluation was developed (Table 2). The list was further divided into three categories: 1) features of major importance, 2) features that are less important, and 3) features that are least important. Engineers at PNL ranked the importance of the listed features in a figure-of-merit analysis. Pumps typically used in slurry applications were then evaluated based on these criteria.

\subsection{SURVEY OF AVAILABLE PUMPS}

There are a wide variety of pumps available in the marketplace and each one can be specially designed to suit a given application. One breakdown of 
TABLE 2. Criteria Used in the Evaluation of Slurry Pumps

Features of Major Importance

- Meters the slurry to the melter at rates of $20-200 \mathrm{~L} / \mathrm{h}$ of low discharge pressures

- Minimizes the number of moving parts in the slurry

- Avoids rotating or sliding shaft seals

- Is constructed of radiationresistant materlals

- Solid deposits and plugs are easily flushed and cleaned without disassembly

- Minimizes inlet suction lift requirements

- Avoids a flow control valve and recirculation loop

- Minimizes the use of valves where their failure will leak waste outslde the tanks or stop the process

- Can be submerged close to the tank bottom to maximize the amount of slurry that can be removed from the tank

- Operation is not dependent on tight tolerances

- Avoids submerged bushlngs, bearings, and gears

- Avoids small orifices and traps where solids can settle or form plugs
Features of Lesser Importance

- Requlres no adjustment as components wear

- Minimlzes service connections

- Enters through the tank IId and Is submerged in the tank

- Uses only large radius bends In piplng

- Provides continuous flow

- Avolds Iubricants or hydraulla flulds wich ore susceptible to radiation damage

- Minimizes pumpage contact with alr

- Provides precise flow control

- Is self-priming

- Has a minimum service Ilfe of 6 mo. to one year

- Avoids pump fluid dilution by seal water
Features of Least Importance

- Has low cavitation potential

- Minimizes area of tank lid and cell space requlred

- Has a hIgh mechanical efficlency 
various types of pumps is shown in Figure 2 (Hydraulic Institute Standards 1983). There are two major pump classifications; kinetic pumps and positive displacement pumps. Kinetic pumps use a velocity force to move fluids, while positive displacement types rely on reciprocating or rotary action to perform this task.

Each pump is designed to provide a specific range of pump capacities and discharge pressures. A useful guide for selection was published by W. H. Stindt (1971). Stindt prepared a nomograph that gives the pump capacity and power as a guide for pump selection (Figure 3 ). Figure 3 can be useful in focusing consideration on two or three types of pumps. This chart indicates that the positive displacement pumps would be capable of metering the slurry to the LFCM at rates of 0.09 to $0.88 \mathrm{gpm}$ at total heads of less than $50 \mathrm{ft}$. As will be discussed, other pumps when properly designed and installed can also be used for this application.

A number of pumps have been typically used for slurry applications. Centrifugal, air (or gas) lifts, and jet kinetic pumps have been used. Reciprocating, rotary, screw, and air-displacement positive displacement pumps have been employed as well.

The kinetic classification of pumps will be discussed in Section 4.2.1 while the positive displacement pumps are discussed in Section 4.2.2.

\subsubsection{Kinetic Pumps}

As their name signifies, kinetic pumps transfer fluids by means of motion, or velocity. The fluid is accelerated, and then all, or most, of the velocity is converted to pressure; that is, kinetic energy in the form of velocity head is converted to pressure head. Three types of kinetic pumps will be discussed: the centrifugal, the air-lift and the jet pump.

\subsubsection{Centrifugal Pumps}

Centrifugal pumps are the most widely used type in the chemical industry for transferring liquids of all types. Numerous types and designs of these pumps are being built today. 

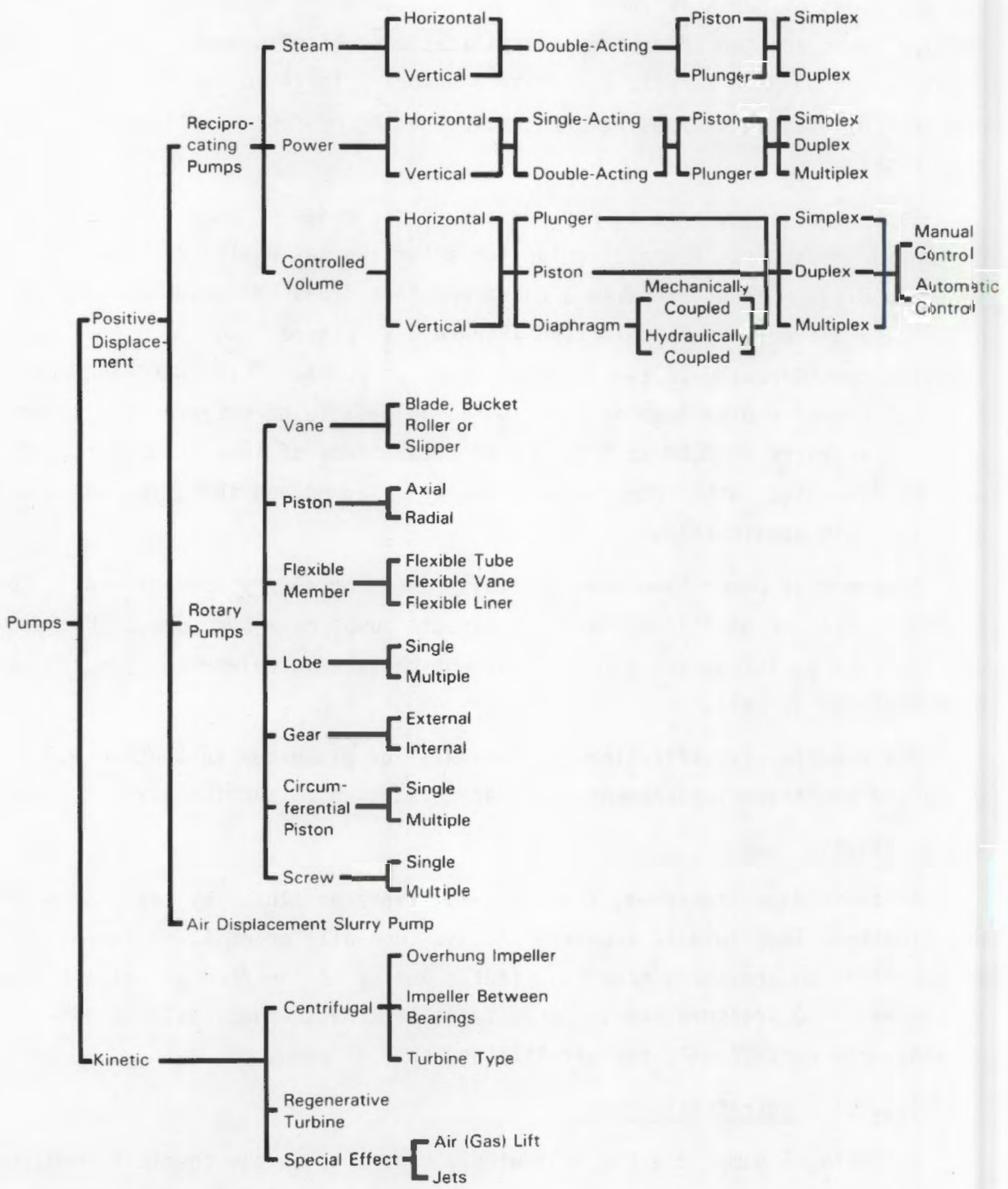

FIGURE 2. Types of Pumps (Hydraulic Institute Standards 1983) 


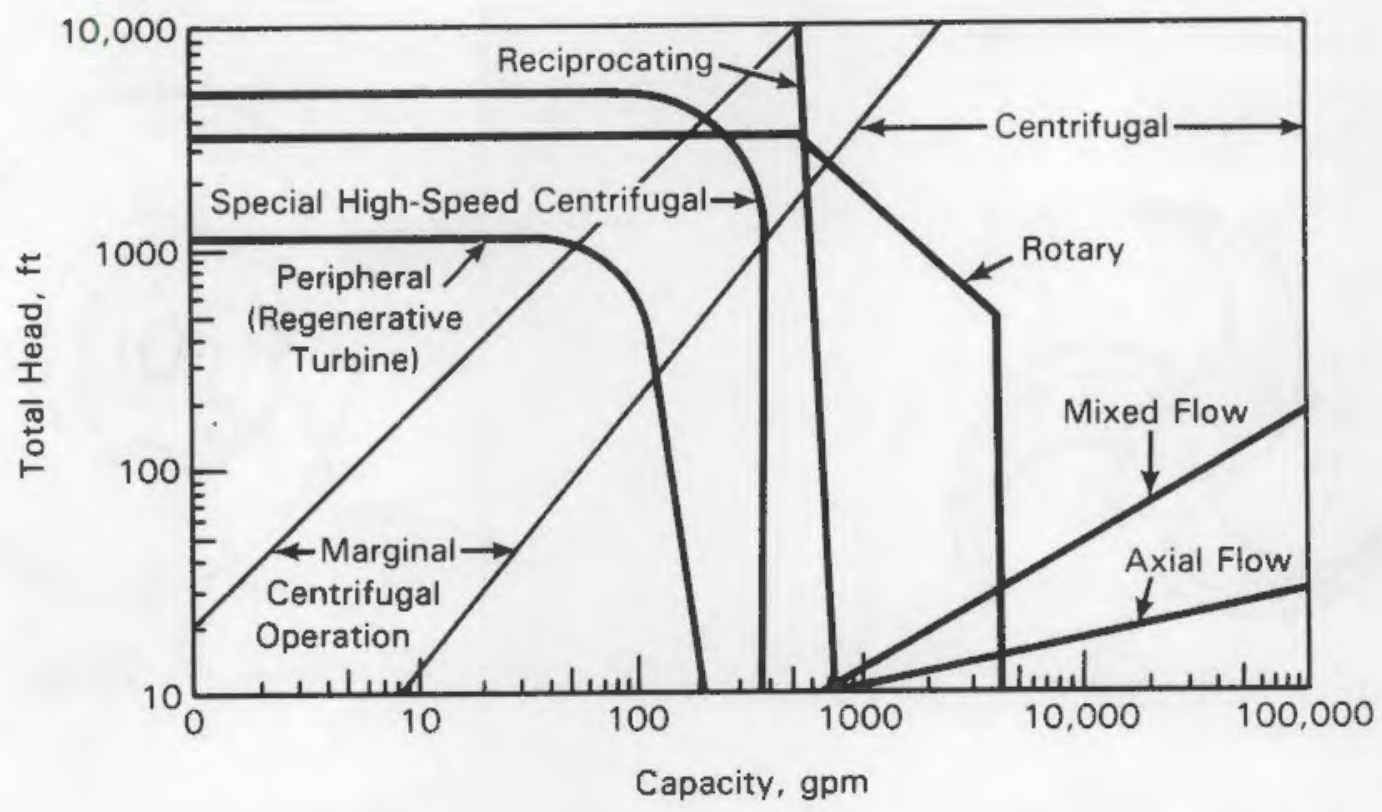

FIGURE 3. Pump Selection Chart (Stindt 1971)

A centrifugal pump is simply an impeller rotating within a casing. This type of pump imparts velocity to the liquid by centrifugal force and then converts some of the velocity to pressure. Numerous impeller and casing designs are available depending on the application. A few of the different types of centrifugal pumps are shown in Figure 4.

Basically, the impeller consists of a number of blades (either open or shrouded) mounted on a shaft that extends outside the casing. There are three general types of casings: circular, volute, and diffuser. Each casing consists of a chamber in which the impeller rotates. It is provided with inlet and exit ports for the liquid being pumped. The most common type of casings are the volute and diffuser. A packing gland or mechanical seal is required on the rotating shaft. A seal water flush system for the gland is installed to protect it from abrasive solids.

Centrifugal pumps are typically available in sizes ranging from $1 \mathrm{gal} / \mathrm{min}$ to $1.75 \times 10^{6} \mathrm{gal} / \mathrm{min}$ with discharge pressures up to $2,000 \mathrm{psi}$. Centrifugal pumps are commonly used in the refineries and chemical process industry to handle hot oils and hot and/or corrosive chemicals. They are used for 


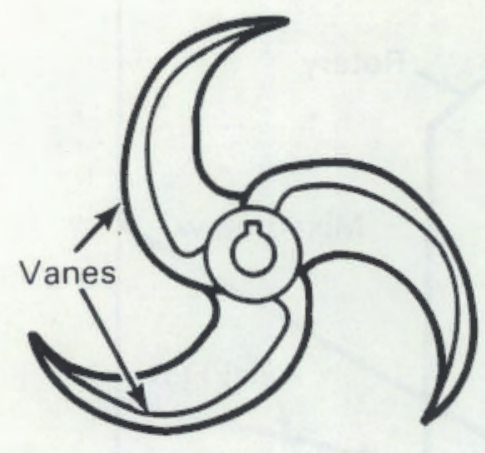

Open Impeller

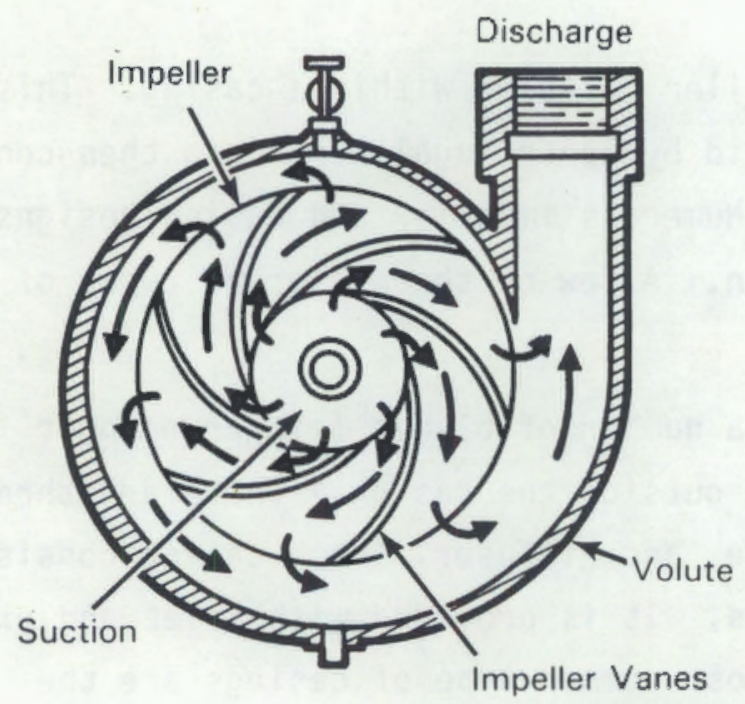

Volute Casing

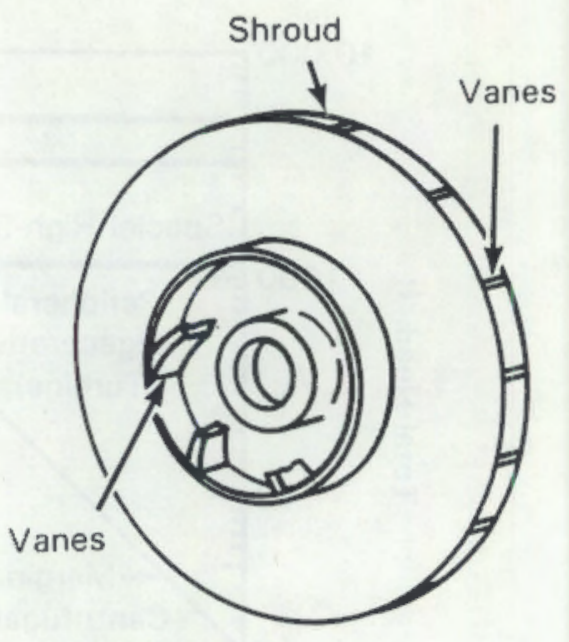

Shrouded Impeller

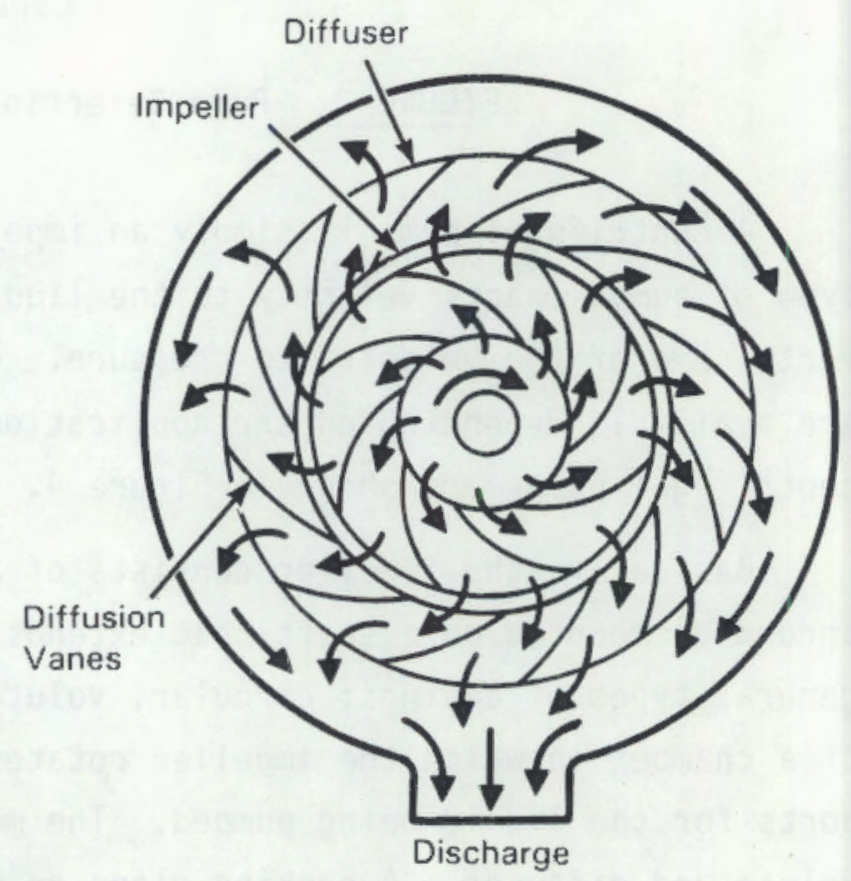

Diffuser Casing

FIGURE 4. Types of Centrifugal Pumps 
transporting sewage, sand, slurries, soap, and paper stock. Other applications include use in sanitary service, well pumping, boiler feed pumping, submerged services, and petroleum pipelines.

The primary advantages of centrifugal pumps include: 1) very few moving and wearing parts; 2) small space requirement; 3) no close clearances, therefore they can easily handle liquids containing dirt, abrasives, and large solids; 4) low maintenance; 5) dependable service; 6) low net positive suction head requirements; 7) wide range of sizes; 8) wide range of operating characteristics; 9) uniform (nonpulsating) flow; 10) no practical restriction on the maximum size of solids that can be handled; and 11) no need for valves for pump operation.

The disadvantages include: 1) they are unstable at low flow rates, 2) packing glands are required along the rotating shaft, 3) seal water is required for good packing life, and 4) the seal water dilutes the liquid being pumped.

The centrifugal pump can be used to meter radioactive slurries to a melter provided the pump is designed properly. The pump must enter through the top of the tank with the suction pipe located close to the tank botton to maximize the amount of slurry that can be pumped. Water is required for priming the pump. The output from a centrifugal pump is unstable at low flow rates and, therefore, cannot be used to directly meter the slurry to the melter. The centrifugal pump can be used in conjunction with a recirculation loop. The slurry is pumped through the line at a high flow rate; a smaller line with a flow control system branches off and transports the slurry to the melter. This system is currently being designed and evaluated at another facility.

\subsubsection{Air-Lift Pumps}

The air-lift pump is a type of kinetic pump that moves a liquid by means of a gas. The theory of operation of an air-lift pump for pumping radioactive liquids has been extensively researched by Chamberlain (1957), Kearsley (1956), and more recently by Dabolt and Plummer (1980). Pumping with air-lifts is accomplished by injecting air into a liquid supply line near its lowest point. The combination of volume displacement and the lower liquid-air mixture 
density in the lift line, relative to the liquid in the supply line, causes liquid to rise/flow from the lower elevation to a higher elevation in the lift line. The maximum lift height attainable is proportional to the ratio of the respective densities of the liquid and liquid-air mixture and is partially determined by the air supply.

A typical air-lift system configuration is shown in Figure 5 . The major design parameter influencing lift height is submergence. Submergence is normally expressed as a percentage of the total lift line length. In Figure 5, the lift line length, $H$, is the distance from the air inlet point, called the footpiece, to the discharge height. The liquid head supplying the lift line is of length L. Submergence is the ratio of $L$ over H. Air-lift efficiency increases as submergence increases. However, most air-lifts are designed to

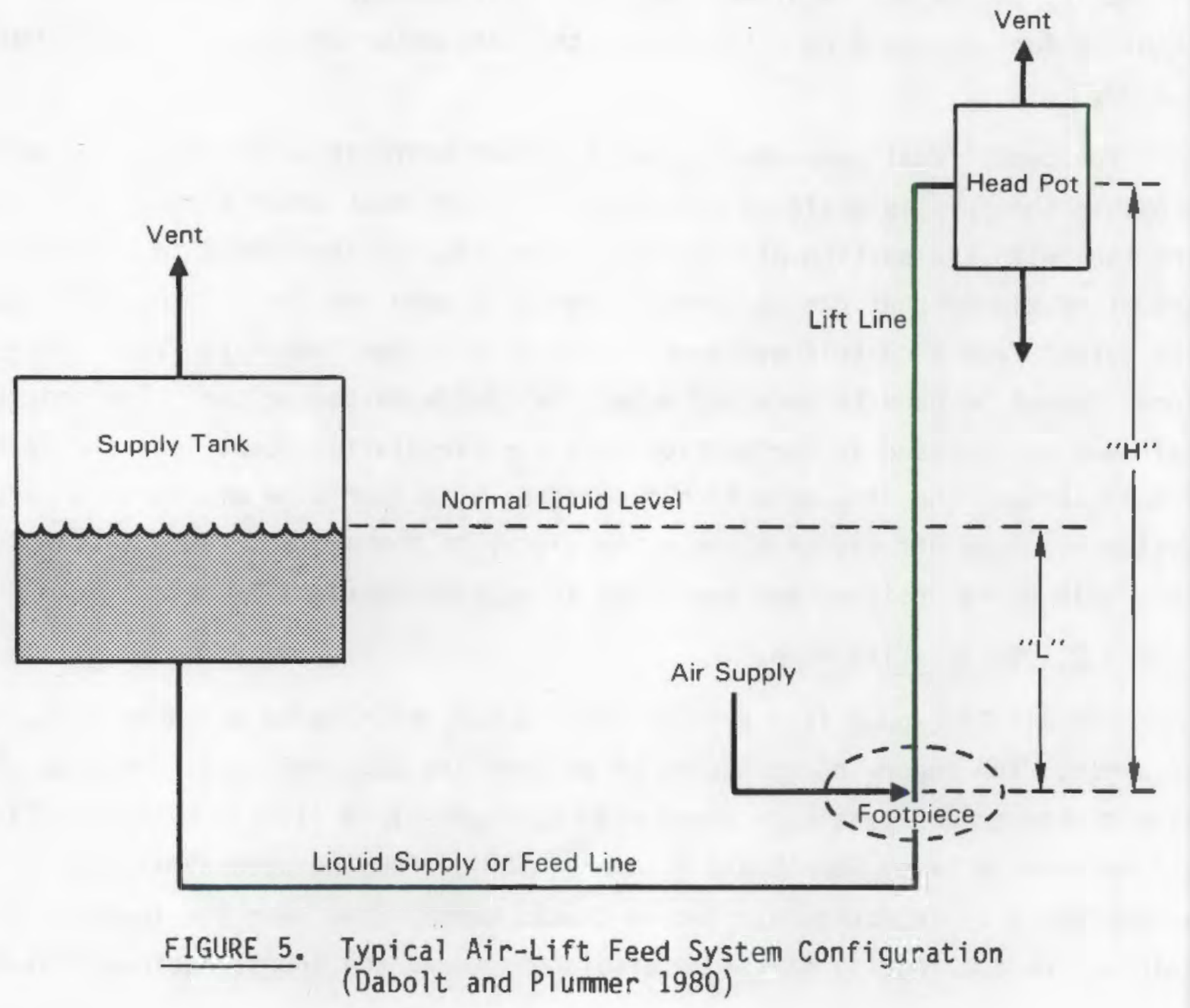


have a submergence between $35 \%$ and $70 \%$ for control of the lift rate over a wide range. A multiple-stage air-lift is used when the total lift line height exceeds the capability of a single lift line. With a two-stage air-lift, the first stage will maintain a fairly constant liquid head supply (L) or submergence for the second stage lift. The second stage flow rate is then a function of the air flow to the second stage lift.

The air-lift can be designed to pump fluids over a wide range of flow rates at relatively low discharge pressures. In the past, it was widely used for pumping water from mine shafts and crude oil from wells. It has been less widely used since the development of efficient centrifugal pumps.

The advantage of this system of pumping lies in the fact that there are no moving mechanical parts in contact with the fluid to be pumped. The pump can be of all-metal construction. Erosion is eliminated due to the low liquid velocities. The required gas/air compressor can be located remotely from the supply tank.

The disadvantages of the air-lift include: 1) air injection can cause foaming of some liquids; 2) the flow pulsates with short lift heights; 3) line velocities are low, which can allow particles to settle; and 4) some liquid carryover in the vent lines can occur.

\subsubsection{Jet Pumps}

Jets, another type of kinetic pump, make use of the momentum of one fluid to move another. Two common types of jets are referred to as ejectors and injectors. The principle of operation of a jet is shown in Figure 6 . Jets use air, steam, or liquid to entrain the liquid to be moved.

Jets are used as liquid pumps when it is desirable to have no moving parts and essentially no maintenance such as in radioactive zones. Other applications include pumping acids, alkalies or liquids containing solids of an abrasive nature, and for emptying sumps. Jets are also used for transferring liquids from one tank to another. They are currently used in high-level waste activities for handling dilute slurries ( $<10 \mathrm{wt} \%$ solids content) and streams with dissolved solids. 


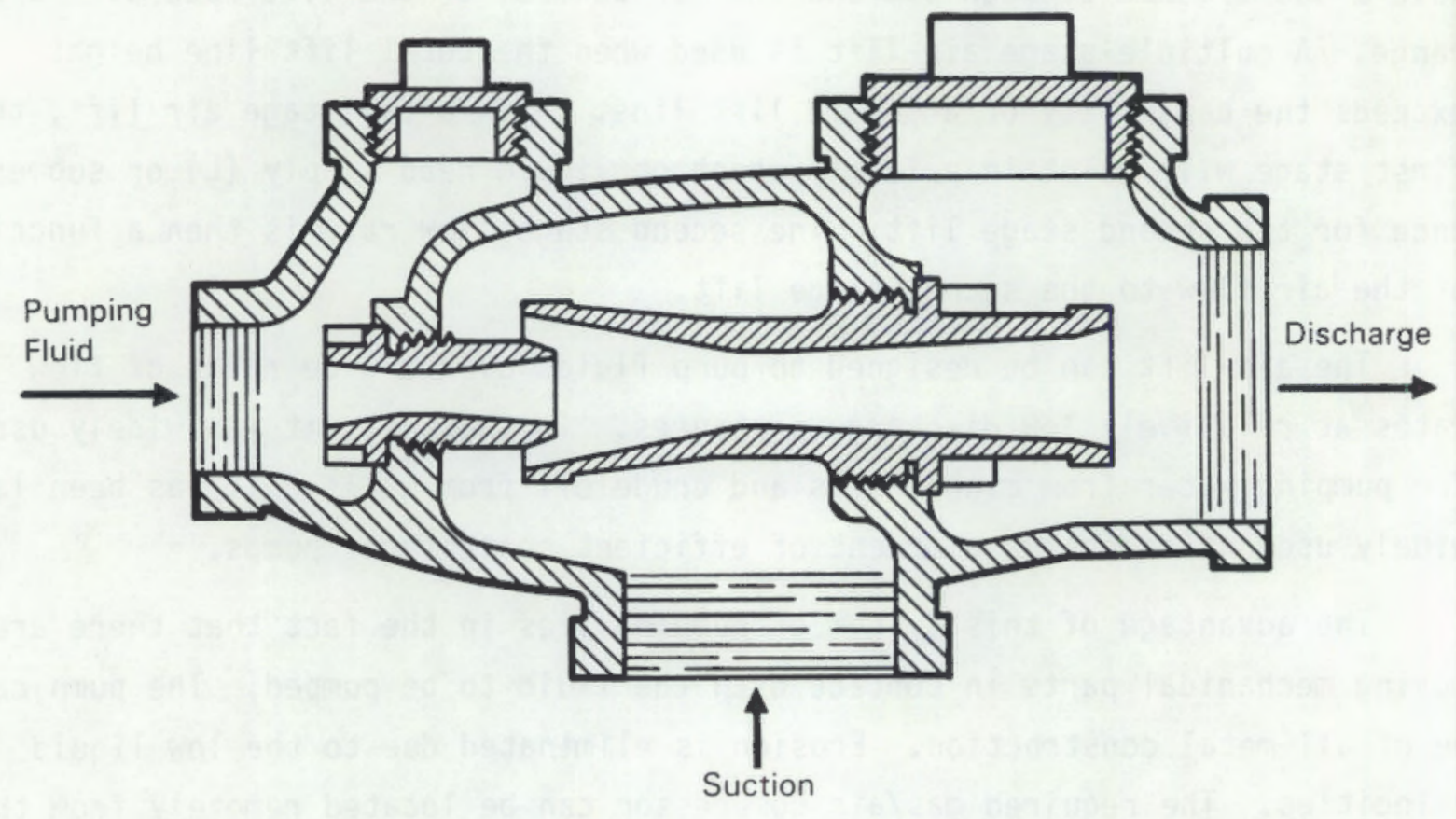

FIGURE 6. Simple Jet

Jets have the advantage of no moving mechanical parts. This device has the disadvantage of diluting the fluid pumped by mixing it with the pumping fluid (if the pumping fluid is a liquid). Gases are not attractive pumping fluids because of the difficulties with disengaging the gas from the liquid and the drying effect of gas pump fluids on slurries that lead to the formation of solids deposits.

\subsubsection{Positive Displacement Pumps}

The second major classification of pumps are the positive displacement pumps. Positive displacement pumps cause liquid to flow in volumetric proportion to an alternating increase and decrease of the volume in the pumping chamber. These pumps can be divided into three general classes depending on the type of action used to fill and empty the chamber: reciprocating, rotary, and air-displacement pumps.

\subsubsection{Reciprocating Pumps}

There are three types of reciprocating pumps: piston, plunger, and diaphragm pumps. The principle of operation of each of these is identical. 
Basically, a piston, plunger, or diaphragm reciprocates, resulting in an alternating increase and decrease in the volume of the pump chamber.

The different types of reciprocating pumps are shown in figure 7 . In the operation of the piston and plunger pumps, the piston/plunger withdraws, creating a negative pressure that causes liquid to enter the pump. As the piston/plunger returns, it displaces the liquid, forcing it out through the
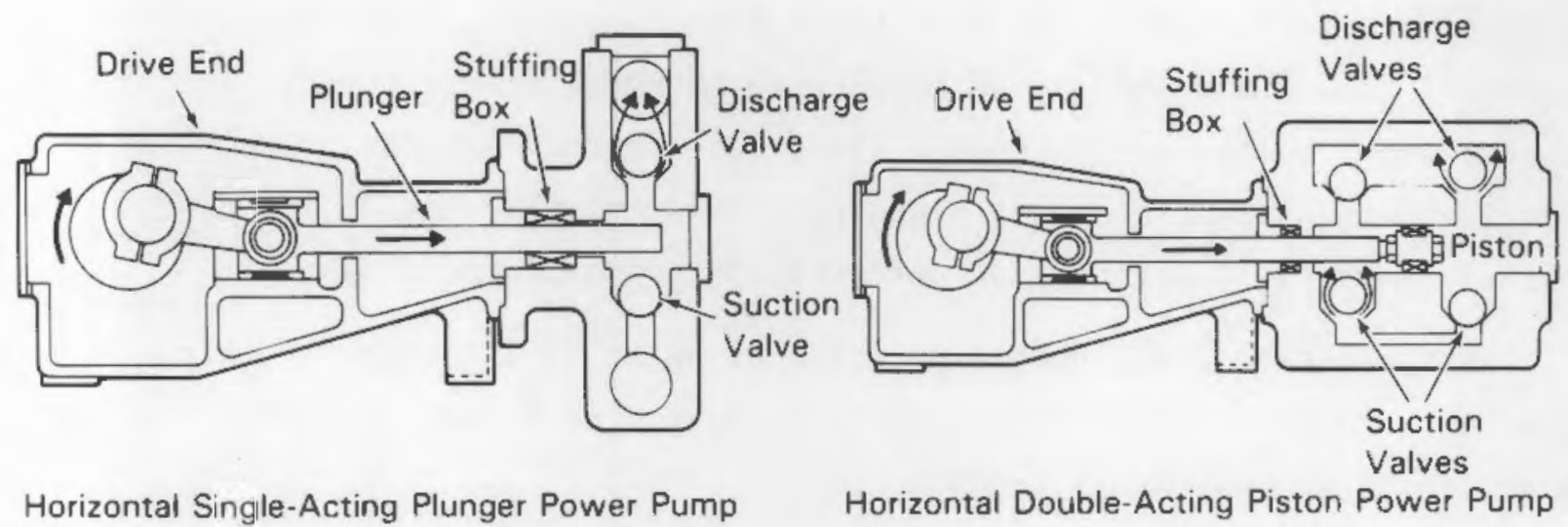

Horizontal Single-Acting Plunger Power Pump

Horizontal Double-Acting Piston Power Pump

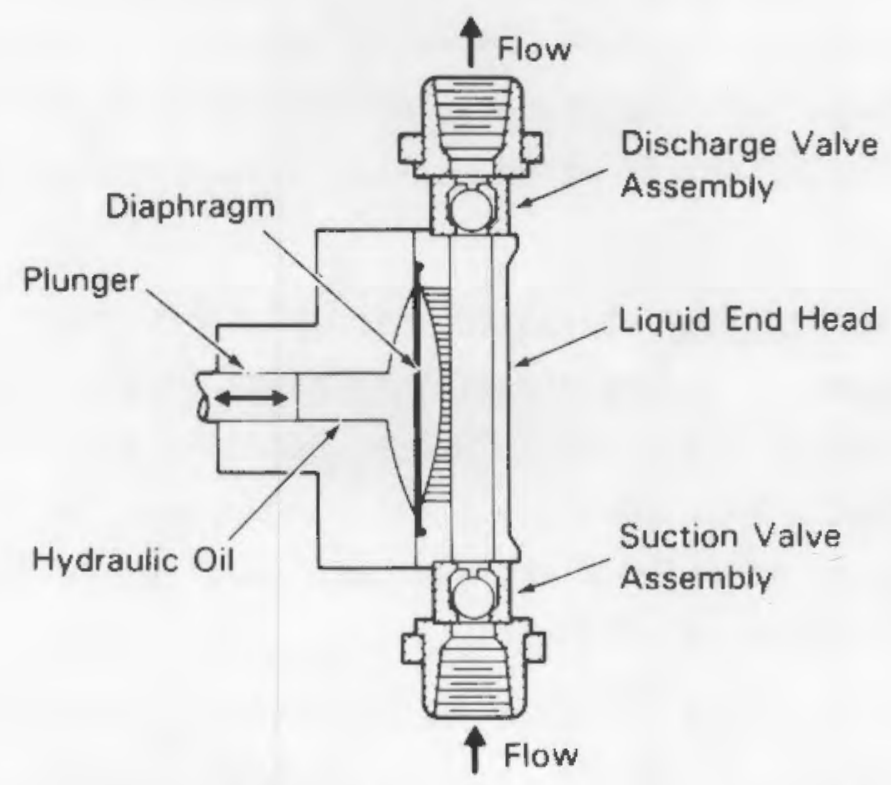

Hydraulically-Actuated Diaphragm Pump

FIGURE 7. Types of Reciprocating Pumps 
discharge. Check valves are present in the suction and discharge ports to prevent backflow. The plunger pumps differ from the piston pumps in the type of mechanism that contacts the liquid. In the plunger pump, a constant diameter plunger reciprocates through packing glands and displaces liquid from the chamber. In piston pumps, a piston displaces liquid from the chamber.

The diaphragm pump is similar to the piston/plunger pump with some additional features. The diaphragm isolates the driving mechanism and the fluid being pumped, eliminating the need for a packing. A diaphragm pump is shown in Figure 7. The diaphragm may be fabricated of metal or elastomer. The diaphragms are actuated by compressed air or oil from an external supply, by oil that is pumped by a piston (or plunger) within the pump itself, or by an entirely mechanical device that deflects and supports the diaphragm.

Reciprocating pumps have capacities of up to $1800 \mathrm{gpm}$ and discharge pressures up to 50,000 psi. These pumps are capable of higher heads and lower capacities than centrifugal pumps.

Piston/plunger pumps are typically used in the oil fields for deep well pumping, in refineries and chemical plants to pump volatile or viscous liquids, in power plants to pump boiler feed and water treatment liquids, and in hydraulic presses. The diaphragm pump is used for the handling of corrosive, toxic, abrasive, or expensive materials where packing leakage cannot be tolerated or packing glands are not suitable.

There are a number of advantages to using piston/plunger pumps. This type of pump is 1) resistant to highly abrasive slurries because high pump discharge pressures are obtained at low piston/plunger speed; 2) easy to control because the capacity is a function of speed, not discharge pressure; and 3) selfpriming and self-contained. The diaphragm pump requires no packing and therefore, no location for leakage of the fluid.

The disadvantages of all types of reciprocating pumps are that they 1) are bulky, with the exception of the diaphragm pumps; 2) require a high net positive suction head (more than $1 \%$ entrained air will cause the pump to fail); 3) are generally unsuitable for handling liquids containing solids, abrasives, or dirt, with the exception of the diaphragm pump; 4) have pulsating flow; 
5) require periodic maintenance of check valves, stuffing box, drive-end hydraulic fluid; 6) usually require stuffing box lubrication; and 7) may require flushing, and flush cleaning may not be possible.

\subsubsection{Rotary Pumps}

Rotary pumps consist of a chamber containing gears, cams, screws, vanes, or similar elements actuated by the rotation of the drive shaft or casing. The pump has no inlet and outlet check valves. In general, as the rotary member turns, it creates cavities that move from suction to discharge forcing the liquid along.

The three most common types of rotary pumps include the gear, lobe, and screw pumps. These pumps are shown in Figure 8 . The gears, lobes, or screw act as the impeller. These impellers rotate with extremely small clearance between the impellers and the casing. The pumped liquid flows into the spaces between the impeller teeth as these cavities pass the suction opening. The fluid is discharged as it passes the discharge opening.

A seal between the suction and discharge is formed by close clearances or sliding or rolling contact. Because of this, the selection of materials of construction is critical. The materials must be corrosion-resistant, compatibie when one part is running against the other, and capable of some abrasion resistance. These materials include machinable metals and alloys and certain types of rubber and plastics.

The flow rate from rotary pumps is proportional to the speed. The capacity of the pumps range up to $5000 \mathrm{gpm}$ with discharge pressures to $2000 \mathrm{psi}$.

Rotary pumps are typically used 1) with clean, nonabrasive, noncorrosive liquids (pumps having resilient elastomer members are exceptions), 2) over a wide range of viscosities varying from solvents to heavy tars, soaps, and greases, 3) at pressures up to 1,000 psi with nonlubricating fluids and higher with lubricating fluids, 4) with low viscosity volatile fluids including entrained gases or vapor, 5) with miscellaneous chemicals, oils, gasoline, solvents, ink, tars, greases, soaps, paint, varnish, and molasses, 6) for metering, and 7) at low flow rates over a wide range of pressures. 


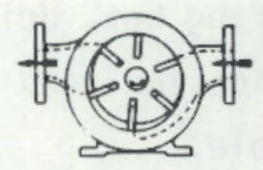

Sliding Vane

Pump

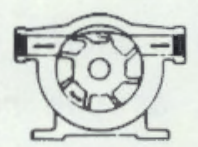

Flexibie Vane

Pump

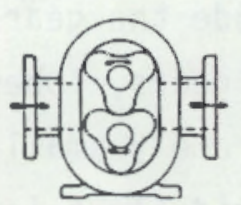

Three-Lobe

Pump

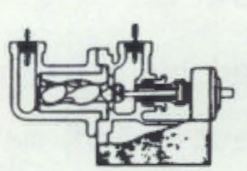

Single Screw

Pump

(progressing cavity)

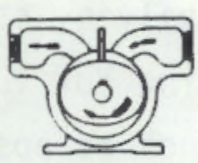

External Vane

Pump

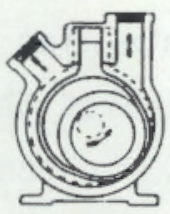

Flexible Liner

Pump

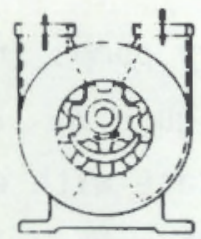

Internal Gear

Pump

(with crescent)

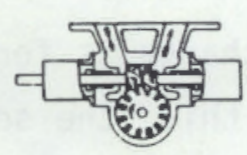

Screw and Wheel

Pump

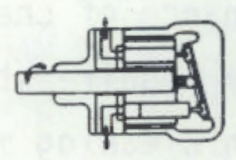

Axial Piston

Pump

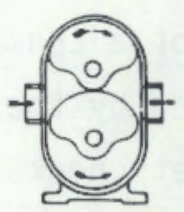

Single Lobe

Pump

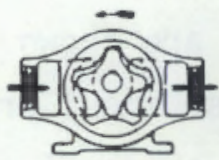

Internal Gear

Pump

(without crescent)

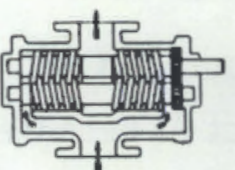

Two Screw

Pump

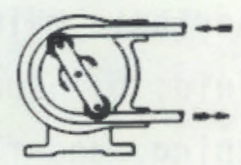

Flexible Tube

Pump

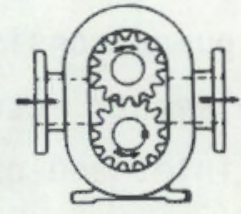

External Gear

Pump

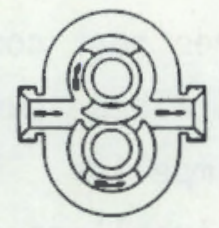

Circumferential Piston Pump

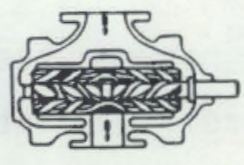

Three Screw Pump

FIGURE 8. Rotary Pumps

The advantages of rotary pumps include: 1) no check valves are used; 2) mechanical seals can be used, which lowers lubrication requirements; 3 ) seal water, if required, can be delivered at a constant pressure; 4) self-priming and no air entrainment problems; 5) constant flow - no pulsations; 6) small space requirement; and 7) simple to use.

The disadvantages include: 1) close clearances and/or rubbing contact limit suitable materials of construction and handling of solids, 2) rotorstator abrasion increases as discharge pressure increases, and 3) protection from overpressurization is required. 


\subsubsection{Air-Displacement Pump}

A third type of positive displacement pump is the air-displacement pump. This type of pump is also referred to as a blow case or acid egg.

The air-displacement pump consists of a chamber filled with liquid. Once filled, valves are actuated to admit into the chamber air or inert gas that is at a pressure high enough to displace the liquid out through the discharge line. The type and location of the valves can vary depending on the application. A wide variety of construction materials can be used depending on the physical properties of the liquid and the operating pressures.

The basic operating principles for an air-displacement pump are shown in Figure 9. The entire operating cycle can be simplified into a series of four steps. The first two steps involve the filling of the chamber with liquid. The first step positions the valve while the second step allows for the filling

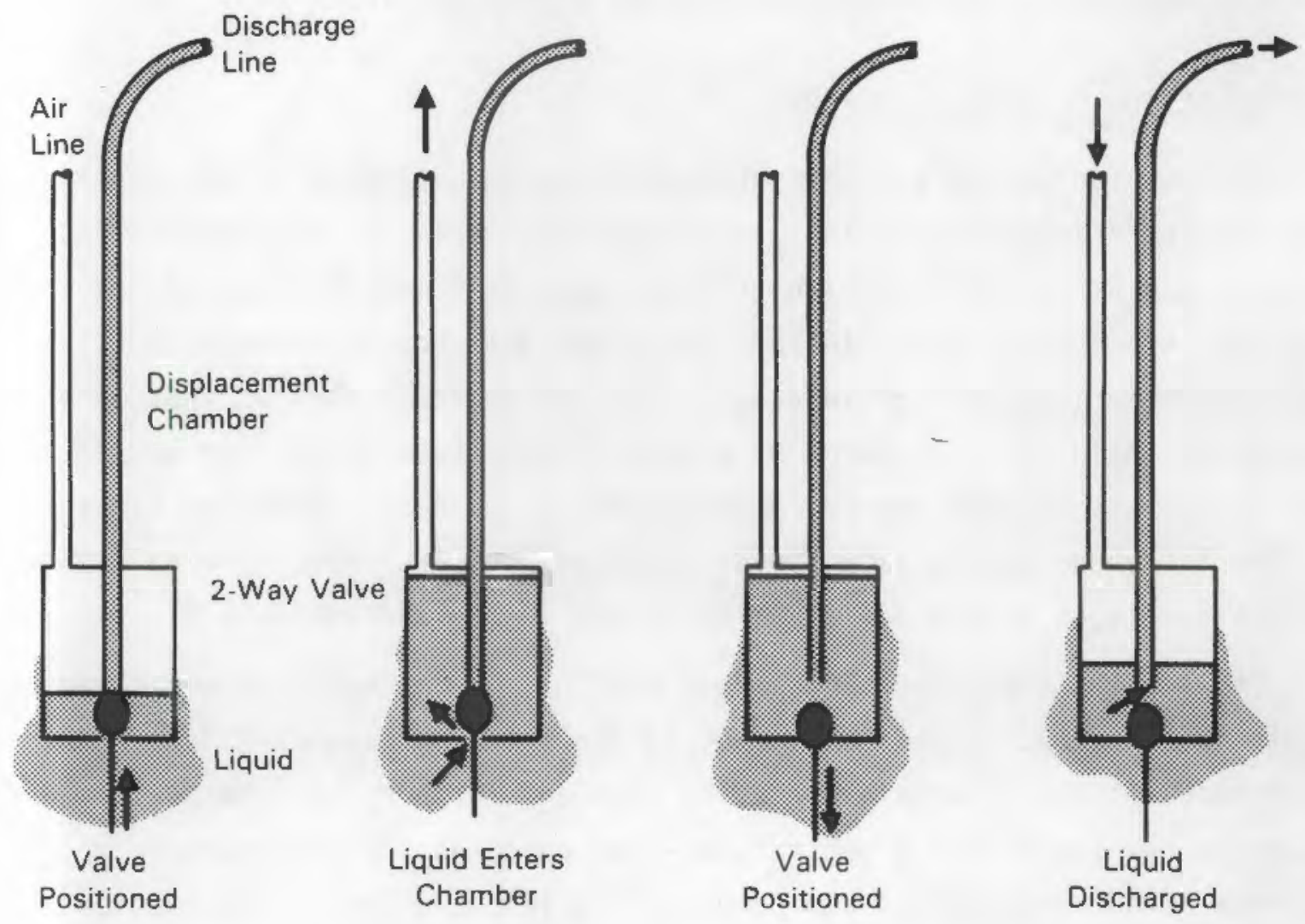

FIGURE 9. Operating Cycles of ADS Pump 
of the chamber. The last two steps involve the discharge of the chamber. The third step repositions the valve. The fourth step is the discharge step, where compressed air or inert gas is valved into the chamber, forcing the slurry out the exit line. The air or gas can be considered as a reciprocating piston, and control of the air or gas determines the flow rate. The duration of each cycle and number of cycles per unit time depend on the size of the chamber. This cycling creates a pulsating flow pattern. These pumps are commonly designed with two chambers. One chamber is filling while the other is discharging. This produces a steady flow pattern.

The air-displacement pumps were used principally for pumping acids before good packings and seals were developed. It is no longer in wide use. The advantages include: 1) all-metal construction, 2) a driven valve, as opposed. to check valves, 3) ability to be easily submerged through the tank lid with the chamber located close to the tank bottom, and 4) low discharge pressure. Its disadvantage is its pulsating flow and air/liquid interface.

\subsection{SELECTION OF CANDIDATE PUMPS}

The pump selection process integrates the requirements of the application with the operating characteristics of pumps available in the marketplace. The process results in the selection of pumps that will meet the design requirements for the application. In this instance, only non-economic (i.e., technical) considerations were of interest. The non-economic factors that were considered included achievement of process flow rates, simplicity of design, ease of operation, maintenance requirements, ruggedness, operating flexibility, service life, and suitability for a radioactive environment. The advantages and disadvantages of the pumps evaluated are summarized in Table 3.

The goal of the selection process was to select pumps that satisfied the specified criteria. Those pumps meeting the criteria were considered for experimental testing to gain operating data and further evaluate performance. Extensive development of a centrifugal-type pump was already underway at Savannah River Laboratory. Jet pumps were eliminated from consideration because they are not suitable as a metering pump and the motive fluid will either dilute (if a liquid) or dry (if a gas) the slurry stream. 
TABLE 3. Advantages and Disadvantages of Pumps Considered for the Vitrification Process

TYPE OF PUMP

\section{Kinetic Pumps}

Centrifugal

Alr-Litt

Jet
ADVANT AGES

Very few moving and wearling parts. Small space requirement.

No close clearances; liquids contalnling dirt, abraslves, and large sollds are easlly handled.

Low maintenance, dependable service.

Lou net positive suction head

requ I rements.

wlde range of slzes and operating

characteristlcs.

Unlform (non-pulsating) flow.

Valves not requlred.

No movlng mechanleal parts in slurry. Alr source can be remotely located.

All-metal construction.

No moving mechanical parts.
DISADVANTAGES

Unstable at low flow rates.

Packlng glands requlred along rotating shatt.

Seal water requlred, wich dilutes

llquid being pumped.

Speclal design requlred for top

entry.

A.lr Injectlon can cause foaming.

Pulsating tlow.

Low veloclty in llft llne can cause sollds to settle.

Liquid can be entralned In vent i ines.

Fluid belng pumped becomes dlluted. Low head. 
TYPE OF PUMP

Positive Displacement Pumps Reciprocating

Rotary

Air Displacement
ADVANTAGES

HIgh pump discharge pressure at low plston/plunger speeds (less abras(on).

HIgh mechanical efficiency (Iomer power requirements).

Capacity is a function of speed, not dlscharge pressure (easy to control dlscharge

capacity).

the drive/llquld end of pumps.

Self-priming.

Selt-contalned.

valves.

Mechanlcal seals can be used - lower lubrication requirements.

Seal water, if required, can be

delivered of a constant pressure as low as 10 psig.

Pump suction requirements

- self-priming

- no sir entralnment problems.

Constant flow - no pulsations.

All-metal construction.

A driven valve Is used instead of check valves.

Easily submerged into tank.
DISADVANTAGES

Pulsating flow (pulsation dampeners needed).

Pump suction requirements (more than 17 entralned air causes pump to tall; pump priming requlred, suction plpling deslgn is criticall.

Requires perlodic malntenance of

check valves, stuffing box, driveand hydraulic fluid.

Stuffing box lubrlcation is recomr mended.

Seal water dellvery pressure must be adjusted to remaln above pump dlscharge pressure, as pump discharge pressure fluctuates.

Flush clesing may not be possible.

Rotor-stator abraslon Increases as discharge pressure increases.

Close clearances and/or rubbing contact limlt sultable materlals of construction and handling of sollds.

Protectlon from overpressurization required.

Pulsating flow. 
The ability to place the pump head remotely from the driven device linked by a hydraulic working fluid made the reciprocating positive displacement pump attractive. However, the tendency for the check valves to foul in the presence of solids and the fatigue-induced faiture of metal diaphragms removed these pumps from further consideration.

Rotary pumps have been shown to be very reliable in nonradioactive applications. The requirement for all-metal wetted parts does raise questions about the pump's reliability with slurries that contain silica. In addition, the water flush that may be required for the mechanical seals has the potential for adding additional water to the slurry stream. Although not selected for the test program reported here, the rotary pump was believed to offer many positive advantages for an application such as ours.

Based on the evaluation of available pumps, two pumps were chosen for further evaluation: a positive displacement pump (the air-displacement pump) and a kinetic pump (the air-lift pump). Because of the limited commercial usage of these pumps, existing operating data was scarce. Both pumps are of all-metal construction. They are designed to enter through the top of the tank with the suction located close to the tank bottom. Both rely on compressed air for their operation which is easily obtained in a radioactive environment. The pump output is a function only of the air pressure applied.

The remainder of this report will discuss the experimental testing that was conducted and present the operating data obtained during long-term testing of both pumps. 


\subsection{PREPARATION AND COMPOSITION OF SIMULATED SLURRIES}

The HLLW slurry metered to the ceramic melter for processing consists of the HLLW, glass forming materials, and modifying agents to enhance the slurry rheology or melter processing. The waste fraction consists of the waste generated during nuclear fuel reprocessing. The glass forming materials can be added as individual glass forming chemicals or as a glass frit. Glass-forming chemicals are usually in the form of metal hydroxides, nitrates, formates, oxalates, or oxides. Glass frit is ground glass that was produced by melting the glass-forming chemicals, cooling the resulting glass product, and milling the product to the required particle size. The design of the slurry begins once the HLLW composition has been specified. An empirical computer model based on many years of glass development data is used to define a firstapproximation glass composition for initial testing (Chick et al. 1984). Next a simulant of the HLLW is prepared. Glass forming materials are added to this simulated waste, the combined slurry is melted, and the properties of resulting glass are analyzed. This procedure is repeated until a working glass is defined that possesses the required physical and chemical properties. The working glass is then subjected to extensive testing with both laboratory-scale and large-scale melter equipment. These tests are designed to optimize the meltability and chemical durability of the glass product and define its tolerance to changes in the waste composition.

The simulated slurries used in the pump tests have been tailored to produce an acceptable glass product based on site-specific HLLW chemical and physical properties. Slurries prepared to simulate the waste-glass composition for two different sites were used. One slurry type evolved from glass development for a defense waste currently stored at the Hanford Site in southeast Washington. The second slurry evolved from glass development for a commercial waste currently stored at the West Valley Demonstration Project in southwest New York. As development of acceptable glass compositions has continued for each site, the slurry compositions have evolved. At the time of each pump test, the then-current composition was used. While these compositions are no longer considered the reference for these sites, their rheological properties are sufficientiy representative of typical HLLW slurries and cover the normal range of 
both alkaline and acidic mixtures. The slurries tested provided a good demonstration of each pump's ability to perform in this application. The slurries used in the long-term pump tests are described in Sections 5.1 and 5.2. The composition and physical properties of these slurries are included in Appendix $A$. The slurries are referenced in Section 6 to the specific pump test in which they were used.

\subsection{SIMULATED SLURRIES USED DURING EXPERIMENTS WITH THE AIR-DISPLACEMENT SLURRY PUMP}

The development and operation of the air-displacement slurry (ADS) pump was conducted with four different slurry compositions. The ADS pump tests were conducted with both alkaline and acidic slurries. Each slurry will be discussed below. Standard laboratory procedures were used to measure the slurry physical properties: density, solids content, oxide content, and viscosity. The composition and physical properties of the slurries are included in Appendix $A$. In the nuclear waste industry, the concentration of the slurry is characterized in terms of grams total oxides produced/L of slurry. During the processing of the slurry in the ceramic melter, the chemical constituents are converted to their stable oxides. The oxide content is shown in the physicalproperty tables (Appendix A).

\section{1 .1 Alkaline Compositions}

Two neutralized slurries were used during ADS pump testing. Test \#1 of the pump was conducted using the simulated slurry shown in Table A.1. This slurry was a neutralized slurry composition in which the glass forming materials were added as a glass frit. This table shows the actual chemicals used to make the simulated slurry. The physical properties of the slurry are shown in Table A.2. The second neutralized slurry, which was used in ADS pump Test \#5, is shown in TabTe A.3. Test \#5 was conducted with the modified ADS pump. The physical properties of this slurry are shown in Table A.4.

\subsubsection{Acidic Compositions}

A11 of the remaining pump tests were conducted using acidic compositions. The composition of the simulated slurries for Test $\sharp 2$ is shown in 
Table A.5. In Test $\$ 2$, the silica was added as 83 wt\% colloidal silica stabilized with sodium sulfate and 17 wt\% ground (-325 mesh) silica. The physical properties of this slurry are shown in Table A.6.

The composition of the slurry that was used during ADS pump Test $\# 3$ is shown in Table A.7. The density of the slurry was $1.4 \mathrm{~g} / \mathrm{ml}$. No other physical properties were measured. The composition of the slurry that was used during ADS pump Test 4 is shown in Table A.8. This slurry is unique in that it contains an ion exchange resin referred to as zeolite. Over $80 \%$ of the zeolite particles have diameters less than 200 mesh. The physical properties of this slurry are shown in Table A.9.

\subsection{SIMULATED SLURRIES USED DURING EXPERIMENTS WITH THE AIR-LIFT PUMP}

Eleven experimental tests of the air-lift pump were conducted using both neutralized and acidic slurry compositions. Each slurry will be discussed below.

\subsubsection{Neutralized Compositions}

Two neutralized slurry compositions were used during air-lift testing. The first eight tests were conducted using the slurry shown in Table A.10. The glass forming materials were added as individual chemicals. Test was conducted using the slurry shown in Table A.11. The only difference between Table A.10 and Table $\mathrm{A} .11$ is that $\mathrm{Nd}\left(\mathrm{NO}_{3}\right)_{3}, \mathrm{Ce}\left(\mathrm{NO}_{3}\right)_{3}$ and $\mathrm{La}_{2} \mathrm{O}_{3}$ were added instead of the natural rare earth nitrate mix $\left(\mathrm{RE}\left(\mathrm{NO}_{3}\right)_{3}\right)$.

\subsubsection{Acidic Compositions}

Two acidic slurry compositions were used. Test \#20 was conducted using the slurry shown in Table A.12. Again, the glass forming materials were added as individual chemicals. Testing of the final reference design of the air-lift (Test 11) was conducted using the acidic slurry shown in Table A.8. This is the same slurry used during AOS pump Test \#4. This slurry is unique in that it contains an ion exchange resin referred to as zeolite. The zeolite is ground so that $80 \%$ of the particle diameters are less than 200 mesh. The physical properties of this slurry are shown in Table A.9. 
.

$\checkmark$ 


\subsection{PUMP EVALUATIONS}

The experimental testing and evaluation of the ADS pump and the air-lift pump were initiated during FY 1983. The objectives of the evaluations were to: 1) operate the feed delivery systems in long-term tests to determine operating parameters and system reliability, 2) identify mechanical weaknesses and operating deficiencies in the pump systems, and 3) evaluate the corrosion and erosion of components of the pumps to obtain estimates of service 1 ife.

Throughout the two years of testing, design modifications were made in order to improve operation, reliability, and eliminate system weaknesses. These design changes have led to the modified pump designs that are currently being used for this application. A discussion of the experimental procedures used to evaluate each pump is provided in Section 6.1. The results of testing using both the initial and modified designs of the ADS and air-lift pumps are described in Sections 6.2 and 6.3 , respectively.

\subsection{EXPERIMENTAL PROCEDURES}

The experimental procedures used to test the ADS pump and the air-iift were identical. The pumps were installed in a mixing tank with the discharge from the pumps connected to a recirculation loop for continuous testing. The slurry was pumped from the tank through the loop and returned to the tank. The recirculation line for the ADS pump was made of 0.305-in.-I.D. stainiess steel tubing. The recirculation line for the air-lift pump was made of 0.75-in.-I.D. plastic tuhing.

The duration of the tests varied from a few hours to over $1000 \mathrm{~h}$ of continuous operation. These pumps were tested through the full range of flow rates expected for full-scale pumps. Pump status and feed rate determinations were taken two to three times each work day and usually once per day during weekends. At these times, pressures, air flows, slurry flow rates, operating set points, and pump stability data were recorded. Downtime periods were recorded including length of time not operating and the probable cause of the 
downtime. When solids deposited in the lines, forming plugs, the lines were typically water flushed. If this was not effective, the lines were disassembled and manually cleaned.

The pumps were calibrated using both water and slurry during initial testing to determine the cycle times and air pressures required to obtain a desired flow rate. The flow rates were periodically checked and compared with the calibration curves.

Flow rate determinations were made by recording the time necessary to fill a 2-L graduated cylinder. The amount of slurry collected was always greater than $1.7 \mathrm{~L}$ to minimize volume measurement errors. In addition, the volume was large enough to overlap several ADS pump cycles and air-ijft pulses which minimize the error due to flow surging over short time periods. A digital or analog stopwatch recorded the elapsed time during sampling. Each rate determination was measured three times and the average flow rate recorded. Flow rate checks were made no sooner than 5 min after set point changes to assure that the pump operation had stabilized.

The pumps were operated through the full range of the expected full-scale operating flow rates. The flow rate range tested was 20-175 L/h. Approximately $25 \%$ of the operating time was spent at or near the maximum rate and $25 \%$ was spent at or near the minimum rate. The pumps were also operated at $125 \%$ of the maximum design flow rate for an extended period of time to determine the maximum stable flow rate.

The operation of both pumps was dependent on the liquid head in the tank. With the ADS pump, the filling of the pump chamber was a function of the tank head. With the air-lift pump, the submergence, which influences lift height, is a function of the liquid head in the tank. Therefore, the effects of tank head changes on the feed rate stability and pump operational characteristics were evaluated. The tank level was varied over a range of $30-100 \%$ of the full liquid level.

Another objective of the testing was to ohtain estimates of the service life of major pump components. An estimate of service life was obtained hy measuring the corrosion/erosion effects of the slurry on various components of 
the pump. Prior to testing, major components of the ADS pump were measured and weighed. These measurements were than repeated at the end of the test period. The results were used to identify critical wear areas, identify areas where special materials should be used, and estimate the expected service life of the pump. Evaluation of the air lift pump for erosion was limited to visual examinations. Because of the very low operating pressures no erosion was expected to warrant more detailed study.

\subsection{EXPERIMENTS WITH THE AIR-DISPLACEMENT SLURRY PUMP}

The experimental testing and evaluation of the ADS pump were initiated in FY 1983. The major objectives of these experiments were to: 1) operate the ADS pump in long-term tests to determine operating parameters and system reliability, 2) evaluate mechanical weaknesses and operating deficiencies in the pump, and 3) evaluate the extent of the corrosion and erosion of pump components to obtain estimates of service life.

The ADS pump design is a PNL design that was inspired by a mercury pump designed by Bechtel in support of the Defense Waste Processing Facility (DWPF) at the for Savannah River site. Since its conception, the design has undergone five design modifications and five long-term testing evaluations. The early test programs identified weaknesses in the pump design that led to modifications, further testing and, after several iterations, a final design. The long-term testing of the final design has been successfully completed. In addition to long-term testing in a recirculation loop, the pump has been satisfactorily operated in pilot-scale vitrification experiments with nonradioactive melter feed slurries. The results of the operation of the pump in these experiments are not included in the scope of this report; the experiments are mentioned merely to indicate that the pump has been used in its intended application.

This section of the report will summarize the results of the ADS pump testing. Section 6.2.1 presents the major design factors that were built into the ADS pump. A summary of the initial pump designs and test results are presented in Section 6.2.2. The final pump design, long-term test results, and corrosion/erosion data are presented in Section 6.2.3. 


\subsubsection{Design Considerations}

The ADS pump was designed at PNL as a slurry delivery system for the vitrification process. In the design of the pump, the operating criteria as well as the requirements for operating in a radioactive environment were considered (see Section 4.0).

The pump chamber is submerged through the top of the melter feed tank with the displacement chamber located close to the tank bottom as shown in Figure 10. The pump is mounted on a standard flange for easy installation and removal. The chamber is positioned close to the tank bottom (approximately $0.5 \mathrm{in.)}$ to maximize the amount of slurry that can be pumped out. All pump parts are metal, which makes it acceptable for use in radioactive environments. A two-way driven valve is used on the inlet to the pump chamber. This valve was operated by a double-acting pneumatic cylinder.. A driven valve was selected to force the valve open and closed. Any solids that may become trapped between the valve and seat would be crushed by the action of the valve, thereby preventing leakage past the valve and seats. The pump operates using standard electric solenoid valves and a controller. The pump can be easity water flushed when necessary because the driven valve can be positioned as required. The pump chamber and lines are sized to deliver the desired fiow rate range.

\subsubsection{Experiments with the Initial ADS Pump Designs}

Prior to the final design, the ADS pump underwent four design modifications based on the results of long-term tests. The four designs ( $a, b, c$, and d) are shown in Figure 10. The results of testing the initial designs are presented here to document the development of the ADS pump.

The general operating principles of the first three pump designs are the same. The complete pump operating cycle can be simplified into a series of four steps (Figure 9). During the first step of the cycle, the two-way valve is driven upward via the double-acting pneumatic cylinder. This permits slurry to flow into the pump chamber and at the same time closes off the feed line going to the melter. During the second step, slurry is drawn into the pump chamber by the suction created by a syringe that is driven by a pneumatic 


$$
\text { furu }
$$


cylinder, which withdraws air from the chamber. In the third step, the two-way valve is driven downward, closing the port into the tank and opening the feed line to the melter. The fourth step of the cycle effects the actual discharge of the slurry. The pneumatic cylinder pushes the syringe down and expels pressurized air into the pump chamber, forcing slurry out the exit line. These four steps are continually repeated, creating a pulsating flow pattern.

The control system is a mechanically operated sequencer that allows the setting of the duration of each of the four steps of the pump cycle. A schematic of this system is shown in Figure 11a. The sequencer works by energizing and de-energizing the electric solenoid valves.

The pump design shown in Figure 10d was operated in two ways. Initially, the pump system was operated identical to the first three designs using the syringe and pneumatic cylinder drive to supply the air. In the second method of operation, the syringe and the pneumatic cylinder drive were replaced, and the air was supplied to the chamber from a main compressed air header. The air pressure was controlled using a standard pressure regulating valve. This change affects steps 2 and 4 of the pump cycle. The second step was still a fill step, but the slurry was allowed to fill the chamber simply as a function of the tank head. There was no suction involved. The time for this step was adjusted as the tank head became smaller. The air, which was in the chamber prior to filling, was vented through a three-way electric solenoid valve back into the tank. In the fourth step, pressurized air ranging from 0 to 20 psig forced the slurry out the feed line and into the melter. This control system is shown in Figure $11 \mathrm{~b}$.

The first design (Figure 10a) is the earliest design of the pump. The pump chamber has a volume of approximately 1 L. A 2-in.-dia stainless steel ball is used for the driven valve. The drive rod for the two-way valve comes through the center of the chamber. Flexible tubing was used as a moving shaft seal to prevent slurry from traveling up along the shaft. The outlet line size was 0.25-in.-0.D. x 0.035-in.-wall-thickness stainless steel tubing. The air supply line was $0.50 \mathrm{in} . \times 0.035 \mathrm{in}$. wall thickness stainless steel tubing. Initial testing of this design led to early failure of the shaft seal. The 
Air to Upstroke of Double Acting

Pneumatic Cylinder

(A)

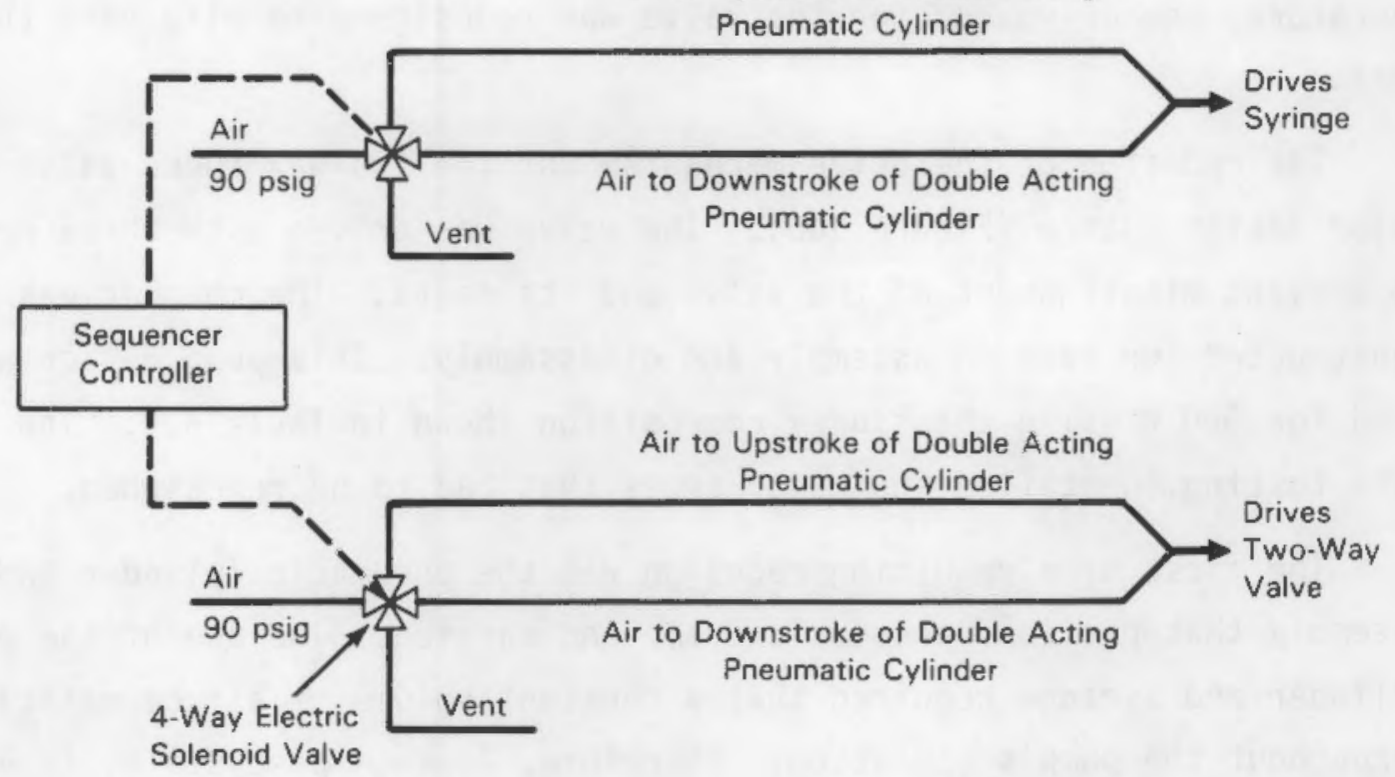

- - - Signal

Flow

(B)

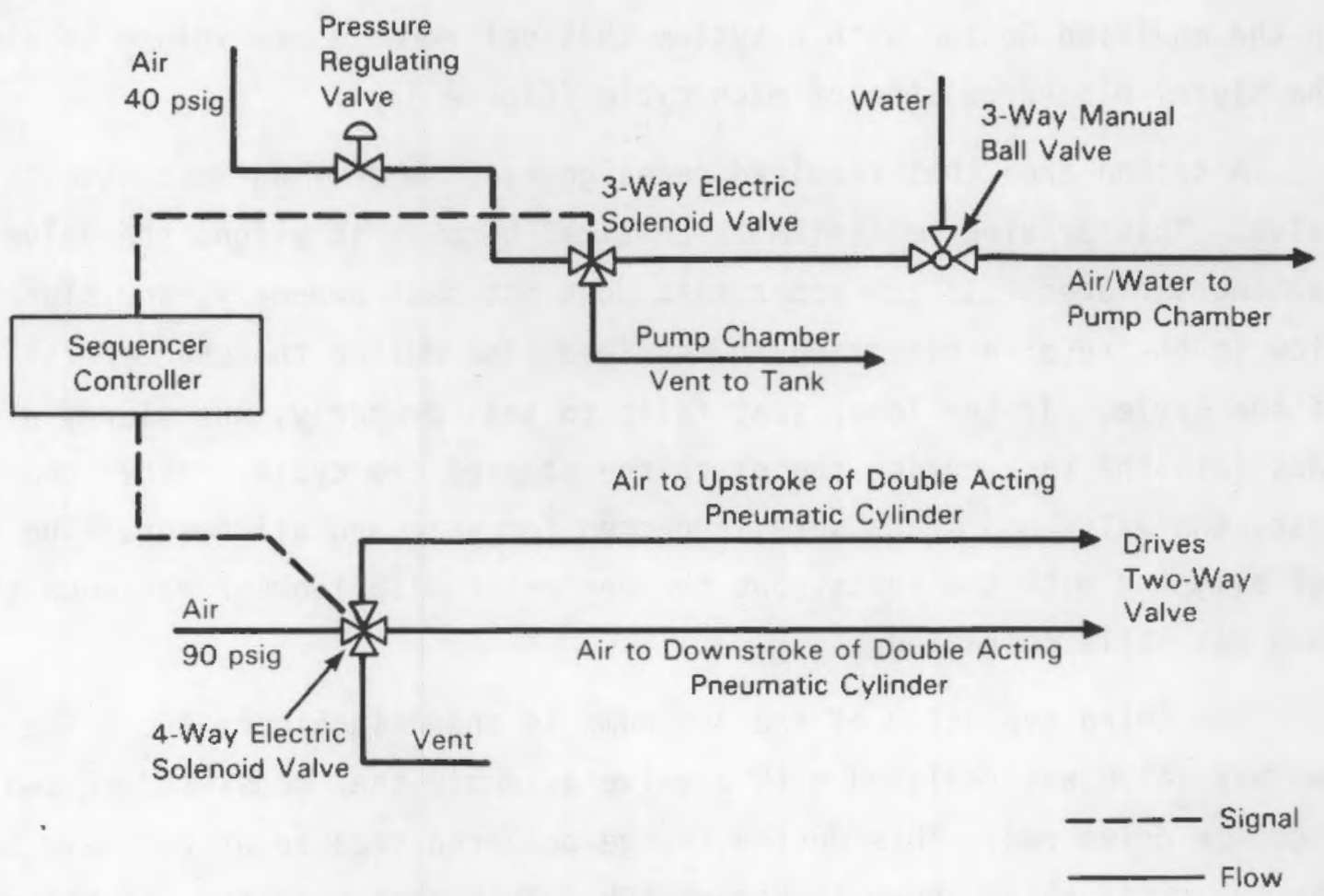

FIGURE 11. Control Schematics for Initial ADS Pump Designs 
flex tubing did not perform as expected, failing after less than 50 cycles. Therefore, the drive rod for the valve was redesigned to eliminate the shaft seal.

The redesign of the drive mechanism for the two-way round valve was the major design change (Figure 10b). The valve was driven with three drive rods to prevent misalignment of the valve and its seats. The chamber was flange constructed for ease in assembly and disassembly. This pump design was operated for $560 \mathrm{~h}$ using the slurry composition shown in Table A.1. The results of this testing identified two major areas that had to be redesigned.

The first area requiring redesign was the pneumatic cylinder and syringe assembly that provided pressurized air and suction. The use of the pneumatic cylinder and syringe required that a constant volume of air be maintained throughout the pump's operation. Therefore, leakage past seals, in valves, and in fittings could not be tolerated unless the pump was stopped and the air volume replenished. It was determined that the air volume had to be replenished every $24 \mathrm{~h}$. This procedure was not appropriate for remote operation due to the relatively short period of continuous operating time. This system was replaced in the modified design with a system that delivered a new volume of air during the slurry discharge step of each cycle (Figure 11b).

A second area that required redesign was the driving mechanism for the valve. This driving mechanism is critical because it aligns the valve and seating surfaces. If the upper seat does not seal properly, the slurry will flow in the reverse direction in the feed line during the chamber-filling step of the cycle. If the lower seat fails to seal properly, the slurry will go back into the tank during the discharge step of the cycle. After the 560-h test, the valve and seats were inspected for wear and alignment. The valve was not aligning with the seats, but the degree of misalignment was such that the pump was still operating.

The third evolution of the ADS pump is shown in Figure 10c. The spherical two-way valve was replaced with a valve assembly that consisted of two discs on a common drive rod. This design change occurred because of the wear shown on the spherical valve shown in Figure 10b. This configuration was tested to determine if the seal between the valve and seats could be improved. The 
outlet line size was increased to 0.38-in.-0.D. $\times 0.35$-in.-wa1l-thickness stainless steel tubing. This change resulted in an approximately $50 \%$ increase in the flow rate. The slurry composition that was used in this testing is shown in Table A. 5 .

This pump design (Figure 10c) was tested for a total of $1060 \mathrm{~h}$. During testing, an alignment problem was encountered with this design that made it difficult to obtain a good seal on the upper valve seat. The pump continued to operate without a good seal on the upper seat, but reverse flow occurred in the slurry exit line. This decreased the efficiency of the pump but still allowed it to cover the flow rate range. Inadequate manufacturing tolerances during the fabrication of the driving mechanism were primarily responsible for the poor alignment.

The disadvantage of using the pneumatic drive cylinder and syringe is that the air supply must be replenished on a regular basis. To eliminate the downtime required for this step, a three-way solenoid valve controlling the delivery of compressed air into the pump chamber was tested in place of the syringe: The three-way solenoid valve allowed a new volume of air into the pump chamber during each cycle and vented the air in the chamber to the feed tank (Figure 11b).

The last of the initial designs of the ADS pump is shown in Figure $10 \mathrm{~d}$. The two-way valve was redesigned, the drive mechanism was strengthened, and tighter tolerances were imposed during fabrication to improve the alignment of the valve and seats. Two slurry compositions were used during the testing of this pump design. The pump was operated for $230 \mathrm{~h}$ using the composition shown in Table A.7 and for $759 \mathrm{~h}$ using the composition shown in Table A.8. The pneumatic cylinder and syringe were used during the 230-h test, while the three-way solenoid valve was used for the 759-h test. As previously discussed, the operating cycles for two control systems are different (Figure 11). The major weaknesses determined in these final tests were with the air delivery systems, mainly the pneumatic cylinder and syringe, as already discussed, and the wear shown on the valve and seats. The valve and seats were fabricated from 300-series stainless steel, which is a relatively soft metal; a harder material is definitely required. 
Testing of the initial pump designs proved the concept of operation. Table 4 provides a summary of the initial designs. A summary of the results of this testing are discussed below.

\subsubsection{Results of Testing with the Initial ADS Pump Design}

To operate the ADS pump one must select the air pressure and cycle time needed to obtain a desired flow rate. The specific objective of the test was to determine how the air pressure, cycle time, and tank head affect the flow rate.

The pneumatic cylinder and syringe for supplying the air to the pump chamber were used with two initial pump designs. With this system, the pressure of the air going to the pump chamber cannot be directly regulated with the air supply system. The pressure to the pump chamber was varied by increasing or decreasing the air pressure to the pneumatic cylinder. Increasing the pressure increases the force exerted by the drive, which in turn increases the pressure output of the syringe.

Theoretically, the volume of air discharged from the syringe is constant. Assuming that the chamber is filled with the same volume of slurry, the volume of slurry displaced would be the same during each cycle. Therefore, the pump flow rate will be equal to the volume of slurry displaced divided by the cycle time.

The operation of the pump creates a pulsating flow pattern. During Test \#1 (Table 4), this pulsating flow pattern was characterized by measuring the pump output at 2-s time intervals using a mass flow meter. A typical curve

\section{TABLE 4. Summary of Initial Pump Designs}

\begin{tabular}{|c|c|c|c|c|}
\hline $\begin{array}{l}\text { Test } \\
\text { No. } \\
\end{array}$ & $\begin{array}{l}\text { Pump } \\
\text { Designs }\end{array}$ & $\begin{array}{l}\text { Total } \\
\text { Hours } \\
\end{array}$ & $\begin{array}{c}\text { Slurry } \\
\text { Composition } \\
\end{array}$ & Air Control System \\
\hline & Figure 1la & 0 & -- & -- \\
\hline 1 & Figure $11 b$ & $560 h$ & Table A.1 & Pneumatic cylinder/syringe \\
\hline 2 & Figure $11 \mathrm{c}$ & $1060 \mathrm{~h}$ & Table A.5 & 3-way electric solenoid valve \\
\hline 3 & Figure 11d & $230 \mathrm{~h}$ & Table A.7 & Pneumatic cylinder/syringe \\
\hline 4 & Figure $11 d$ & $759 \mathrm{~h}$ & Table A. 8 & 3-way electric solenoid valve \\
\hline
\end{tabular}


using slurry with a composition listed in Table A.1 is shown in Figure 12. When the pump is used to feed a melter, the average flow rate, not the instantaneous flow rate, is monitored. The flow rate rapidly increases at the beginning of Step 4 of the pump cycle. The majority of the chamber volume is displaced in the early stages of Step 4 . Towards the end of Step 4 and during Steps 1, 2, and 3 of another pump cycle, the flow rate is zero.

The effect of cycle time on the slurry flow pattern is shown in Figure 12. The average flow rate was affected only slightly when the cycle time was reduced by half. This was an unexpected result because the flow rate pattern was significantly changed. We want to minimize the amount of time the pump operates at the low flow rates (i.e., <10 L/h), therefore, the preferred flow pattern would be at the shorter cycle times because the amount of time the flow rate is less than $10 \mathrm{~L} / \mathrm{h}$ is shorter. At the low end of the range, the solids have a greater tendency to settle out, causing potential plugging problems.

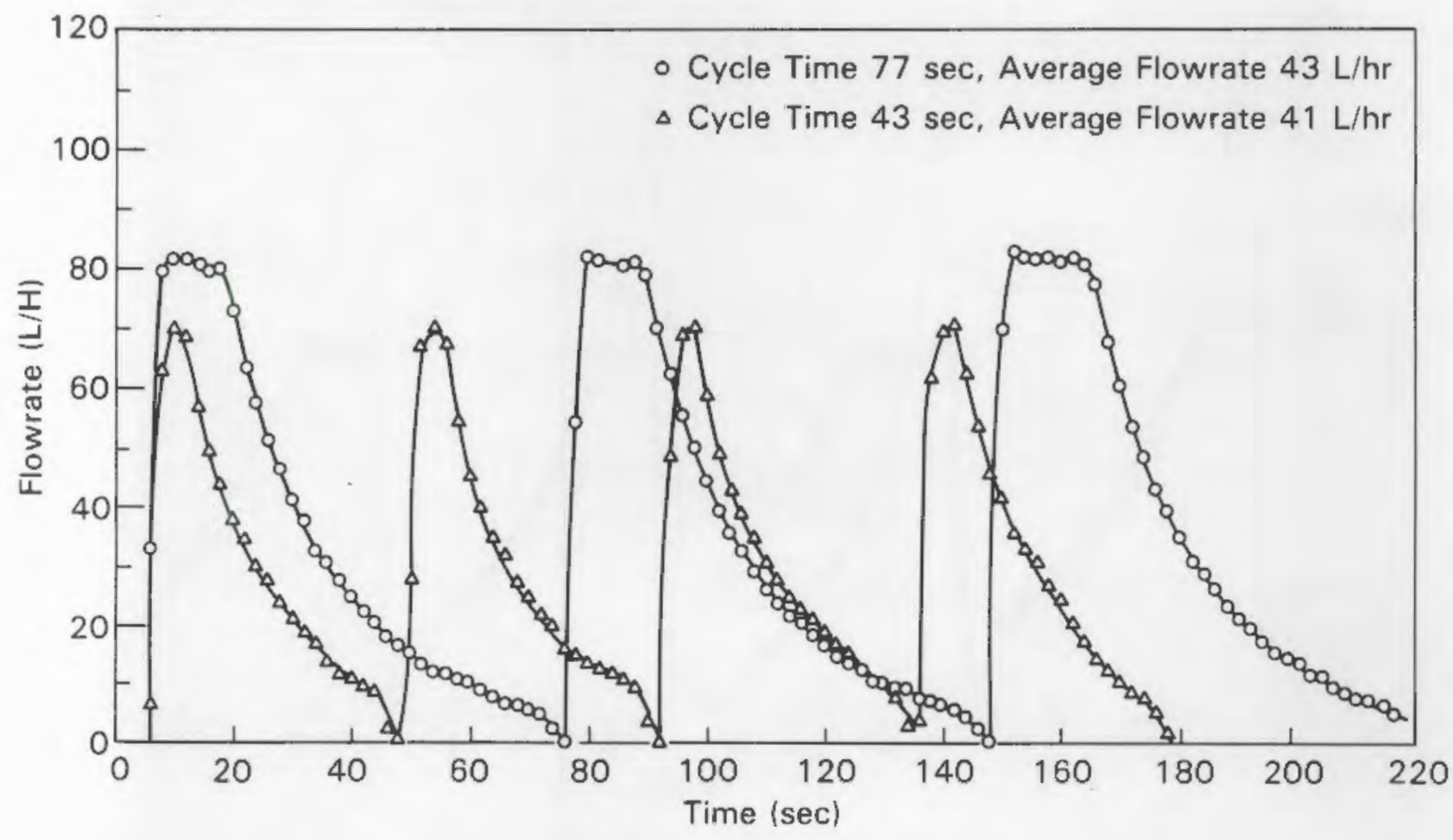

FIGURE 12. Effect of Cycle Time on the Flow Pattern of the Air-Displacement Pump 
The next parameter that was varied was the air pressure to the pump chamber. This was accomplished by varying the pressure to the drive from 52 to 90 psig, which in turn varied the pressure to the pump chamber between 3 and 6 psig. The maximum pressure measured in the slurry line was 10 psig. The effect of this factor on the flow pattern and average flow rate is shown in Figure 13. The average flow rate, which was measured with a graduated cylinder and stopwatch, did not change with the increase in pressure. However, integrating the area under the curves indicates, in all but one case, that the flow rate increased at the higher pressure. Errors in the instantaneous readings from the mass flowmeter, was attributed to these differences. The slurry discharge was visually observed. The increase in pressure did increase the force which should have increased the flow rate.

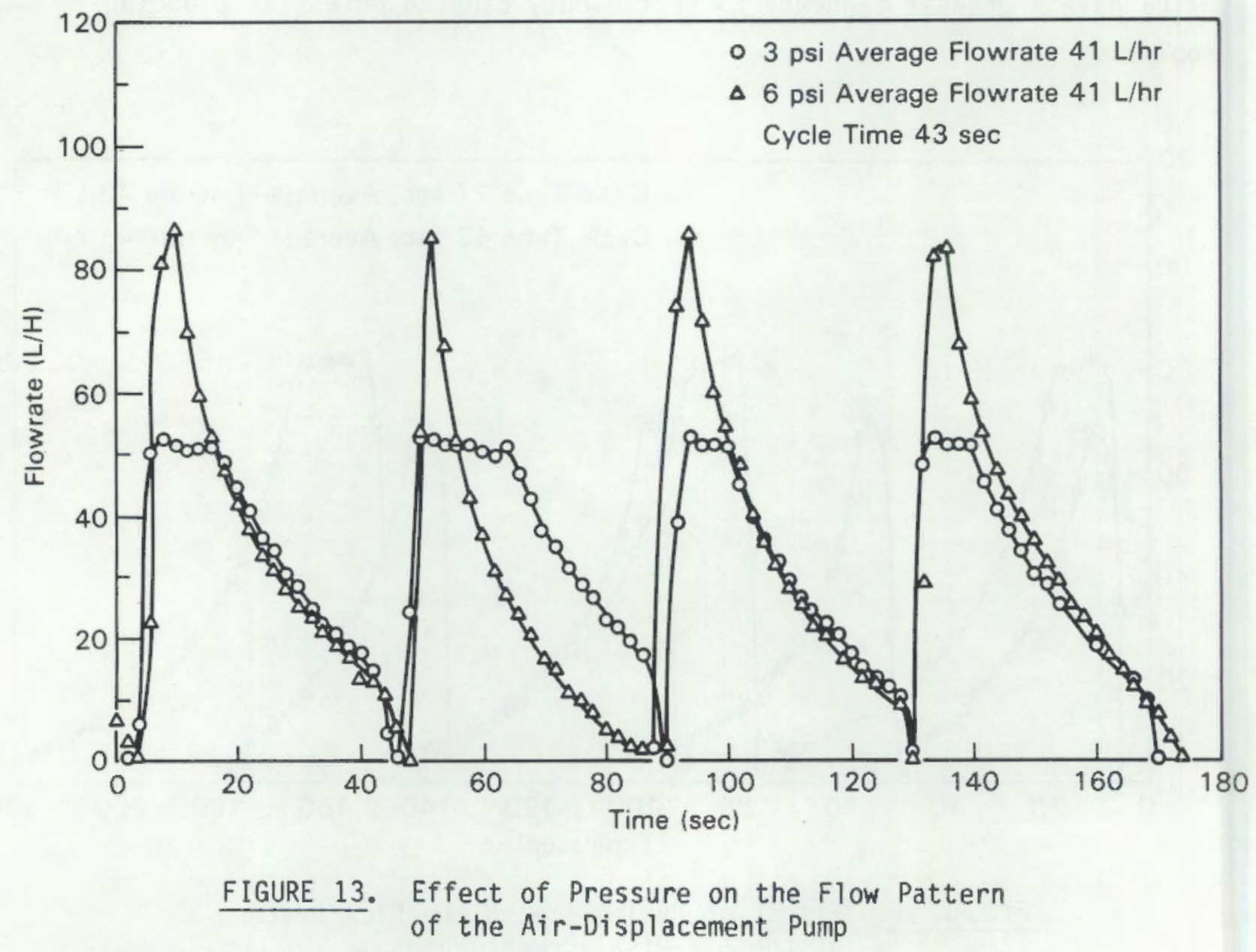


The inability of this pump to achieve flow rates in a range of $20-135 \mathrm{~L} / \mathrm{h}$ was evaluated. It was determined that the slurry exit line, which was $0.18 \mathrm{in}$. I.D., was restricting the flow rate. This $0.18-i n .-I . D$. line size was selected to provide velocities in the turbulent flow region to prevent the settling of solids. The line size was increased to $0.305 \mathrm{in}$. I.D. to obtain flow rates in the range of $20-135 \mathrm{~L} / \mathrm{h}$. The effect of cycle time and air pressure on the flow rate was determined in the second test of the ADS pump.

The third test of the ADS pump (Table 4) was completed with a modified pump design and increased exit-line size. During the majority of the test, a three-way solenoid valve was used instead of the pneumatic cylinder and syringe (for a system description see Section 6.2.2). Flow rates in a range of 49-154 L/h were obtained. The effects of cycle time and air pressure on the slurry flow rate were evaluated and are shown in Figure 14. The volume of the pump chamber, and hence the volume of slurry, are constant throughout the operating cycles. Therefore, the flow rate is approximately equal to this volume divided by the cycle time. At lower flow rates, the pulsating flow pattern is more pronounced. At the low flow rates, the slurry volume is expelled in the early stages of the discharge step, no slurry is discharged through the end of the cycle, and solids can settle in and block the lines.

During most of the test, the air pressure was controlled with the pressure-regulating valve and the pump chamber was filled as a function of tank head. The effect of tank head on the pump output at various cycle times is shown in Figure 15. At a tank head of approximately 1.2 psi, the pump output begins to decrease. Below a head of $1.2 \mathrm{psi}$, the fill time must be increased to obtain the same output flow rate. At a tank head of $0.34 \mathrm{psi}$, the pump would no longer operate.

The last of the test results for the initial pump designs were obtained during Test \#4 using the pump shown in Figure 11d. The pump was able to achieve flow rates as high as $200 \mathrm{~L} / \mathrm{h}$ and as low as $60 \mathrm{~L} / \mathrm{h}$. The effect of cycle time and air pressure on the pump output is shown in Figure 16 . This indicated that the output flow rate is sensitive to changes in cycle time at the higher air pressures. This test also identified the need for better control of the air pressure going into the chamber. At long cycle times the 


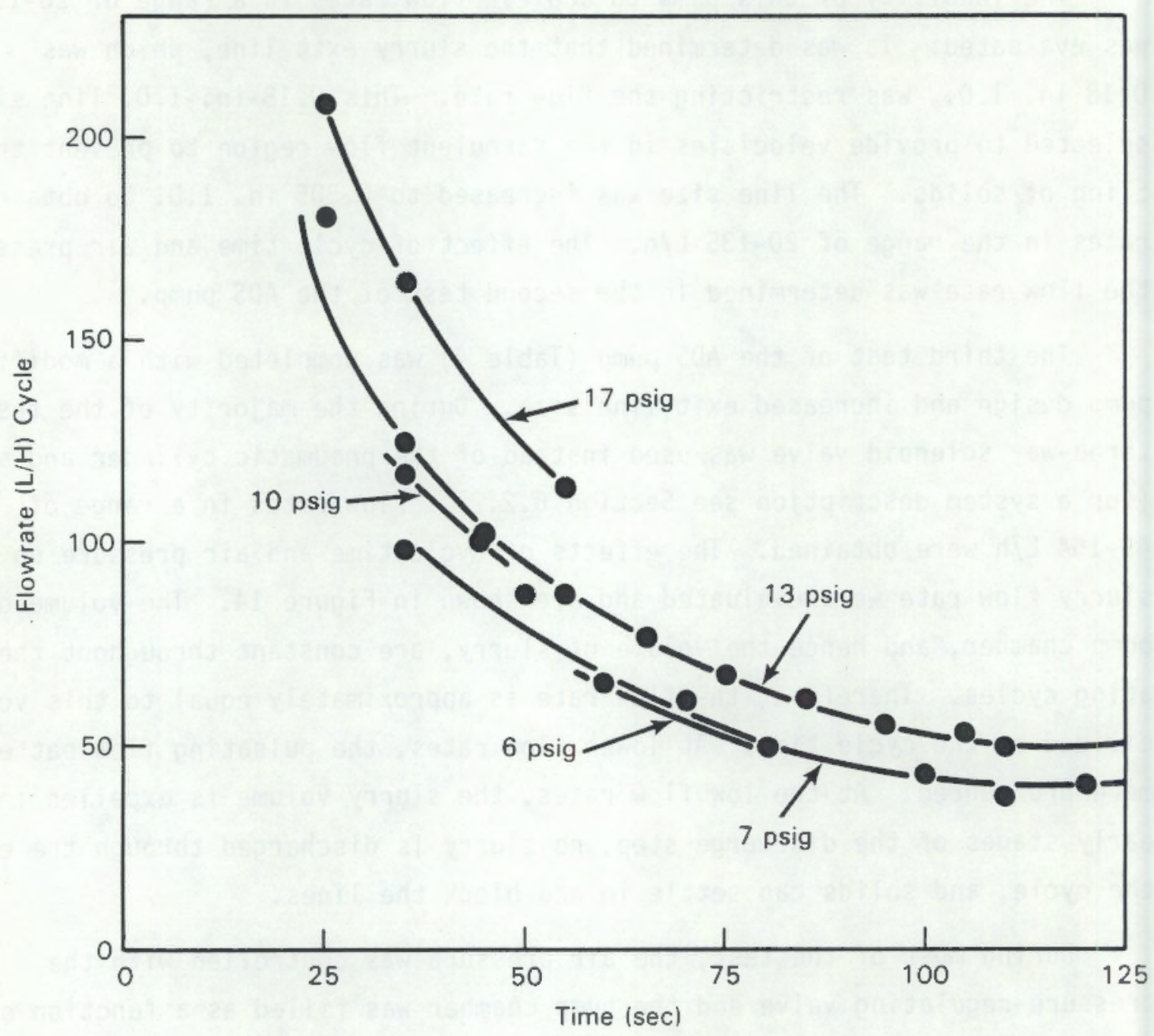

FIGURE 14. Effect of Cycle Time and Air Pressure on the Flow Rate Using Electric Solenoid Valve

constant-pressure air would displace the entire volume of slurry out prior to the end of the discharge step. Air would then continue to blow through the lines. This problem would be eliminated if the air pressure was varied throughout the discharge. A new air-control system was included in the modified design.

\subsubsection{Experiments with the Modified ADS Pump Design}

The long-term testing using the initial designs demonstrated the viability of using an ADS pump for metering a slurry. The positive initial test results and the commitment to continue pump development led to a major redesign of the 


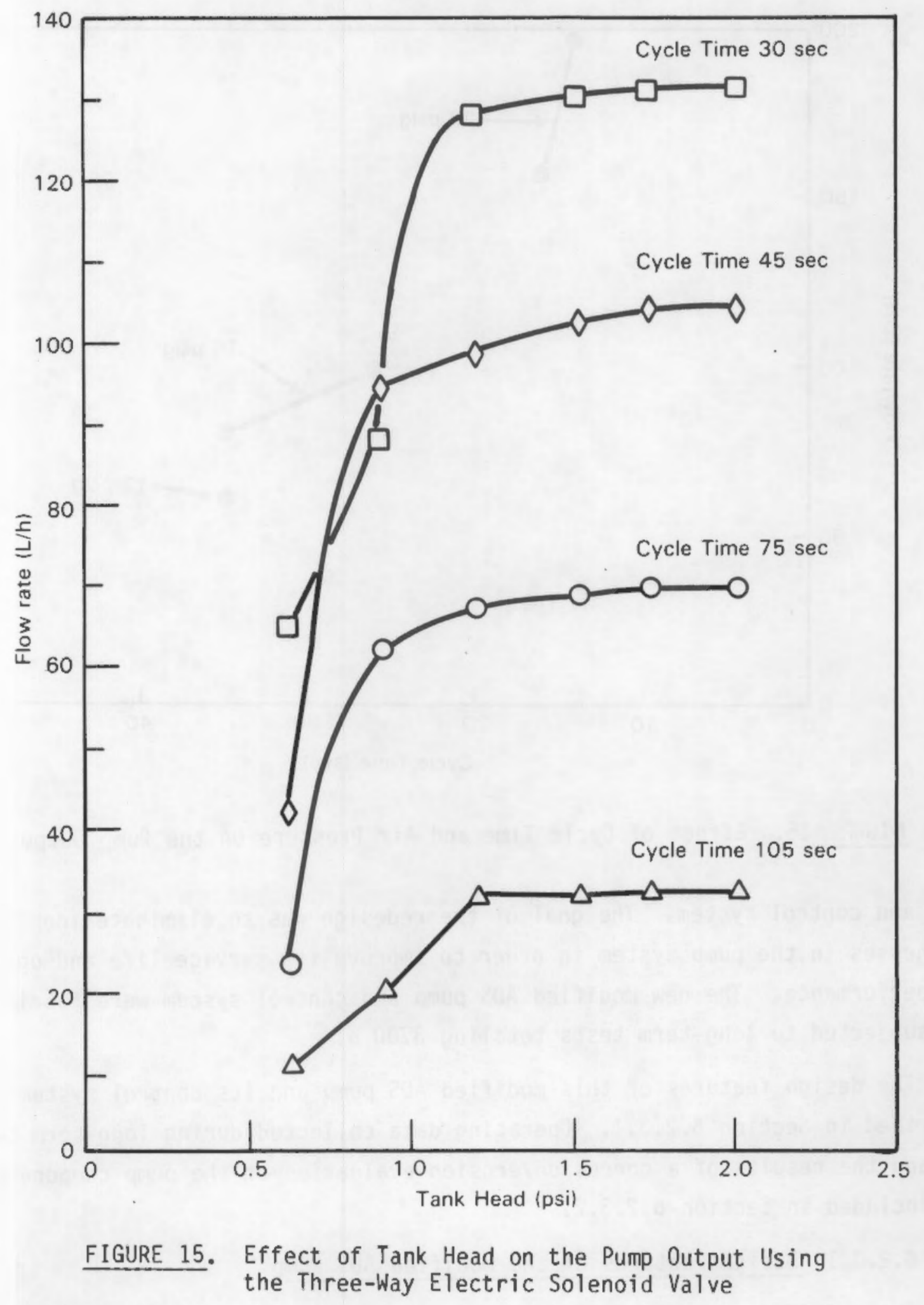




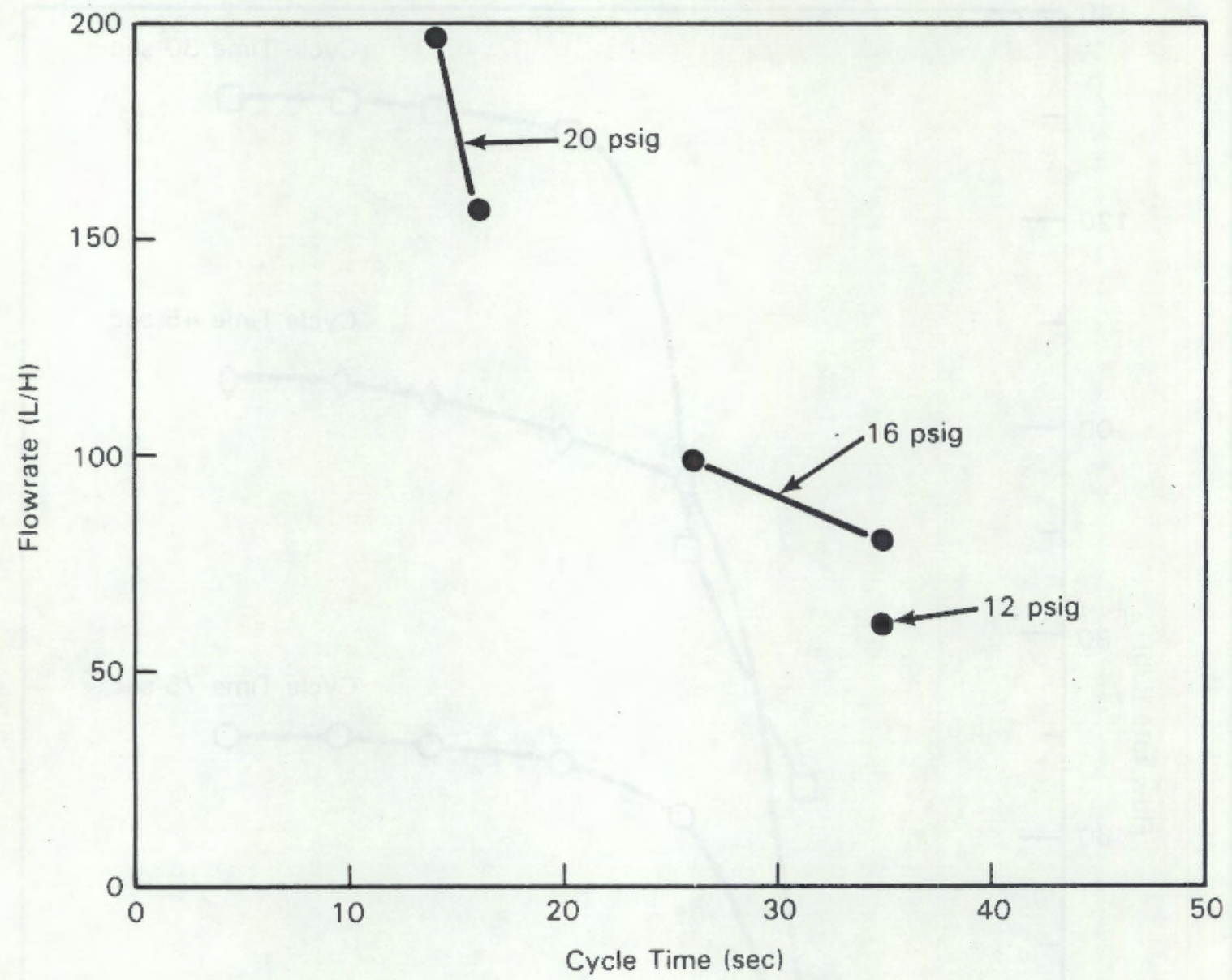

FIGURE 16. Effect of.Cycle Time and Air Pressure on the Pump Output

pump and control system. The goal of the redesign was to eliminate identified weaknesses in the pump system in order to improve its service life and operating performance. The new modified ADS pump and control system were fabricated and subjected to long-term tests totaling $3700 \mathrm{~h}$.

The design features of this modified ADS pump and its control system are described in Section 6.2.3.1. Operating data collected during long-term testing and the results of a corrosion/erosion evaluation of the pump components are included in Section 6.2.3.2.

\subsubsection{Design Features of the Modified ADS Pump}

The modified and current ADS pump (Figure 17) has a displacement chamber with a volume of approximately $1.7 \mathrm{~L}$. The chamber is secured to a flange with 


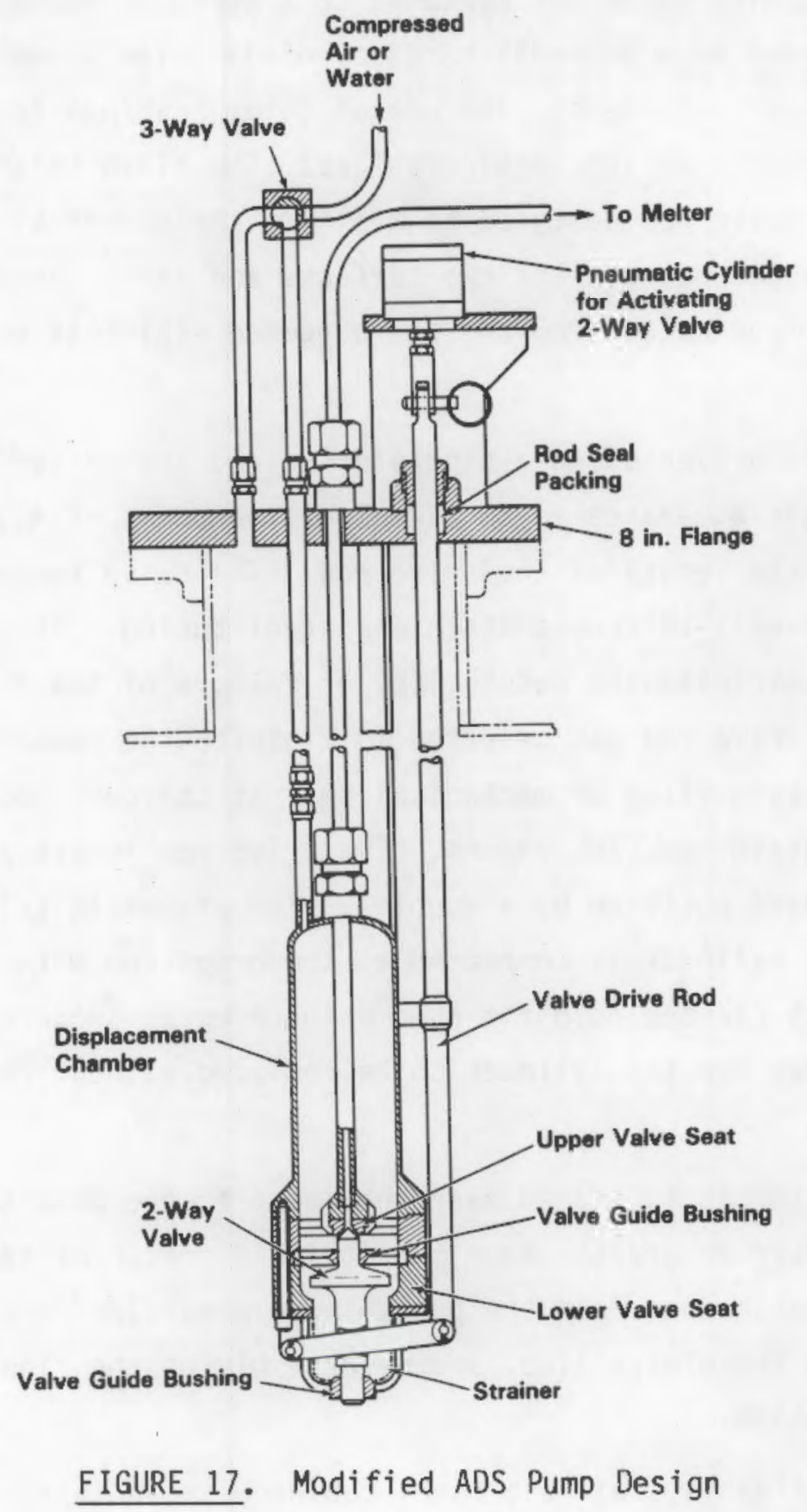

the use of support structures and is located close to the tank bottom. The design of the chamber enables it to be easily disassembled for inspection after experimentation.

The two-way valve and valve seats have been designed to minimize wear and to assure alignment. The valve and seats were fabricated from an age-hardened 
stainless steel. The valve was hardened to a Rockwell hardness of 37 , and the seats were hardened to a Rockwell hardness of 41 . Two guide bushings on the valve assure proper alignment. The use of guide bushings in a slurry application required special design considerations. The close tolerance between the bushing and the valve was designed to minimize the number of particles that could become trapped between the two surfaces and cause increased wear. Also, the bushing was fabricated from the age-hardened stainless steel (Rockwell hardness of 41 ).

The valve is driven using a single drive rod and rocker arm mechanism. The rocker arm was age-hardened to a Rockwell hardness of 41. Three guides were used along the length of the drive rod. The drive rod was fabricated from 0.75-in. $\times 0.095$-wall-thickness stainless steel tubing. The thick-wall tubing was selected to minimize the possibility of failure of the drive rod due to wear. A single drive rod was selected to minimize the number of seals required. A packing gland or mechanical seal at the pump mounting flange is necessary to contain the tank vapors. The drive rod is actuated in both the open and the closed position by a double-acting pneumatic cylinder. The shaft of the pneumatic cylinder is connected to the drive rod with a pin. The pneumatic cylinder is clamped onto the pump using a metal support structure. This arrangement allows for the cylinder to be replaced without removing the main pump body.

A 4.5-mesh screen is placed over the inlet to the pump to prevent particles whose diameter is greater than the inside diameter of the slurry line from entering the pump chamber. In the past, large particles/foreign objects have become wedged in the slurry line, and disassembly of the line was required in order to remove them.

The slurry line is stainless steel tubing with an inside diameter of 0.375. The line bringing air to the chamber is $0.50-i n$. stainless steel tubing.

\subsubsection{Control System for the Modified ADS Pump}

The control system (i.e., air delivery system) was a major weakness in the design and operation of the pump during initial tests. The results of this 
past testing were used to establish the criteria for the design of a new control system. The control system must 1) sequence and control the four steps of the pump cycle; 2) deliver a new volume of air to the pump chamber during each cycle; 3) control and vary the air pressure as a function of time; 4) vary the chamber fill time as a function of the tank head; 5) automatically and manually permit the pump to be water flushed; and 6 ) permit flexibility in the operation of the pump (i.e., cycle time, step times, and air pressure can be adjusted in many ways so that the effect on the pump output can be determined).

A microprocessor controller was designed and fabricated at PNL for this application. The control schematic is shown in Figure 18. Recall (see Figure 9) that steps 1 and 3 of the pump cycle are associated with the opening and closing of the two-way valve. The controller sends a signal to a four-way electric solenoid valve at these steps in the cycle. This solenoid valve operates the pneumatic cylinder which drives the valve. The operator selects the amount of time for steps 1 and 3 : usually $1 / 2-1 \mathrm{~s}$.

Step 2 is the fill step of the cycle. The two-way valve is open, allowing slurry to flow into the chamber as a function of the tank head. Testing has

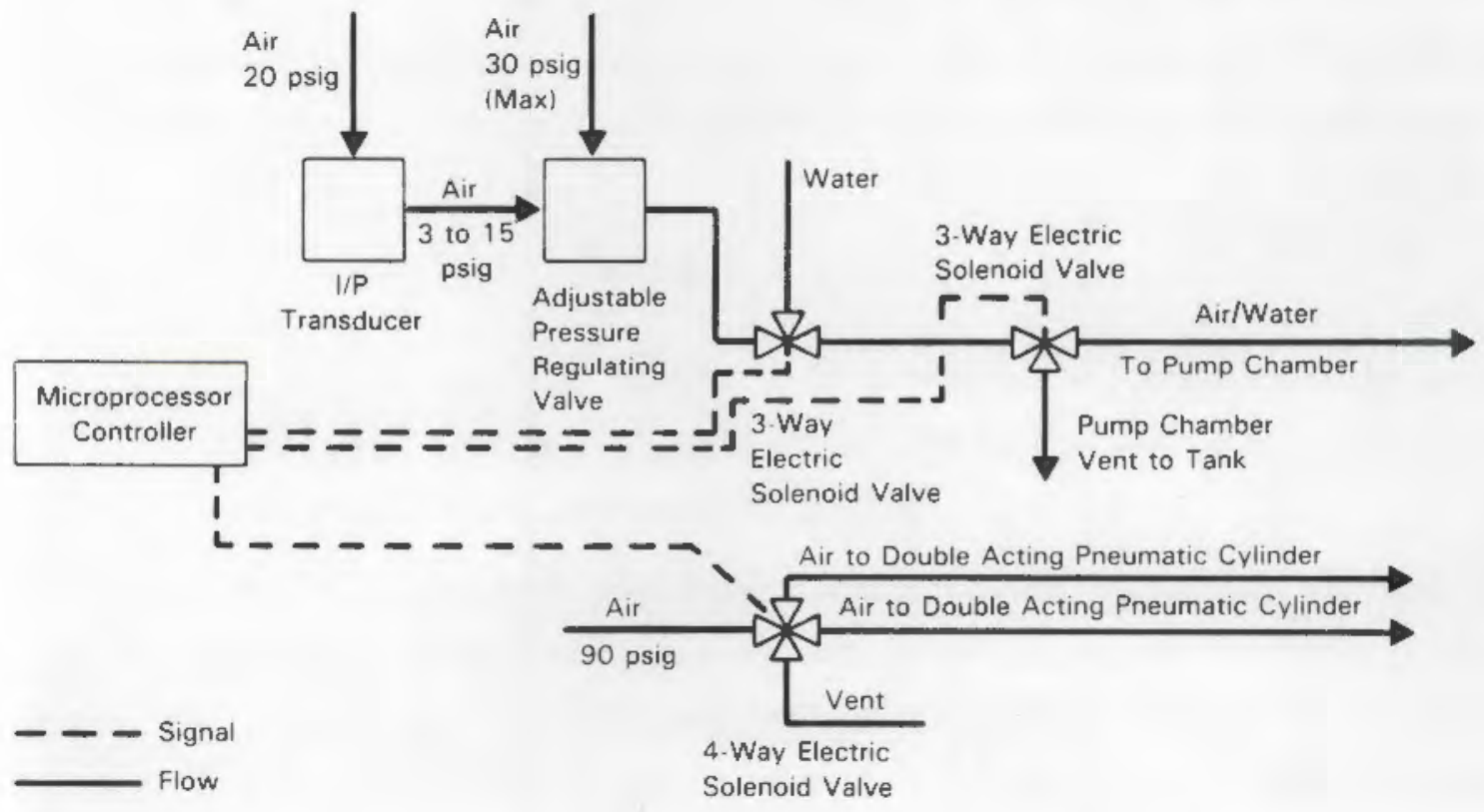

FIGURE 18. Control Schematic for Modified ADS Pump Design 
been completed (Section 6.2.3.3) to determine how the pump output varies as a function of the tank head. The results have shown that the output does not vary until a specific minimum head is reached. Once this head is reached and continues to decrease, the fill time must be increased to achieve the same output. The programmed controller can make these adjustments. Because most of the long-term tests were conducted with a full tank of slurry, this feature was not needed and the fill time was set at a constant value. During step 2, the controller energizes the three-way solenoid which permits any air in the pump chamber to be vented back to the tank through the solenoid valve and enables the chamber to fill.

During the discharge step of the pump cycle (Step 4), pressurized air is valved into the chamber, which forces the slurry out and into the slurry line. The output from the pump is a function of the air pressure. The desired air pressure was achieved using an electrical-to-pneumatic (I/P) transducer and an adjustable pressure regulating valve. A signal is generated by the controller and sent to the I/P transducer. The I/P transducer converts the electric signal to a pressure signal and sends the pressure signal to the adjustable pressure-regulating valve. The adjustable pressure-regulating valve supplies an air volume at the correct pressure to the pump chamber. The pressure of the air going to the chamber can be held constant throughout the duration of step 4 or can be varied as a function of time. This relationship is described below:

$$
y=A+k_{1} x+k_{2} x^{2}+k_{3} x^{3}
$$

where $A, K_{1}, K_{2}, K_{3}=$ constants selected by the operator

$x=$ instantaneous time in the discharge step

$y=\%$ of full-scale pressure to the pump.

The constants are varied to create an optimum pressure curve for pump operation with a specific slurry. The instantaneous time in the discharge step is determined and updated continuously by the controller. The $y$ term correlates to the pressure that is supplied to the pump chamber. When $k_{1}, k_{2}$, and $k_{3}$ are 0 , a constant pressure curve results. 
Electric solenoid valves were also installed to operate the water flush system. The controller can be programmed to do this automatically, or it can be done manually.

The microprocessor controller permitted a great deal of flexibility in the way the pump was operated. Long-term testing permitted the optimization of the pump operation.

\subsubsection{Results of Testing with the Modified ADS Pump Design}

The objectives of the modified ADS pump testing program were to operate the pump in long-term tests to obtain estimates of service life, determine operating parameters, evaluate weaknesses in the pump system, and evaluate the corrosion of the pump components. The slurry composition used in the long-term testing (Test \#5) was a neutralized composition shown in Table A.3. The evaluation of the corrosion and erosion data obtained during Test \#5 is presented in Section 6.2.3.4.

The modified ADS pump was operated continuously in long-term tests for a total of $3700 \mathrm{~h}$. In addition, it has been used as the primary feed system for three pilot-scale ceramic melter experiments, thus putting the total number of hours in operation well over 4000. The service life of the pump was based on the total number of continuous hours and the results of the corrosion and erosion evaluation. A service life of at least 6 mo. (4400 h) was required for operation in a radioactive environment. The service life of the modified ADS pump design is estimated to be in excess of $6 \mathrm{mo}$.

The primary operating parameter of the pump is the flow rate and the ability to achieve any desired flow rate. The flow rate is selected by varying the pump cycle time and the air pressure. During testing, flow rates ranging from 10 to $185 \mathrm{~L} / \mathrm{h}$ were achieved. The flow rate was stable in a range of 20 to $185 \mathrm{~L} / \mathrm{h}$. Degradations in the flow rate were monitored with a magnetic flow meter and were attributed to solids depositing in the lines, which creates potential plugs. When flow degradation increased to $20 \%$ of the set flow rate, the lines were water flushed and the set-point flow rate was resumed.

The initial testing of the modified design involved the determination of the effect of the air pressure curve and the cycle time, including the fill 
time and the discharge time, on the output from the pump. Earlier testing of the design concept had alluded to the issue of dead time--the period when no slurry is flowing through the lines. In order to minimize the chance of solids depositing, drying in the lines and creating plugs, this dead time needs to be minimized. Steps 1 through 3 of the pump cycle (positioning the valve and filling the chamber) are definite periods of dead time. This dead time will also exist during step 4 after the entire slurry volume in the chamber is discharged. Ideal operation of the pump involves keeping the time for steps 1 through 3 short and setting the time for step 4 so that slurry is always being discharged. The fill time must be set to fill the chamber to the maximum level (1.7 L) during each cycle.

The air pressure and the delivery of the air to the chamber strongly affect the output from the pump. A number of air pressure curves were evaluated to determine the effect of different curves on the flow rate. Three of the curves typically used are shown in Figure 19. The curves were generated using Eq. (1) and selecting values for the constants $A, K_{1}, K_{2}$, and $K_{3}$. The actual pressure to the pump was calculated using the $y$ term. These curves, along with a constant pressure mode, were tested. The curve was optimum if the slurry flow in the line was steady over the entire discharge step. The curve $10 x-10 x^{2}$ was the optimum followed by the constant pressure curves. It was undesirable to "blast" the slurry out during the early stages because this results in a very low flow during the final stages, as occurred when the curve $6+10 x+10 x^{2}+10 x^{3}$ was used.

Initially, the pump was operated at various pressures and cycle times with water. The fill time and the discharge time were varied in order to determine their effect on the output from the pump. These effects are shown in Figures 20 and 21. The chamber fill time was varied by holding the discharge time and the air pressure constant. As the chamber fill time is increased, the flow rate decreases. The flow rate is calculated over the entire pump cycle including the fill step. Therefore, increasing the fill time decreases the effective flow rate. The effect of discharge time takes the form of a parabola with a maximum point. Prior to reaching the maximum point, as the cycle time is increased, the flow rate increases. After reaching the maximum, the flow rate 


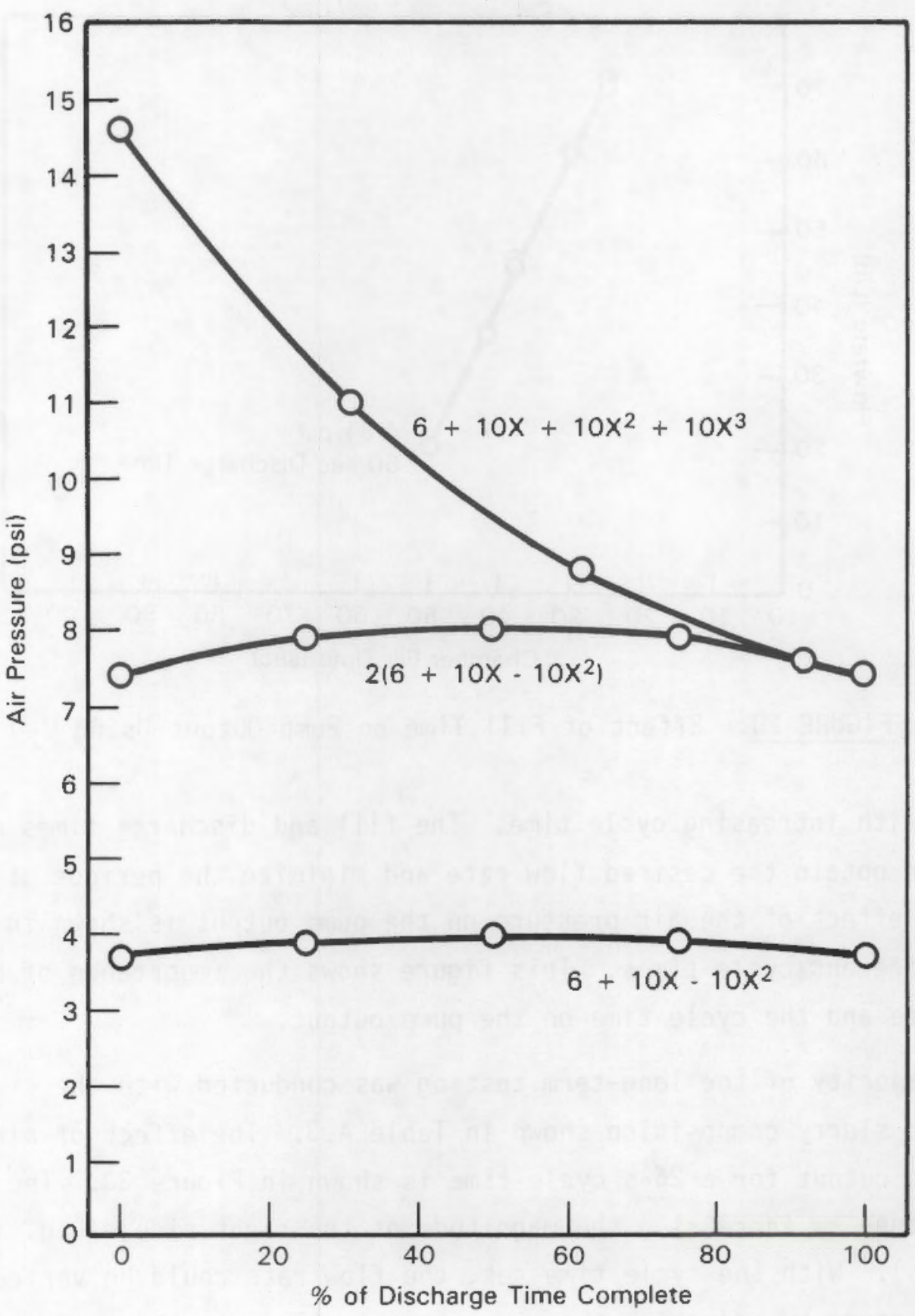

FIGURE 19. Air Pressure Curves Tested with Modified ADS Pump 


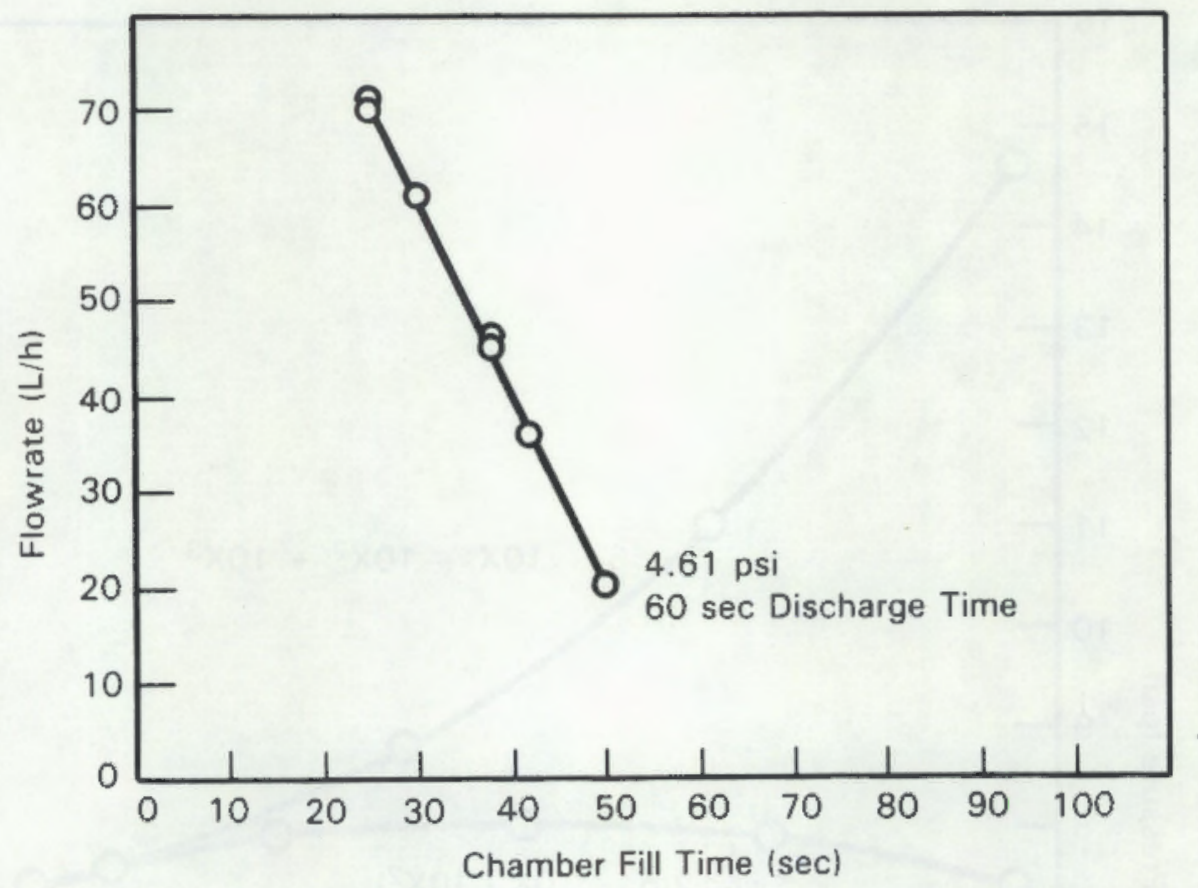

FIGURE 20. Effect of Fill Time on Pump Output Using $\mathrm{H}_{2} \mathrm{O}$

decreases with increasing cycle time. The fill and discharge times must be selected to obtain the desired flow rate and minimize the periods of dead time. The effect of the air pressure on the pump output is shown in Figure 22 for two different cycle times. This figure shows the importance of both the air pressure and the cycle time on the pump output.

The majority of the long-term testing was conducted with the simulated neutralized slurry composition shown in Table A.3. The effect of air pressure on the pump output for a 26-s cycle time is shown in Figure 23. The pressure was determined by increasing the magnitude of the right side of Eq. (1) by some constant (b). With the cycle time set, the flow rate could be varied over a very broad range by adjusting the air pressure. This is the preferred mode of operation of the pump. First the air pressure curve and the cycle time should be selected so that the entire flow rate range is obtained. The desired flow rate is obtained by selecting the air pressure.

The effect of the fill time on the pump output is shown in Figure 24 . The flow rate decreases as the fill time is increased because the overall cycle 


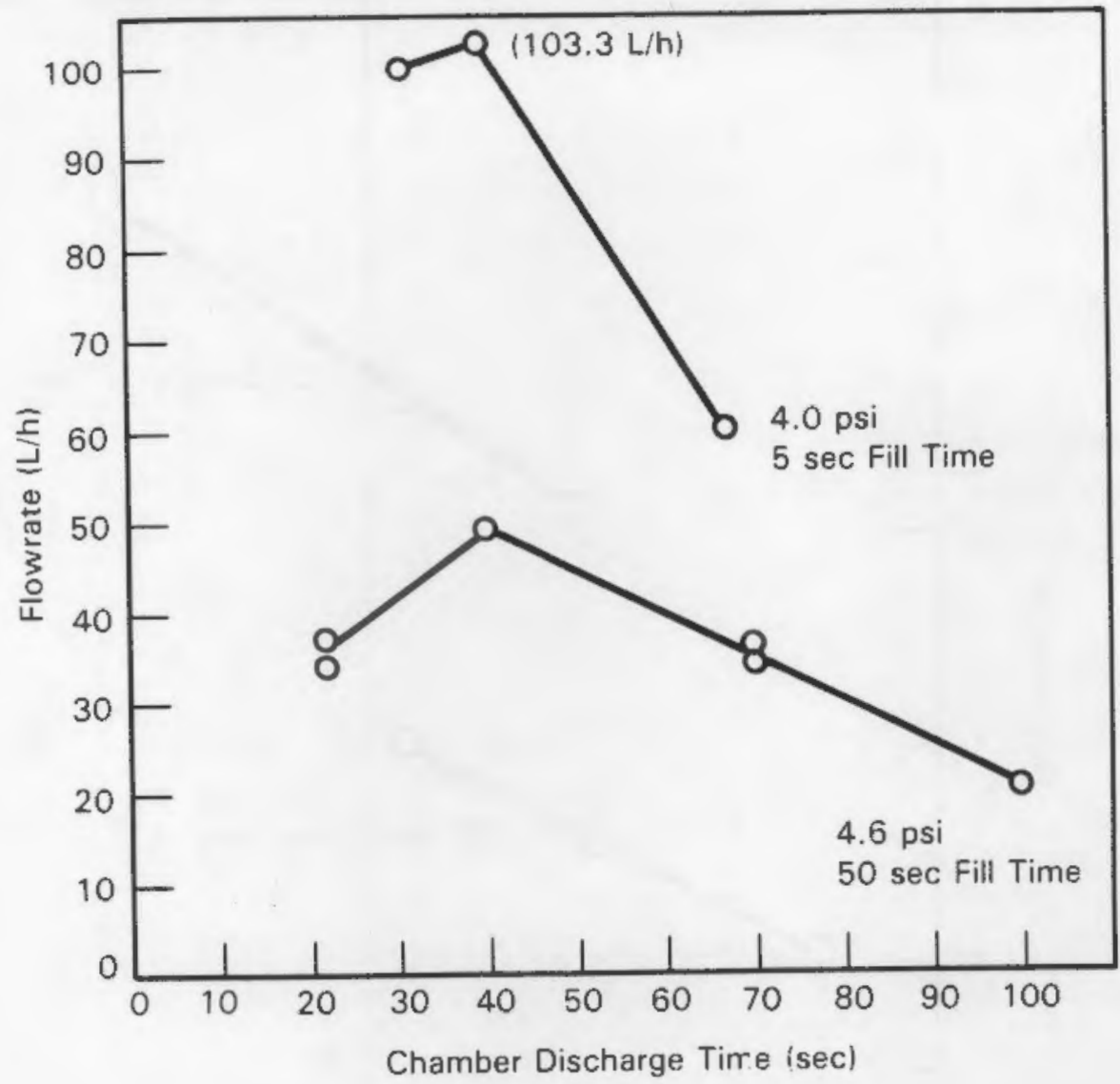

FIGURE 21. Effect of Discharge Time on Flow Rate Using $\mathrm{H}_{2} \mathrm{O}$

time increases. The discharge time is the same, implying that the same volume of slurry will be discharged. The same volume of slurry over a longer cycle time decreases the flow rate.

The pump was also tested with the simulated acidic slurry shown in Table A.12. The effect of air pressure on the pump output is shown in Figure 25. This curve is essentially the same shape as the curve in Figure 23 using neutralized slurry. The air pressure was varied by selecting a different constant, $A$, in Eq. (1).

The final parameter that was evaluated was the effect of tank head on the flow rate. The pump chamber is gravity filled. The output from the pump will remain constant provided the chamber is always filled to the same level. In the vitrification process, the tank level will be varied over a broad range. 


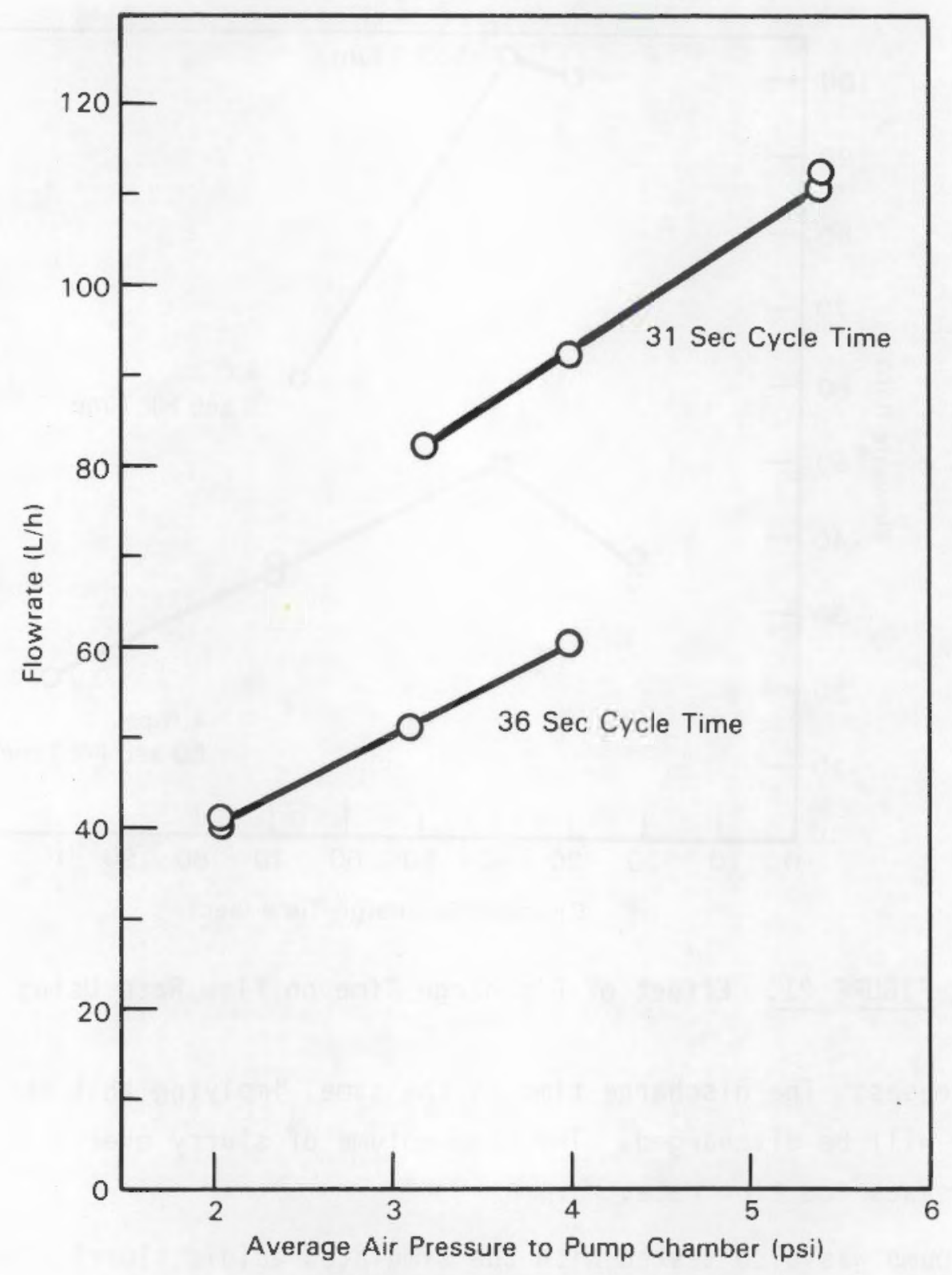

FIGURE 22. Effect of Air Pressure on the Pump Flow Rate Using $\mathrm{H}_{2} \mathrm{O}$

The effect of tank head on the flow rate for different chamber fill times is shown in Figure 26. With the short fill times, the output is affected at heads less than 1.4 psi, while the longer fill times were not affected until heads of 1.0 psi were achieved. The melter feed tank head should be maintained above these levels for proper operation of the ADS pump. 


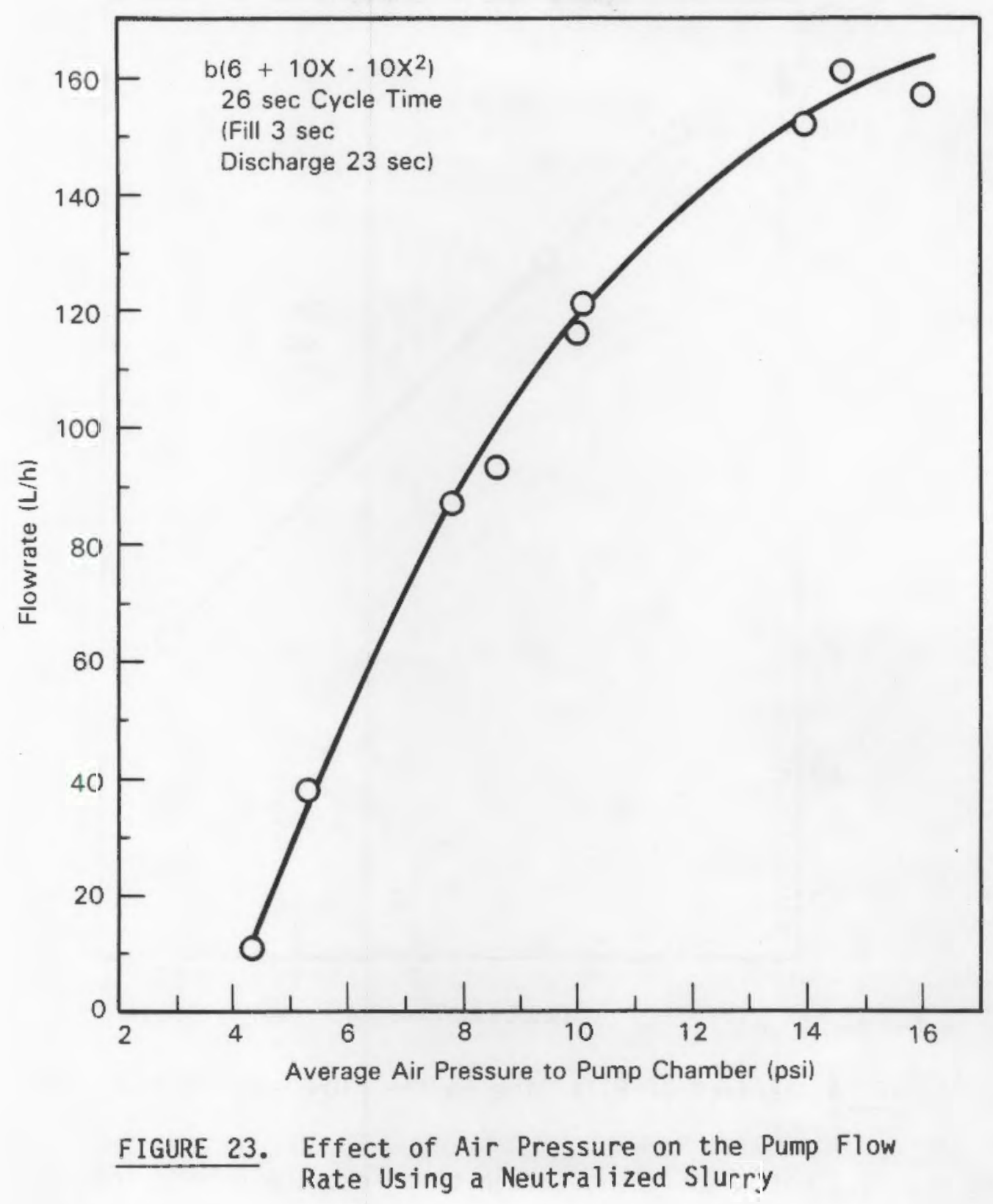

\subsubsection{Corrosion/Erosion Results}

After the modified ADS pump had operated for a total of $3696 \mathrm{~h}(0.42 \mathrm{y})$, the pump was disassembled and inspected to identify high-wear areas. Weight and dimensional measurements of the pump components were made and the amount of change from the previous measurements was calculated. These results are shown in Table 5. In general, the pump components were in good condition, and the 


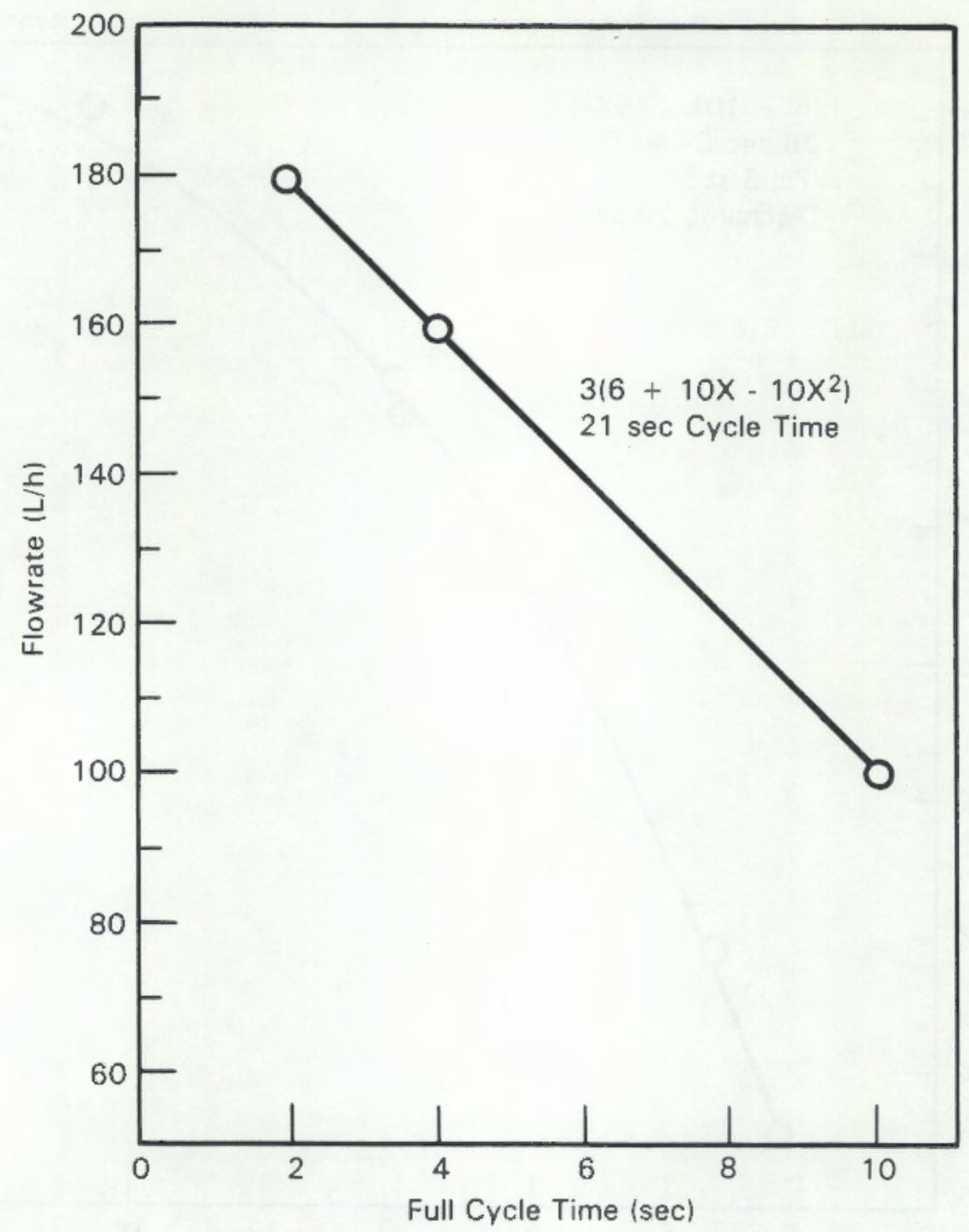

FIGURE 24. Effect of Fill Time on the Flow Rate Using Slurry

resulting wear was not significant enough to affect the pump operation. The age-hardened materials and design considerations used in this pump were successful in minimizing the corrosion/erosion effects.

The areas of primary interest in terms of pump operation were the two-way valve, seats, and drive mechanism. The two-way valve had wear on the seating surfaces and areas where contact was made with the guides. A sharp edge was evident on the lower seat of the valve, which corresponded with an increased width of the valve impression in the mating surface. This probably resulted 


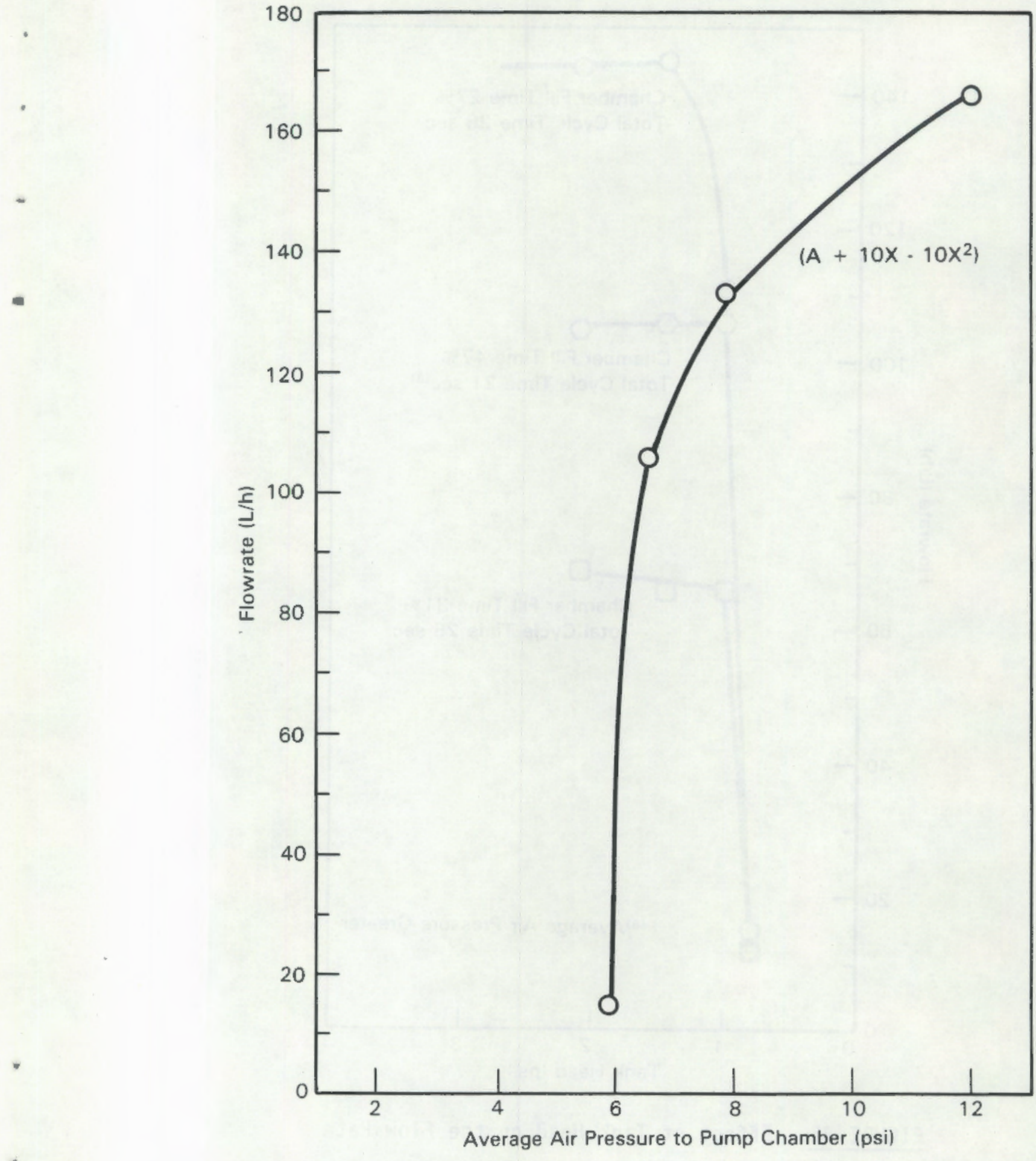

FIGURE 25. Effect of Air Pressure on the Flow Rate Using an Acidic Slurry 


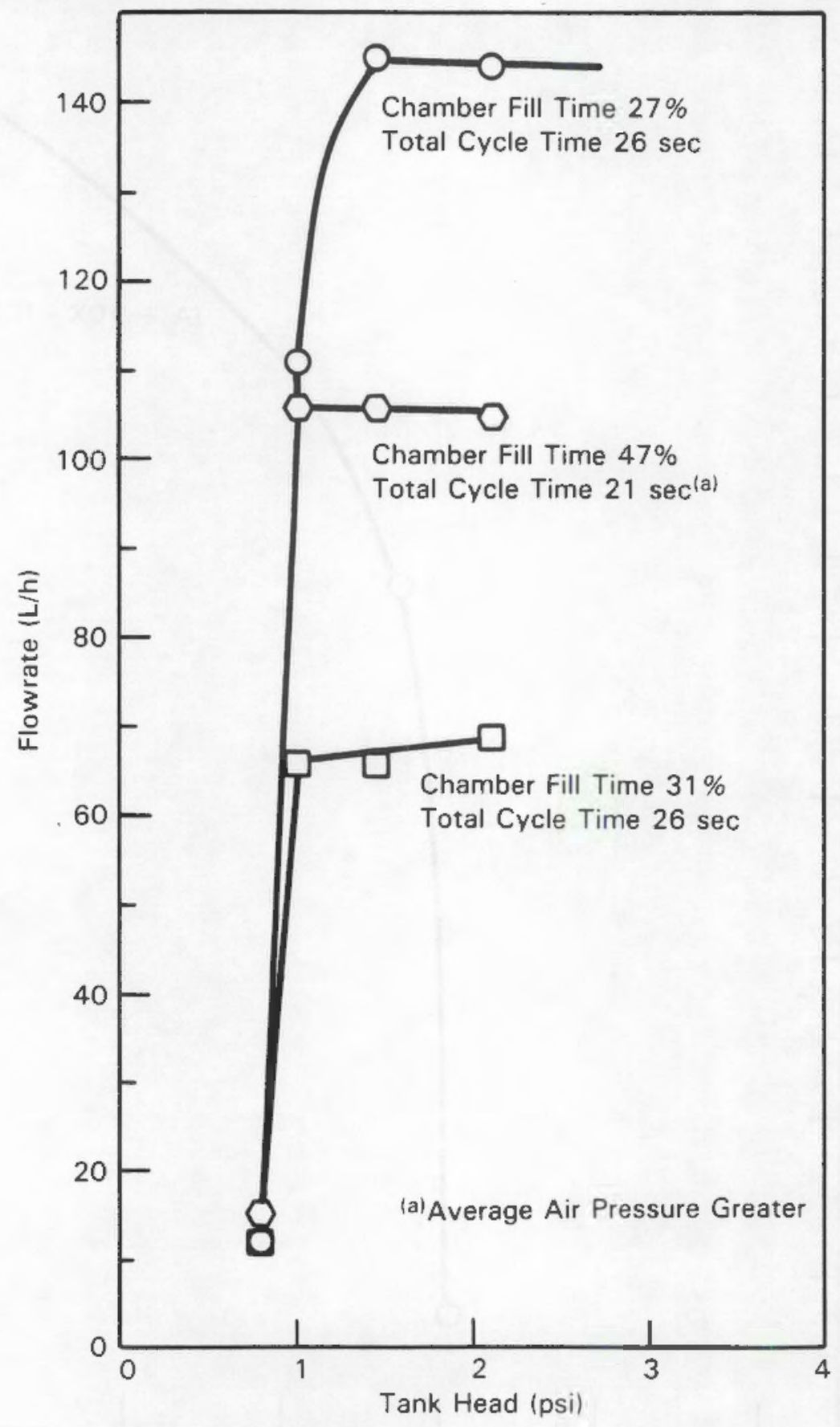

FIGURE 26. Effect of Tank Head on the Flow Rate 
TABLE 5. Weight and Dimensional Changes in ADS Pump Components

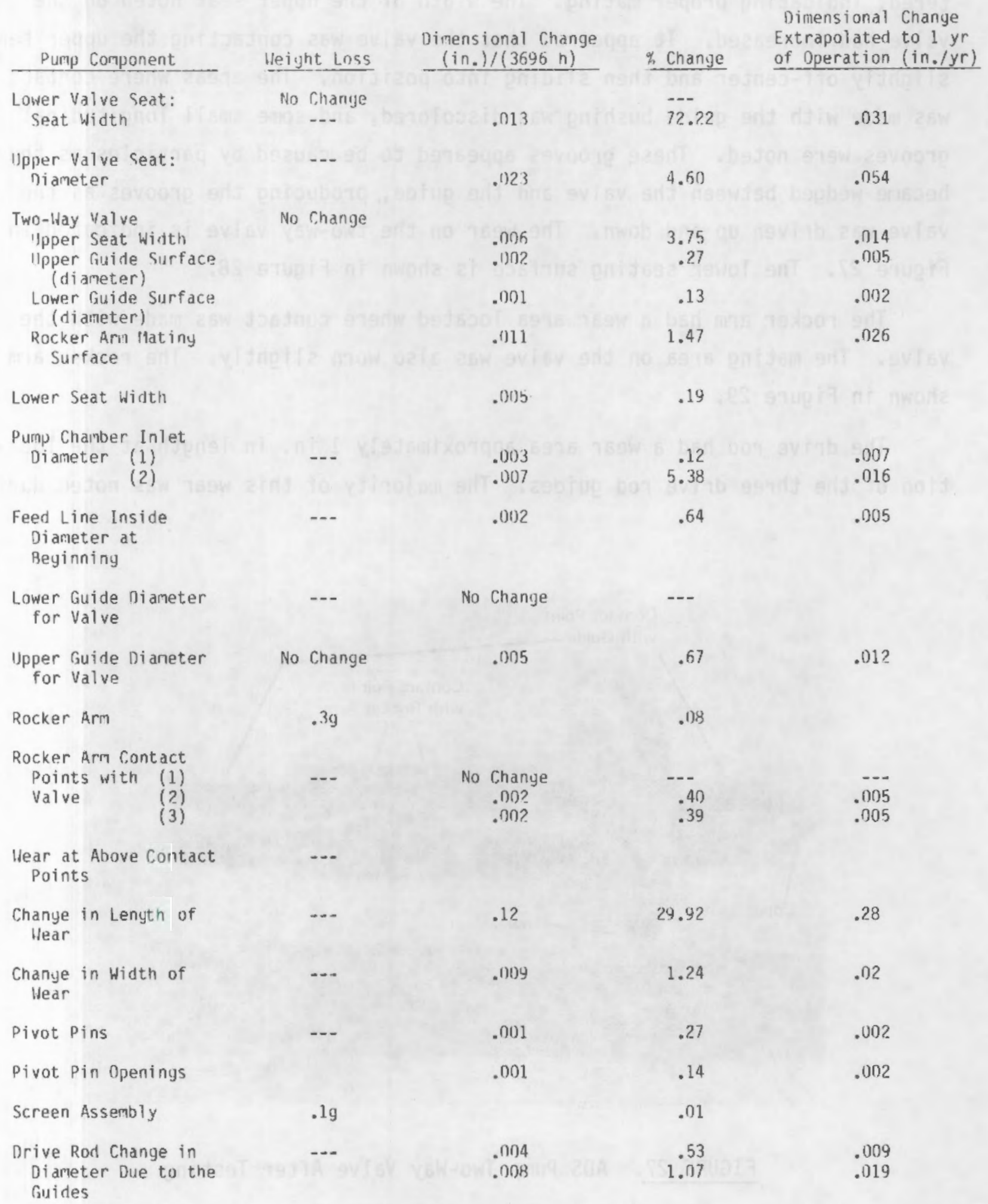


from the wear that occurred on the rocker arm (discussed below) which drives the valve and adjusts the position of the seat. This seating surface was centered, indicating proper mating. The width of the upper seat noted on the valve had increased. It appeared that the valve was contacting the upper seat slightly off-center and then sliding into position. The areas where contact was made with the guide bushing was discolored, and some small longitudinal grooves were noted. These grooves appeared to be caused by particles as they became wedged between the valve and the guide, producing the grooves as the valve was driven up and down. The wear on the two-way valve is indicated in Figure 27. The lower seating surface is shown in Figure 28.

The rocker arm had a wear area located where contact was made with the valve. The mating area on the valve was also worn slightly. The rocker arm is shown in Figure 29.

The drive rod had a wear area approximately $1 \mathrm{in}$. in length at the location of the three drive rod guides. The majority of this wear was noted during

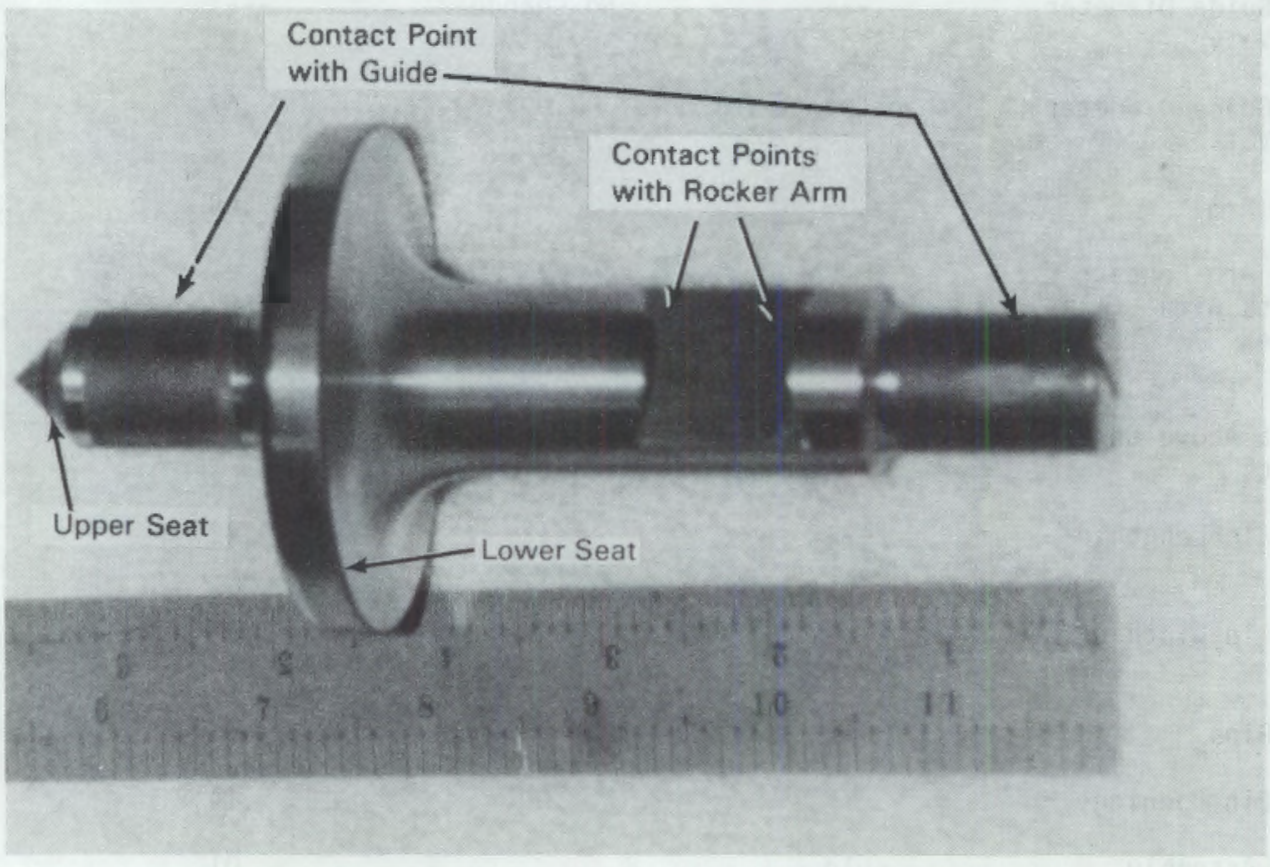

FIGURE 27. ADS Pump Two-Way Valve After Testing 


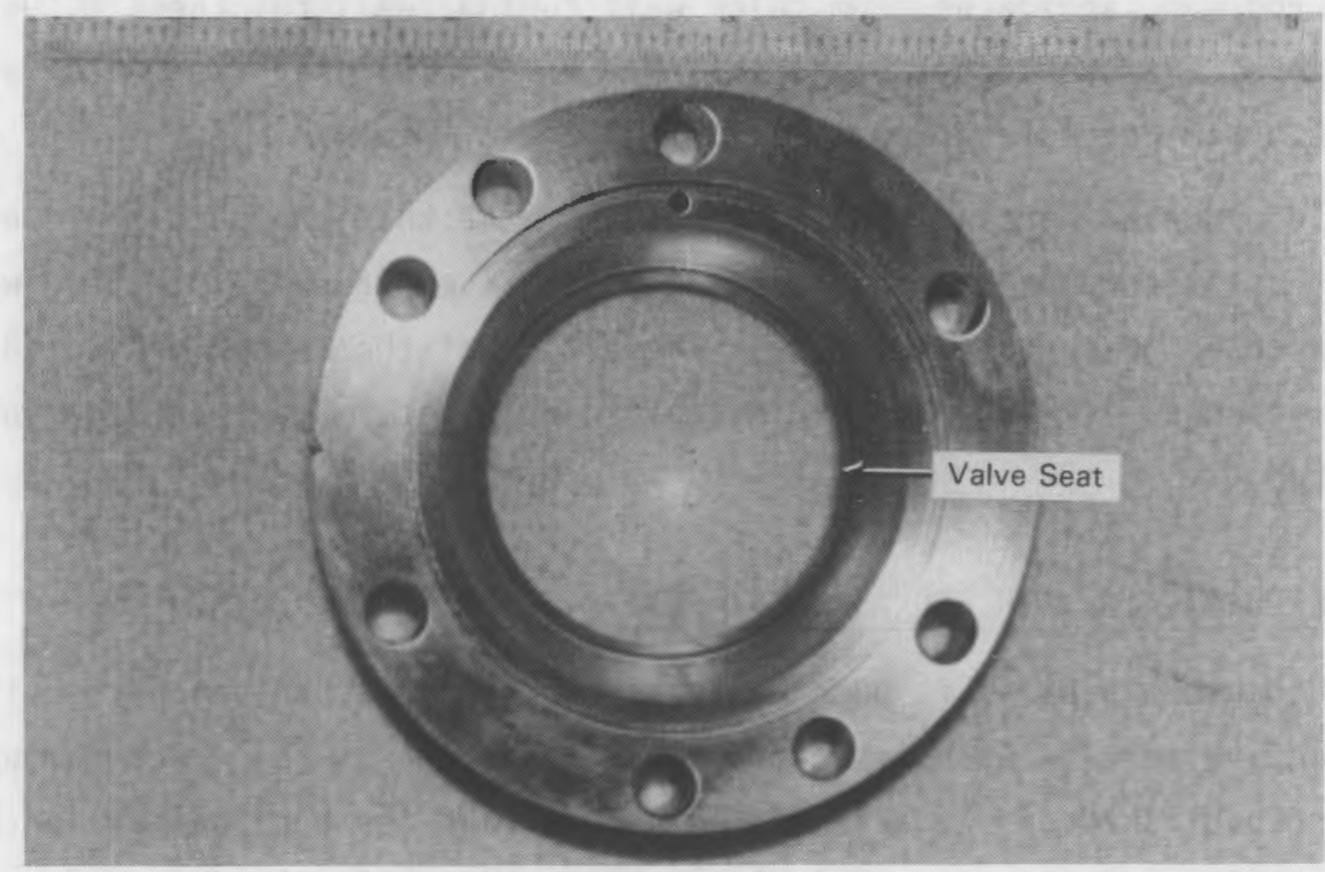

FIGURE 28. ADS Pump Lower Valve Seating Surface After Testing

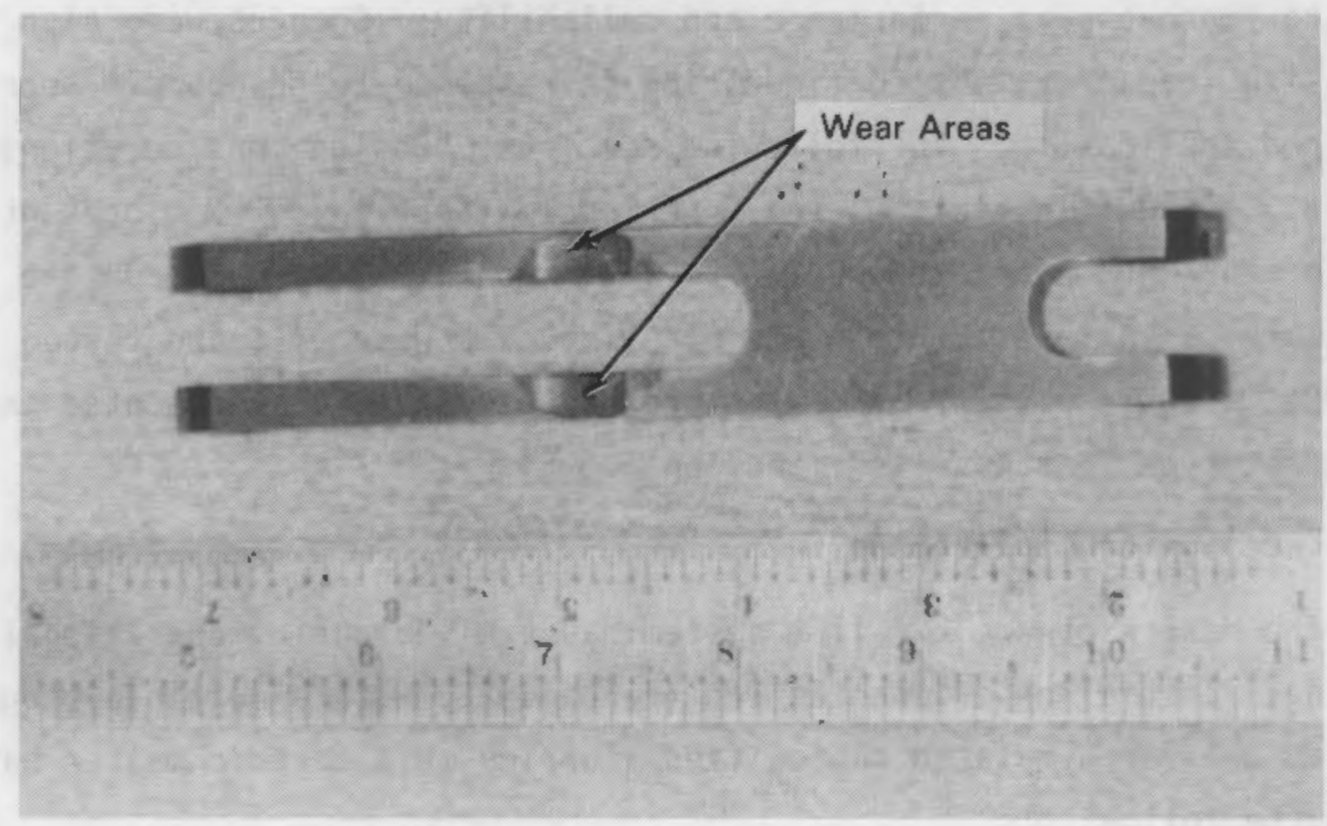

FIGURE 29. Rocker Arm of ADS Pump After Testing 
the initial $500 \mathrm{~h}$ of operation. However, no measurements were made. This drive rod was fabricated from thick wall tubing (wall thickness $0.095 \mathrm{in.}$ ) so additional wear could be tolerated. The pivot pins used for the drive rod/ rocker arm mechanism showed a minimum amount of wear.

In order to obtain an estimate of the wear that the pump could experience in 1 year of continuous operation, the data after $3696 \mathrm{~h}$ of testing were extrapolated to 1 year (Table 5). The effect of the 1 -year projected dimensional changes is judged to be insignificant (i.e., pump operation would not be affected).

\subsection{EXPERIMENTS WITH THE AIR-LIFT PUMP SYSTEM}

Because the air-lift pump contains no moving mechanical parts, its use in radioactive service was very attractive. There was also a large amount of literature published on the air-lift in general and its application in the nuclear reprocessing industry in particular. Using primarily the data and design parameters developed by Dabolt and Plummer (1.980), a two-stage air-lift system was sized, constructed and tested. As testing progressed, design changes were made to improve pump performance and reliability. Changes were also made in pump size (capacity) and configuration in response to the pump's sponsorrequired application. The following sections, "Design Considerations" (Section 6.3.1) and "Initial Testing Experience" (Section 6.3.2), present the development work conducted during FY 1982 and FY 1983. Based on the results of this work, a full-scale prototype air-lift pump was built and tested in FY 1984. The results of long-term prototype testing are presented in "LongTerm Prototype Test Results" (Section 6.3.3).

\subsubsection{Design Considerations}

The design of the air-lift system has evolved during operational testing. Initial experience at PNL (Perez 1983) with a multiple-stage air-lift pump to deliver simulated neutralized slurries to a ceramic melter had determined the following:

- Due to high undissolved-solids concentrations, air-lift line diameters must be as small as possible to maintain maximum linear 
velocities. The higher resultant turbulence and reduced residence time of the slurry in these lines reduce the risk of solids settling.

- Horizontal sections should be minimized or eliminated to decrease areas of possible settling.

- The first-stage constant submergence head pot should have separate lines for the recycling feed slurry and disengaging air to prevent drying at the air/liquid interface.

- With neutralized slurries, humidified air or inert gas should be used to minimize the drying effects of the air.

During the development period, 10 tests, totaling $667 \mathrm{~h}$ of operation, were conducted. Numerous system design changes were made to improve the pump's performance and reliability. Figure 30 shows an early prototype two-stage airlift pump and process flowsheet. The following sections present the principal design improvements that led to the final design recommendations.

\subsubsection{Footpiece Design}

To determine the minimum orifice diameter size based on pressure drop across the orifice, Dabolt and Plummer (1980) recommend the following equation:

$$
D^{2}=\frac{Q\left(T_{1}\right)}{(C)\left(P_{1}-P_{2}\right)\left(P_{2}\right)}
$$

where $D=$ orifice diameter, in.

$Q=125 \%$ of the maximum air requirement, SCFM

$P_{1}=$ air-supply pressure at footpiece, psia

$P_{2}=$ minimum head requirements, psia

$T_{1}=$ absolute temperature of air, degrees Rankine

$\mathrm{C}=$ temperature constant, $435^{\circ} \mathrm{R}$.

Starting with this recommendation as a basis, first-stage orifice diameters of $0.25 \mathrm{in}$. to $0.125 \mathrm{in}$. were selected. These diameters were up to $50 \%$ larger than the minimum diameter size recommended by Eq. (2) because of the potential for solids plugging to occur. Second-stage orifice sizes ranging from $0.0625 \mathrm{in}$. to $0.125 \mathrm{in}$. were tested. The $0.0625-\mathrm{in}$.-dia orifice was found 


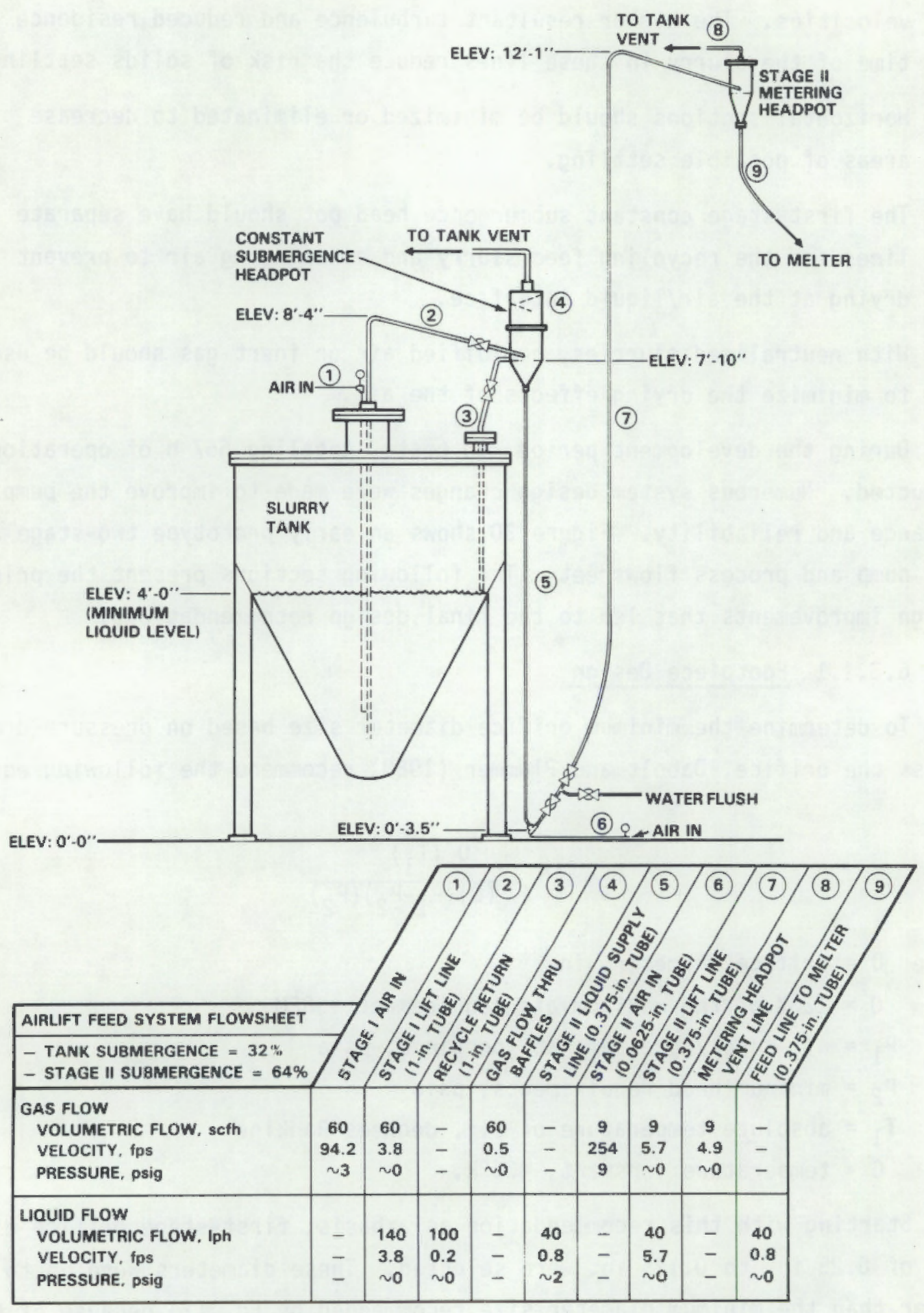

FIGURE 30. Air-Lift Feed System and Process Flowsheet 
to be unacceptable in the presence of solids. Blockage of the orifice occurred after only a few hours of operation. Orifice sizes of 0.0965 and $0.125 \mathrm{in}$. were tested and found to be acceptable.

Kearsley (1956) and Chamberlain (1957) have stated that simple footpieces consisting of an orifice flush with the inside wall are sufficient. An initial design with the first-stage air line projecting into the centerline of the lift 1 ine was tested. The footpiece design, shown in Figure 31 , was chosen to minimize the separation distance between the air inlet point and bottom of the $1 \mathrm{ift}$ tube. The separation was required to prevent air from being blown back into the tank. In directing the air flow upward, the chance of air being blown back into the tank was lessened. Unfortunately, plugging problems were encountered with this design during its use with neutralized slurries. Slurry leaked back into the horizontal section and deposited solids that eventually plugged of $f$

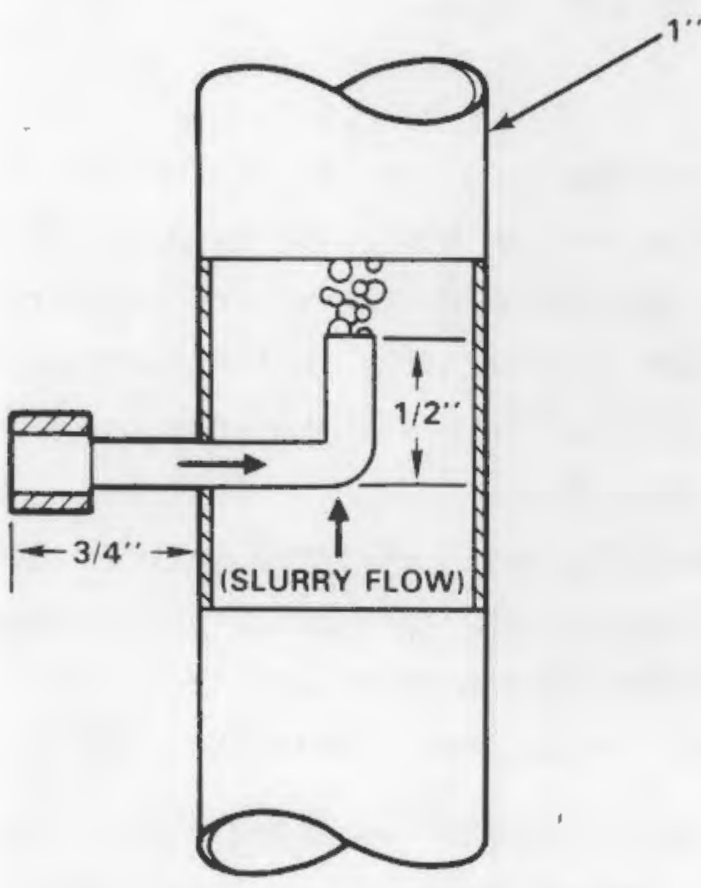

INITIAL STAGE I AIR INLET FOOTPIECE
S/S TUBE

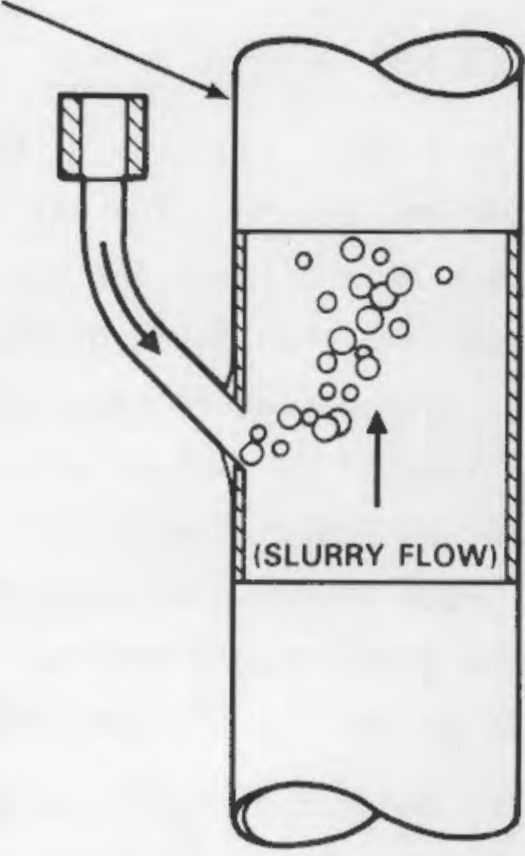

MODIFIED STAGE I AIR INLET FOOTPIECE

FIGURE 31. Stage I Air-Lift Footpiece Design 
the tube. The tube was modified to have the air inlet point flush to the tube wall. The air line leading to the inlet was placed at a $45^{\circ}$ angle to eliminate the potential for solids settling.

The initial and modified second-stage air inlet designs are shown in Figure 32. The initial design placed the air inlet just 1 in. from the liquidsupply line. Many investigators have suggested that the footpiece be located at least $12 \mathrm{in.}$ up the lift line from its lowest point. The main reason cited was to prohibit the backflow of air up the liquid-supply leg during startup (Dabolt and Plummer 1980, Kearsley 1956). Chamberlain (1957), however, placed the inlet air nozzle tips between 2 in. and 6 in. above the lowest point of the slurry-supply line and reported a negligible change in air-lift efficiency. The modified design located the air infection point $7.5 \mathrm{in}$. above the lowest point of the liquid supply line. The final footpiece design adopted was similar to the final first-stage design (Figure 31 ) in which a 0.125-in.-dia tube was placed at a $45^{\circ}$ angle relative to the lift line.

\subsubsection{Headpot Design}

The primary function of the headpots was to allow for separation of the lift air and slurry. The lift lines entering the headpots had 3-in./ft declinations. This allowed for the initial separation of the slurry and air, therefore reducing the amount of feed splatter that occurred in the headpots. Another design feature that minimized splatter involved the attachment of the slurry inlet line tangentially to the body of the headpot. This also created a swirling motion of the slurry in the headpot, which enhanced solids suspension. Both the downward-sloping lift line and the tangential positioning of the line designs were adopted from air-lift design work done by German researchers at the KFK (Nuclear Research Center) near Karlsruhe, FRG.

The headpot diameters were sized based upon the expected air volumes to be used during pump operation. To prevent the carryover of mist from the headpot, superficial air velocities less than 5 fps were recommended (Dabolt and Plummer 1980). First-stage headpot diameters of $6 \mathrm{in}$. and $8 \mathrm{in}$. were tested. Secondstage headpot diameters of $2 \mathrm{in}$. and $4 \mathrm{in}$. were tested. Each of these sizes was found to allow good air/slurry disengagement with slurries that did not 


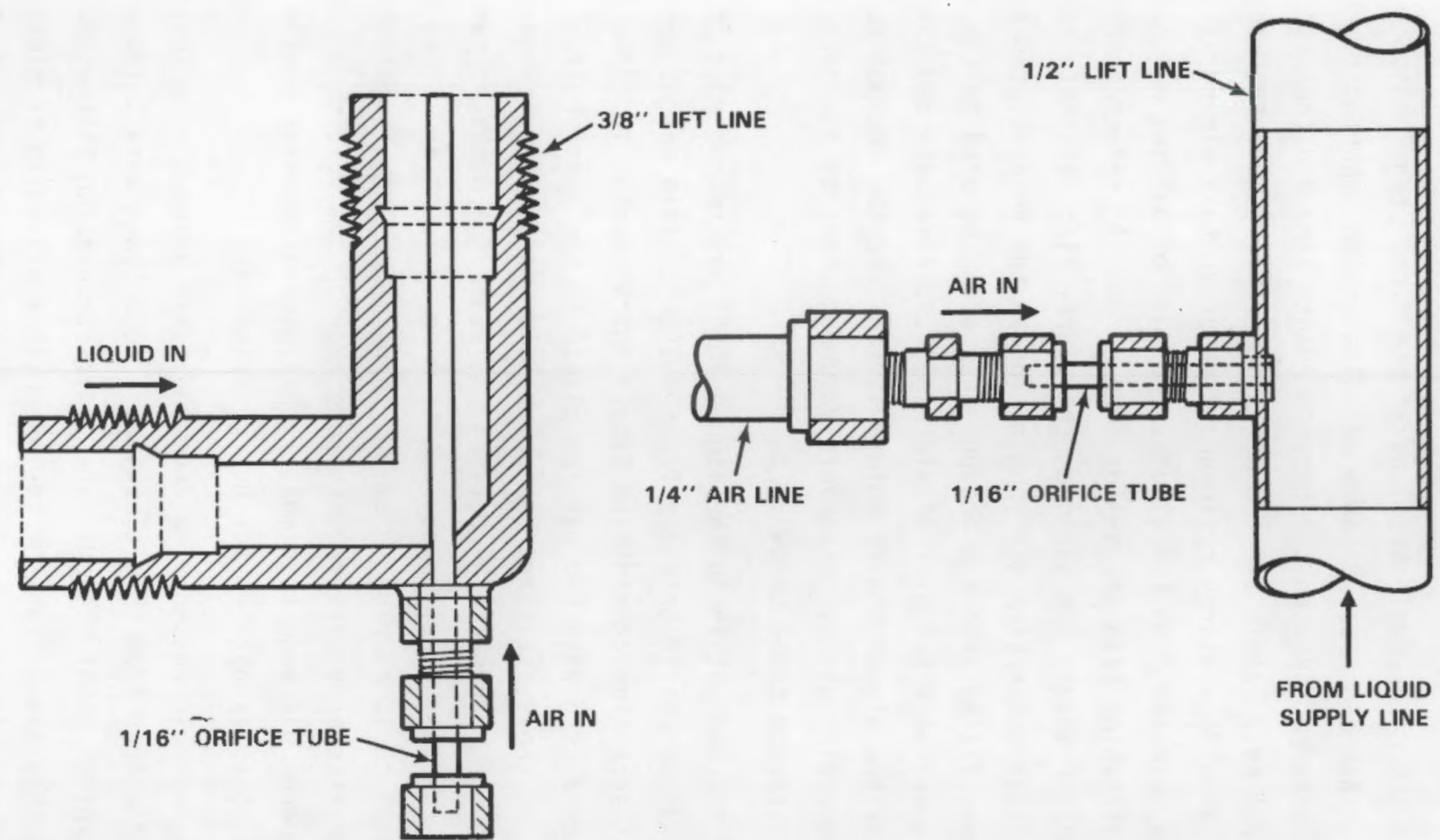


exhibit a tendency to form foam. Slurries that were very alkaline ( $\mathrm{pH}>12)$ or acidic $(\mathrm{pH}<2)$ were found to have very poor air disengaging properties.

In the 1-to 2-liter reservoir sections of the first-stage headpots good mixing was evident. Based on mass balance calculations no apparent segregation of solid particles occurred between the recycle return line and the second stage liquid supply line. Dabolt and Plummer (1980) recommended that the reservoir be sized to provide a slurry residence time of up to 1 min to allow small bubbles to be released from the liquid. Release of bubbles was less of a concern in this application than was solids suspension. A preferred criterion in sizing the reservoir volume was based on the slurry lift rate into the headpot. To promote solids suspension and good mixing in the headpot, two to three times more slurry was lifted into the headpot than could be used by the secondstage lift. This continuous turnover of slurry in the reservoir and the physical mixing caused by the higher slurry volume lifted into the headpot resulted in a well-mixed reservoir volume. Reservoir volume designs by PNL have therefore resulted in residence times below $30 \mathrm{~s}$.

The height of the headpot above the liquid level was recommended to be a minimum of two pot diameters (Dabolt and Plummer 1980). This height provided a sufficient gas residence time to minimize liquid entrainment. In addition, all early testing was conducted with two baffles placed in the upper half of the disengagement zone of the first-stage headpot to aid air/slurry disengagement. The final design abandoned the baffles in favor of a demister pad placed in the entrance of the vent line. Measurements made by Kearsley (1956) showed that liquid carryover could be reduced by $80 \%$ through the use of demister pads. Although no efficiency measurements were made on the baffles or demister pads, the design change was made to simplify the internal headpot design to facilitate the use of spray nozzles for headpot cleanout.

Initially, the recycle return line from the first headpot back to the tank was located $90^{\circ}$ off-center from the inlet line. Both lines were 1-in.-0.D., 0.065-in.-wall stainless steel tubing. The radial separation between both lines was just one tube diameter. The logic for this was again to minimize the splashing action of the slurry as it entered the headpot. The recycle line entered the feed tank and extended down to the minimum operating liquid level 
to assure that the return line port remained wetted to prevent any solids buildup. This design did not work well when slurries that tended to establish a stable surface foam layer were pumped. As time progressed, the foam layer in the headpot rose to completely cover the inlet line. Once this occurred, the direct injection of the lift air from the lift line beneath for foam only aggravated the problem at hand. Also, because the return line was submerged below the tank slurry line, the foam could not be carried into the tank where it could be dispersed. Based on these early problems, the final design eliminated the submerged return line. The separation between the inlet line and outlet line was also increased to allow $2 \mathrm{in}$. between the top of the return line and the bottom of the inlet line. This amounted to a 3.5-in. radial separation.

\subsubsection{Slurry Supply and Lift Line Design}

The slurry supply line extends from the point of entrance to the supply line to the point where air is introduced into the slurry (the footpiece). In the first-stage lift the supply line is at most $12 \mathrm{in.}$ long. The second-stage liquid supply line extends from the first headpot to the second-stage air footpiece. The design criteria used in sizing the liquid supply lines were 1) to assure the liquid velocities exceeded the solid particle settling velocity and 2) that the line size did not restrict the flow such that the air-lift efficiency dropped. The design terminal settling velocity of solid particles was based on a maximum particle diameter of 0.01 in. Based on hindered settling theory for spherical particles, in a Newtonian fluid the maximum particle velocity was calculated from Eq. (3) (Perry and Chilton 1973). Although the slurries are non-Newtonian, this calculation would be considered to provide a conservative estimate.

$$
U_{t s}=\left[\frac{4 g D p\left(\rho_{p}-\rho\right)}{3 p C}\right]^{1 / 2}\{1-f)^{n}
$$

where $U_{t s}=$ terminal velocity in the suspension, in. $/ \mathrm{s}$

$\mathrm{g}=$ acceleration due to gravity, $386 \mathrm{in.} / \mathrm{s}^{2}$

$D_{p}=$ particle diameter, 0.01 in.

$\rho_{p}=$ particle density, $0.08 \mathrm{lb} / \mathrm{in}^{3}{ }^{3}$ 
$\rho=$ fluid density, $0.051 \mathrm{~b} / \mathrm{in} .^{3}$

$C=$ drag coefficient, 3.5 (dimensionless)

$f=$ volume fraction of solids in the suspension, 0.2 (dimensionless)

$n=$ function of the Reynolds number $\cong 4.3$ (dimensionless)

For the types of slurries tested, a maximum hundred terminal settling velocity of $0.4 \mathrm{in.} / \mathrm{s}$ was estimated. Testing also determined that minimum supply line diameters equal to the lift line diameters did not affect air-lift efficiency. For first-stage slurry rates less than $300 \mathrm{~L} / \mathrm{h}$, a $0.93-i n .-1 . D$. tube was satisfactory. With rates above $300 \mathrm{~L} / \mathrm{h}$, a 1.5 -in. schedule 40 pipe supply line was used.

The lift lines are sized based on expected air flow. Dabolt and Plumer (1980) advise air velocities of 3 to $4 \mathrm{ft} / \mathrm{s}$ for maximum efficiency. The first-stage lift line length was fixed by the requirement of maintaining a minimum submergence of $30 \%$. The second-stage lift lines had submergence ratios of between $55 \%$ and $65 \%$ under various test configurations. This is we 11 within the advised $35 \%$ to $70 \%$ submergence ratio range commonly recommended for best operational control.

Initial testing at a maximum designed feed rate of $50 \mathrm{~L} / \mathrm{h}$ required a 0.375-in.-0.D., 0.035-in.-wall stainless steel lift line. Figure 30 shows the early design along with a flowsheet that presents typical values for the liquid and gas flows, velocities and pressures. As the air-lift was redesigned for a higher capacity, the second-stage lift line was increased to a $0.5-i n .-0 . D$., 0.035-in.-wall stainless steel tubing.

The initial second-stage slurry supply-line/lift-line design was prone to plugging problems. Settling of solids at the low point of the supply line was the primary concern. To minimize the settling potential, the second stage was modified as shown in Figure 33. The $\sim 70^{\circ}$ bend at the juncture of the supply line and lift line was replaced by a gradual 4.5 -in.-radius bend. This change occurred following the realization that the fluid and solid particles lost most of their momentum when they encountered the $70^{\circ}$ juncture, therefore making settling more likely. Addition of the gradual-radius bend resulted in the air inlet footpiece being located $7.5 \mathrm{in}$. above the low point of the liquid supply line. 


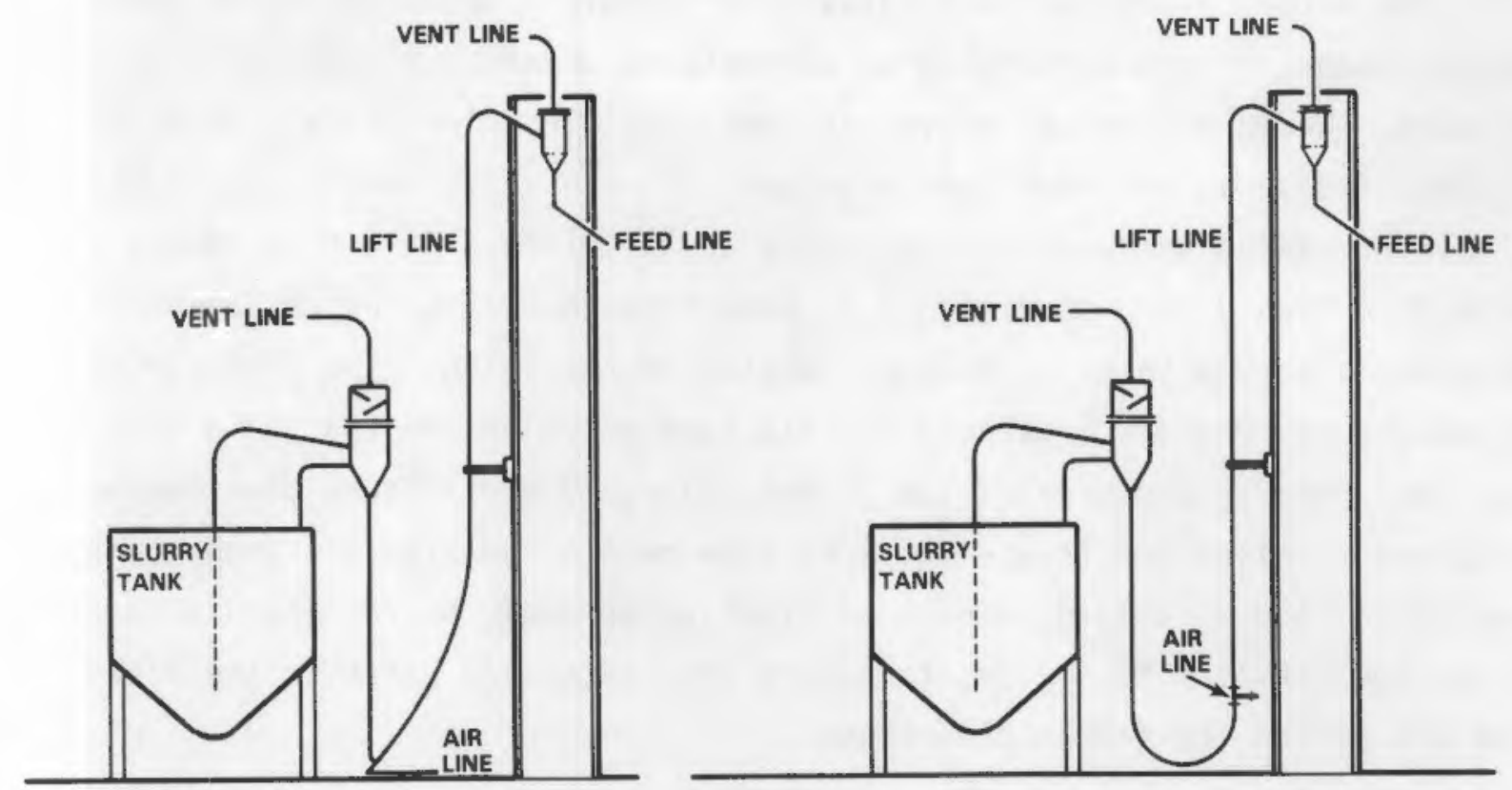

FIGURE 33. Modification of Stage II Lift Line

\subsubsection{Valve and Flush Designs}

The capability of flushing air footpieces and liquid lines is essential when solids are present. The liquid velocity in the supply lines is not sufficient to maintain turbulent mixing. Figure 30 shows the system of valves that was required to assure that the air-lift pump could recover from a plug in any of its lines. A flush capability was also placed in both air supply lines for flushing the orifices. The first-stage lift and recycle return lines contained valves so that the entire headpot could be filled and washed with water from a water add line located just above the lift line port. The water add line also provided water to the second-stage lift during normal shutdown to flush the second stage of any solids. A similar flushing capability existed in the second-stage headpot.

In the modified design (Figure 33 ), ball valves were placed in the secondstage line on either side of the second-stage footpiece. Should a plug form in the second stage, that section could be isolated, and water from the secondstage footpiece could be used to flush away the plug solids. 
For actual plant use, electrically or remotely actuated valves are recommended when a liquid containing an appreciable quantity of insoluble solids is present. Where mechanical valves are not possible or practical, strategically located freeze valves have been proposed. Freeze valves are simply a metal sleeve or casing surrounding the supply or lift line. If a plug should form, a cryogenic liquid such as nitrogen is pumped to the valve, which freezes the stagnant slurry within the encased section of the valve. The plug can then be flushed out. Obvious drawbacks to this type of valve are that 1) a second plug may be formed in the area of the freeze valve, 2) significant downtime would be incurred to allow the freeze valve to thaw before the air-lift pump can be restarted, and 3) a large amount of flush water would be required to thoroughly flush the air-lift pump lines to assure that no solids exist in the lines during the period the frozen plug thaws.

\subsubsection{Initial Testing Experience}

A total of ten tests were conducted during FY 1982 and FY 1983. These tests accounted for $667 \mathrm{~h}$ of operation in which approximately 36,000 L (9500 gal) of slurry was pumped by the second-stage lift. Both neutralized and acid slurries were tested in the air-lift pump. Table 6 summarizes the ten tests. The first eight tests were performed with a neutralized slurry composition shown in Table A.10. The slurry composition used during Test \#9, shown in Table A.11, was very similar to the previous slurry. The final test was conducted with an acidic slurry with a composition shown in Table A.12.

The first three continuous operations tests (COT) were conducted to obtain initial operating data on the pump. A plot of the stage-2 lift rate versus air flow rate for the three tests and an initial calibration test is shown in Figure 34. A considerable froth layer occurred in the first-stage headpot, indicating that poor air/liquid disengagement was occurring. To prevent the froth accumulation from completely filling the headpot, first-stage 1 ift rates less than $100 \mathrm{~L} / \mathrm{h}$ ( $1 / 3$ capacity) were required. The drop in capacity during the third COT was believed to be due to the gradual incorporation of air into the slurry. The slurry tank agitation was provided by a pulser system. Therefore, forced de-entrainment of air from the slurry did not occur. As a result, the liquid stream density declined and the pump efficiency dropped. 
TABLF 6. Air-Lift Pump Test Summary

Approx. Vol. Pumped

\begin{tabular}{|c|c|c|c|c|c|}
\hline t No. & Duration (h) & L & gal & Slurry Type & Test Objective/Design Modification \\
\hline 1 & 6 & 168 & 44 & Table A.10 & Initial evaluation of system design \\
\hline ? & 12 & 435 & 115 & Table A.10 & Study surface foam buildup phenomenon \\
\hline 3 & 32 & 1152 & 304 & Table A.10 & Additional testing of current design \\
\hline 4 & 59 & 3900 & 1030 & Table A.10 & $\begin{array}{l}\text { Headpots enlarged to aid } \\
\text { disengagement, Stage } 2 \text { lift-line dia. } \\
\text { increased, Stage } 1 \text { footpiece modified } \\
\text { to be flush with tube wall }\end{array}$ \\
\hline
\end{tabular}

$\begin{array}{rrrrrl}5 & 72 & 4934 & 1304 & \text { Table A.10 } & \text { Additional testing of current design } \\ 6 & 7 & 400 & 106 & \text { Table A.10 } & \text { Additional testing of current design } \\ 7 & 76 & 3900 & 1030 & \text { Table A.10 } & \text { Additional testing of current design } \\ 8 & 142 & 9100 & 2404 & \text { Table A.10 } & \begin{array}{l}\text { Stage } 2 \text { modified as shown in } \\ \text { Figs. } 32 \text { \& } 33\end{array} \\ 9 & 80 & 3830 & 1012 & \text { Table A.11 } & \text { Test feeding a ceramic melter } \\ 10 & 182 & 8600 & 2272 & \text { Table A.12 } & \text { Test feeding a ceramic melter }\end{array}$




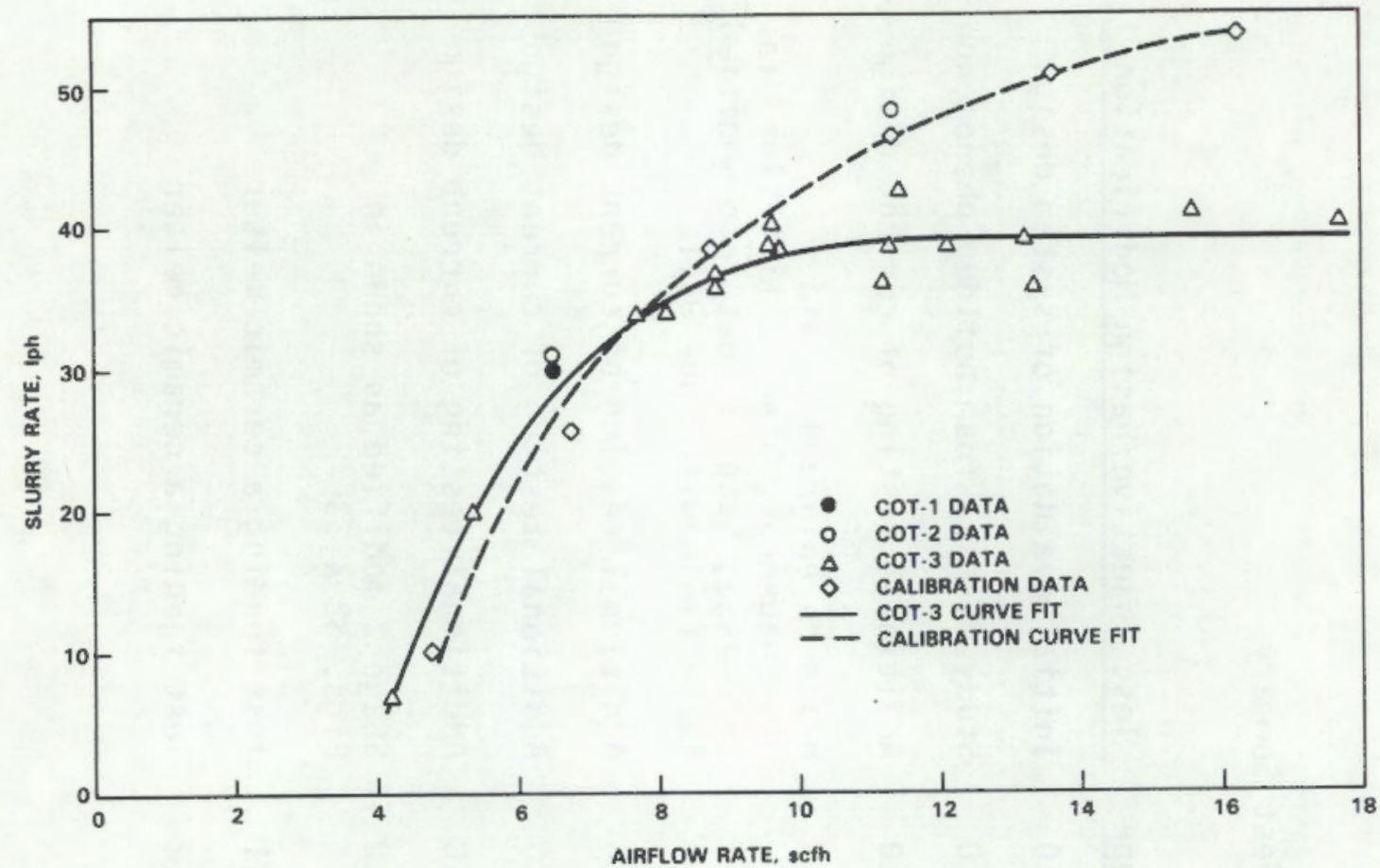

FIGURE 34. Air-Lift Calibration and Test Results of Tests 1, 2, and 3

In order to provide additional slurry residence time in the headpots, to facilitate slurry disengagement, the reservoir sections were enlarged following the third СОT. The effect of increasing the reservoir volume of the firststage headpot from $1 \mathrm{~L}$ to $2 \mathrm{~L}$ can be seen graphically in Figure 35 . The maximum pump capacity increased approximately $100 \%$ to $76 \mathrm{~L} / \mathrm{h}$ during COT-4. Both COT -4 and COT-5 demonstrated higher capacities than previous testing. The principal objective of COT-5 was to evaluate pump stability over an extended period at a constant air rate. A slurry lift rate of $69 \mathrm{~L} / \mathrm{h} \pm 5 \%$ was obtained.

The sixth continuous test, COT-6, was terminated just $7 \mathrm{~h}$ after it started due to poor performance. Maximum rates of only $50 \mathrm{~L} / \mathrm{h}$ were achieved. Posttest examination discovered that the flexible vent line from the second-stage headpot had become submerged below the slurry level in the tank. This caused the headpot to become pressurized. The second-stage submergence was therefore lowered, resulting in a lowered lifting capacity.

The seventh COT was performed to further characterize the delivery rate of the air-lift over time. As shown in Figure 36, the system operated for a total 


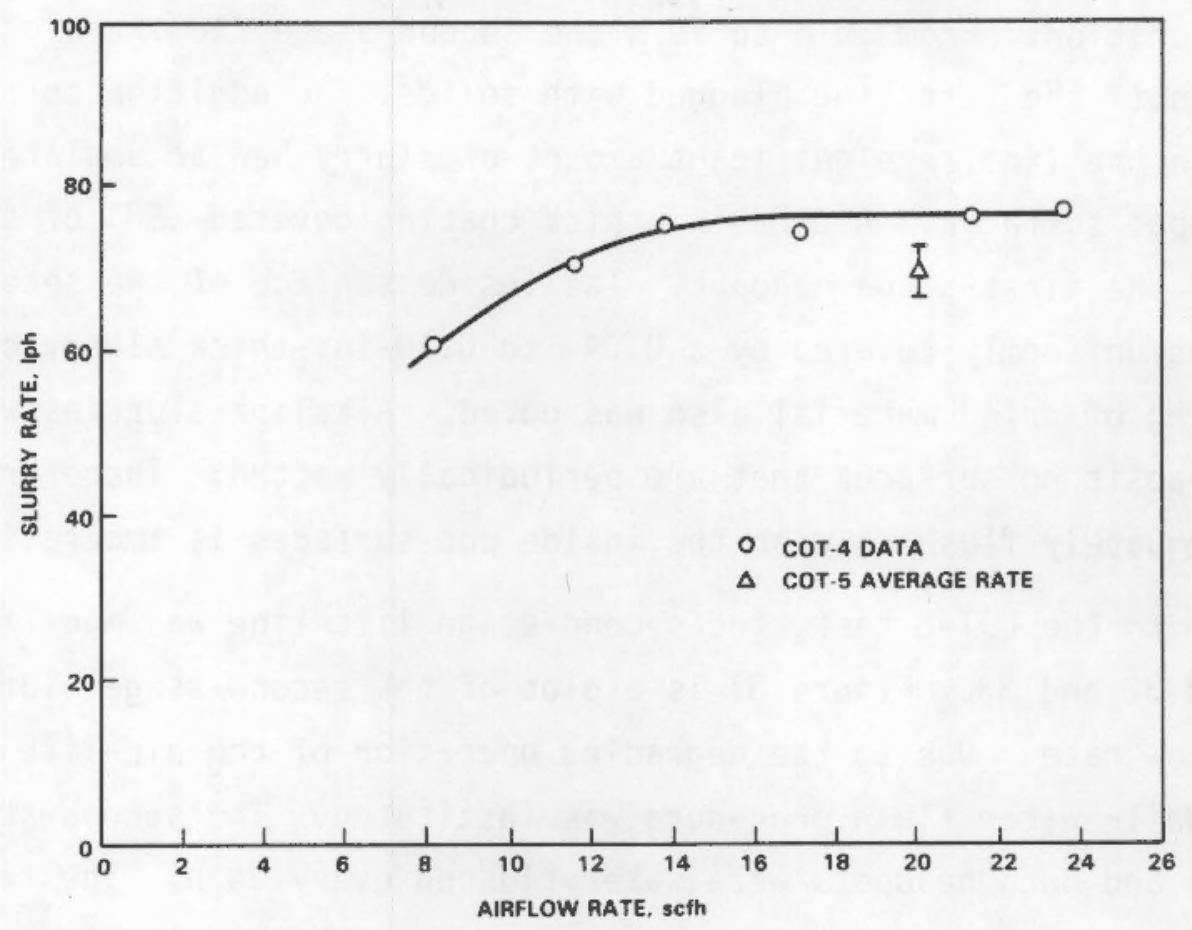

FIGURE 35. Test Results of Tests 4 and 5

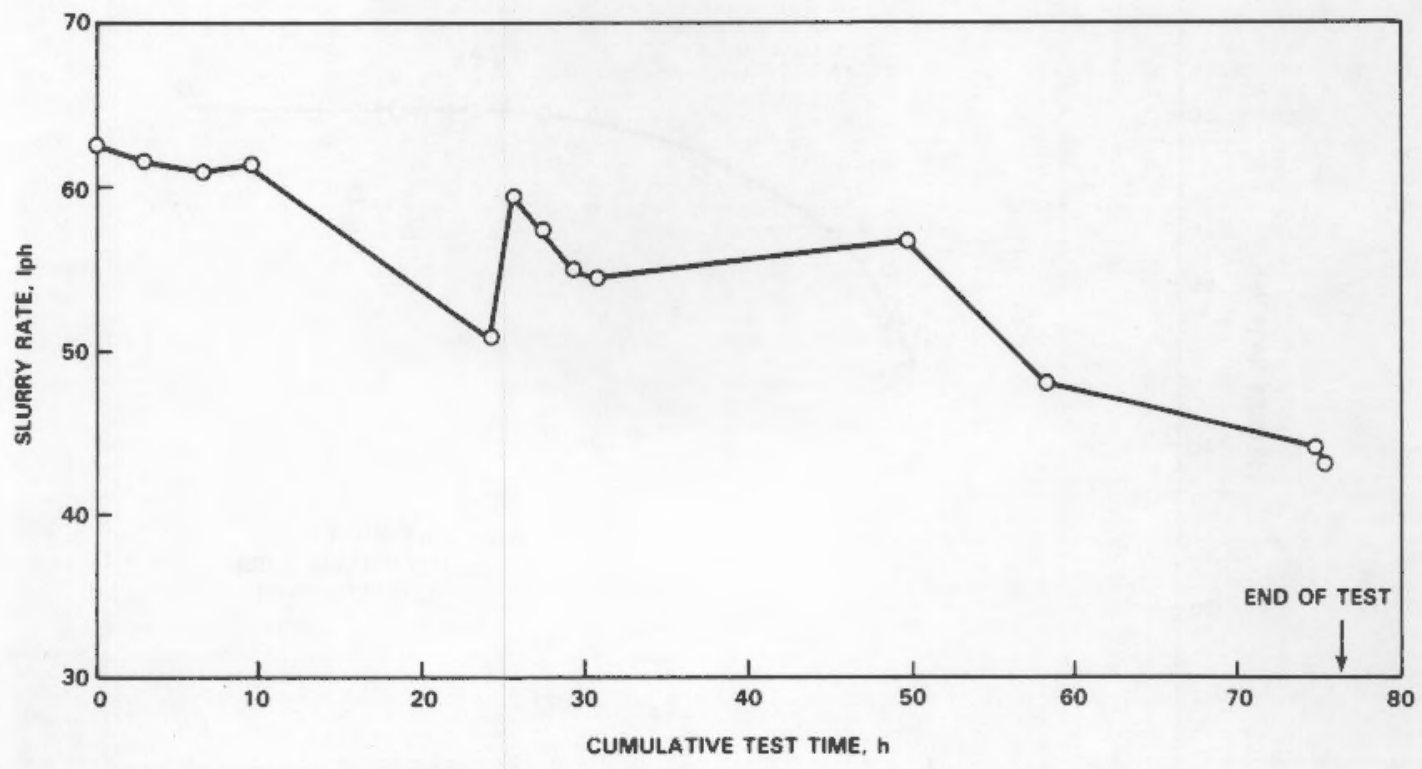

FIGURE 36. Drop in Feed Rate Over Time During Test 7 
of $76 \mathrm{~h}$. The flow rate of slurry ranged from $62 \mathrm{~L} / \mathrm{h}$ to $51 \mathrm{~L} / \mathrm{h}$ during the first $50 \mathrm{~h}$ of operation. From $50 \mathrm{~h}$ to $76 \mathrm{~h}$ the second-stage flow rate of slurry degraded until the lift line plugged with solids. In addition to the plug that occurred in the line, a significant amount of slurry had accumulated on the inner headpot surfaces. A $0.04-i n$.-thick coating covered $\rightarrow 90 \%$ of the inside surface of the first-stage headpot. The inside surface of the second-stage headpot was uniformly covered by a 0.04 - to 0.10 -in.-thick slurry coating. Some flaking of dried material also was noted. Alkaline slurries will readily wet and deposit on surfaces that are periodically wetted. Therefore, the ability to adequately flush or wash the inside pot surfaces is imperative.

Prior to the COT-8 test, the second-stage lift line was modified as shown in Figures 32 and 33. Figure 37 is a plot of the second-stage slurry rate versus air flow rate. Due to the degrading operation of the air-lift during COT-7, a daily water flush procedure was instituted. The second-stage air inlet line and both headpots were water-flushed every $24 \mathrm{~h}$. The flush procedure required a total of $1 \mathrm{~L}$ of water per cycle. As seen in Figure 37, the

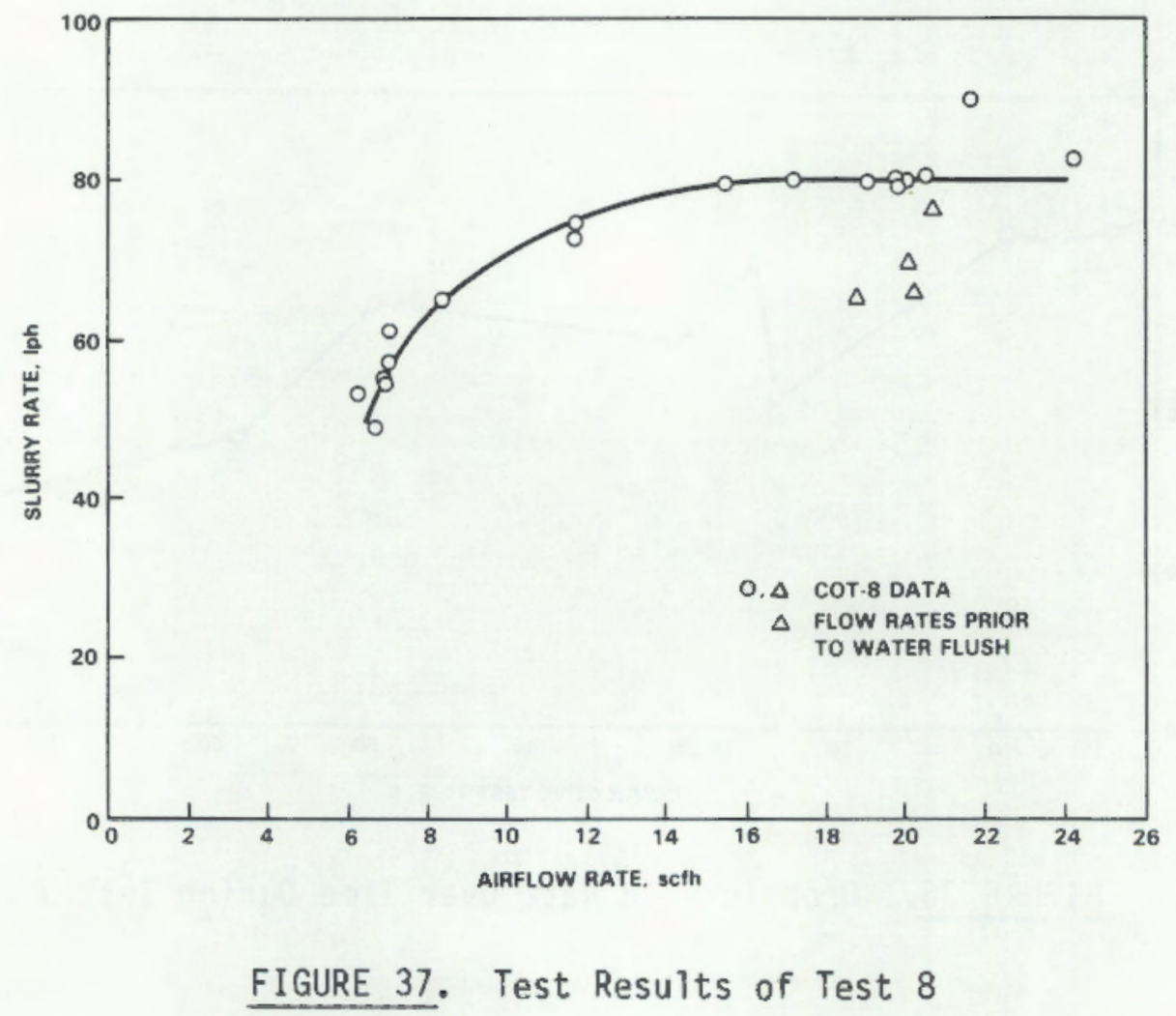


flushes had a definite effect on the pump's performance. Prior to many of the flushes, the feed rates had decreased to 80 to $90 \%$ of their previous values. Following each flush, the system reestablished the previous high rates. The implication is that the air inlet area was slowly becoming plugged by solid deposits. The use of routine water flushes was then essential to the continued operation of the air-lift pump.

The final two continuous operation tests were conducted to deliver slurries to the PNL pilot-scale ceramic melter. COT-9 and COT-10 pumped slurries of the compositions shown in Tables A.11 and A.12, respectively. Second-stage rates of $20 \mathrm{~L} / \mathrm{h}$ to $70 \mathrm{~L} / \mathrm{h}$ were used during the experiments. The development of a stable foam in the headpots was again a problem. The slurry used during COT-9 entrained air much more easily than did the slurry used during the first eight tests. During the final $59 \mathrm{~h}$ of COT-9 the melter feed slurry was diluted $20 \%$ with water. The resulting, more dilute slurry, was much more fluid and disengaged from the air more readily.

COT-10 was the first experience gained pumping a nitric-acid-based feed slurry. The air-lift operated well except for poor air/slurry disengaging properties. During the $182 \mathrm{~h}$ of testing no plugging of the air-lift pump occurred.

\subsubsection{Full-Scale Air-Lift Pump Test Results}

Following prototype testing, a full-scale air-lift pump was designed and constructed. The application of the pump was demonstrated during a long-term testing experiment conducted in FY 1984. The pump was designed based on fu11scale flowsheet requirements and equipment layout for the West Valley Demonstration Project. Following design and construction, the air-lift pump was successfully operated for $1067 \mathrm{~h}$, during which an estimated 124,726 L of simulated melter feed slurry was pumped. Test objectives were to: 1) characterize the lifting capacity and stability of the two-stage lift;2) document operational problems such as plugging, solids settling and solids scaling associated with the slurry composition; 3) demonstrate long-term reliability of the airlift pump; and 4) inspect the pump for wear following testing and document the expected service lift of the pump. 


\subsubsection{Full-Scale Air-Lift Pump Design}

The air-lift pump system was designed to operate with a full-scale melter that could process up to $180 \mathrm{~L} / \mathrm{h}$ of slurry. A schematic of the air-lift pump is shown in Figure 38. The first-stage lift line was $72.5 \mathrm{in}$. long and constructed of 1.5-in.-dia schedule 40 pipe. The motive air entered the lift line $9 \mathrm{in}$. from the bottom of the entrance of the lift line. The air supply line was reduced from a 0.5-in. nominal-diameter line to 0.125-in. nominal-diameter pipe at the injection point. The injection point was attached flush to the inside wall of the lift line at a $45^{\circ}$ angle.

The top of the lift line sloped downward 15 degrees into the headpot to allow some initial disengagement between the slurry and the air. The lift line entered the headpot tangentially, which past testing had shown to promote headpot mixing and minimized slurry splatter.

The headpot had an internal diameter of $8 \mathrm{in}$. and a total height of $24 \mathrm{in}$. The lower section tapered into a 1.7-L cone section that served as a slurry reservoir. The 0.5-in.-0.D. second-stage liquid supply line was attached to the very bottom of the cone. The pot dimensions were determined by the expected air requirement and slurry rate. The cross-sectional area of the pot was determined experimentally to be adequate for providing good slurry mixing. The 1.5-in.-dia return line was larger than previous return-line sizes of $1 \mathrm{in}$. to prevent the headpot from becoming flooded at the higher first-stage lift rates. A $2-i n$. separation between the inlet and return lines ensured that any froth or foam that accumulated would not obstruct the inlet.

Two full-cone spray nozzles were placed in the headpot to provide full spray coverage to periodically wash the inner surface of the pot. Periodic washing was shown to prevent the buildup of solids that could cause potential plugs. The wash capability also cleaned the plexiglas portion of the headpot, which allowed for unobstructed viewing of the headpot internals during operation.

As the lift air disengaged with the slurry, the air passed out of the headpot into the 3-in.-dia vent line. The initial 4-in. section contained a demister pad to minimize the amount of liquid carryover in the existing gas 


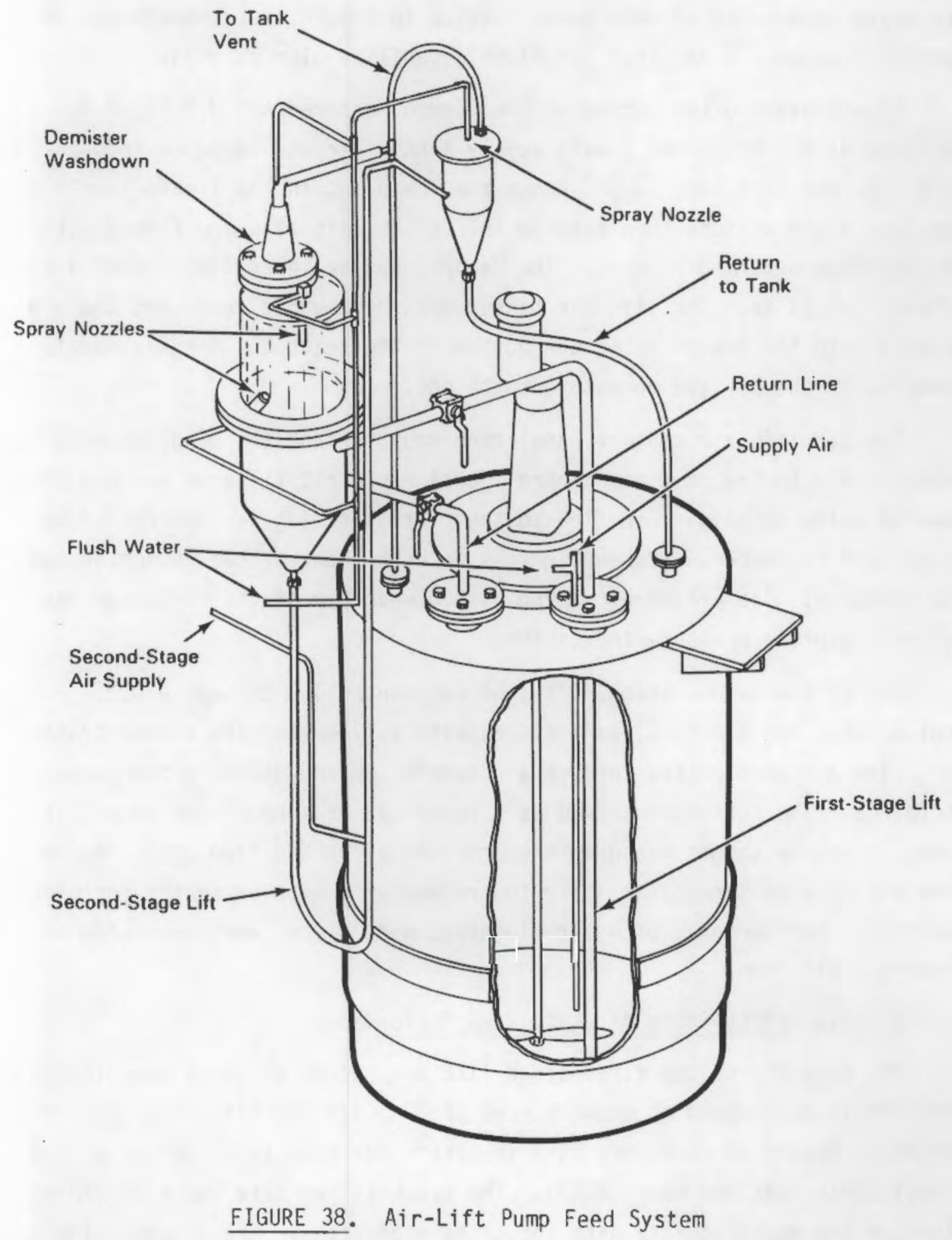


stream. The demister section was chosen over a baffle design because the latter would have required more spray nozzles to ensure that the headpot was adequately cleaned. A demister pad flush capability also existed.

Slurry exiting the bottom of the headpot entered the $0.5-i n .-0 . D$. (0.43-in.-I.D.) stage-two liquid supply line. Air was injected into the opposite leg, the lift leg, $12 \mathrm{in.}$ above the low point in the liquid supply line. The liquid/air mixture then rose $56 \mathrm{in}$. up the lift line and flowed into the second-stage metering headpot. The headpot had an inner diameter of $4 \mathrm{in}$. and a length of $11 \mathrm{in.}$. The lift air passed out the headpot vent, and the slurry drained into the feed line at the bottom of the headpot. A spray nozzle was centered in the pot lid to wash out the pot.

The air-lift air control panel received air from the 90-psig building air header. Air to the pump air control panel was first filtered and the pressure lowered below 20 psig. Air flow to the first lift leg was controlled by a 0-300 SCFH rotameter. Pressure gauges on both sides of the rotameter monitored the pressure. The pressure reading just downstream of the rotameter was taken as the footpiece pressure indication.

Air to the second-stage lift line was controlled through a $0.25-i n$. control valve. The air flow was measured with a flowmeter and signal transmitter. The air then passed through a rotameter before going to the second-stage footpiece. The rotameter served as a redundant measure of the second-stage air flow. Pressure gauges measured the pressure along the flow path. Again, the line pressure measured just after the rotameter was taken as the footpiece pressure. For purposes of water flushing, water lines were connected to each footpiece air line.

\subsubsection{First-Stage Air-Lift Pump Performance}

The capacity of the first-stage lift was tested at three tank levels. The tank levels correspond to submergences of $32 \%, 37 \%$ and $41 \%$. The data is presented in Figure 39 as slurry rate in liters per hour $(L / h)$ versus air rate in actual cubic feet per hour (ACFH). The brackets indicate the standard deviations of the measured rate data about the mean value. The absence of brackets indicates that only a single sample was taken at the particular air rate. 


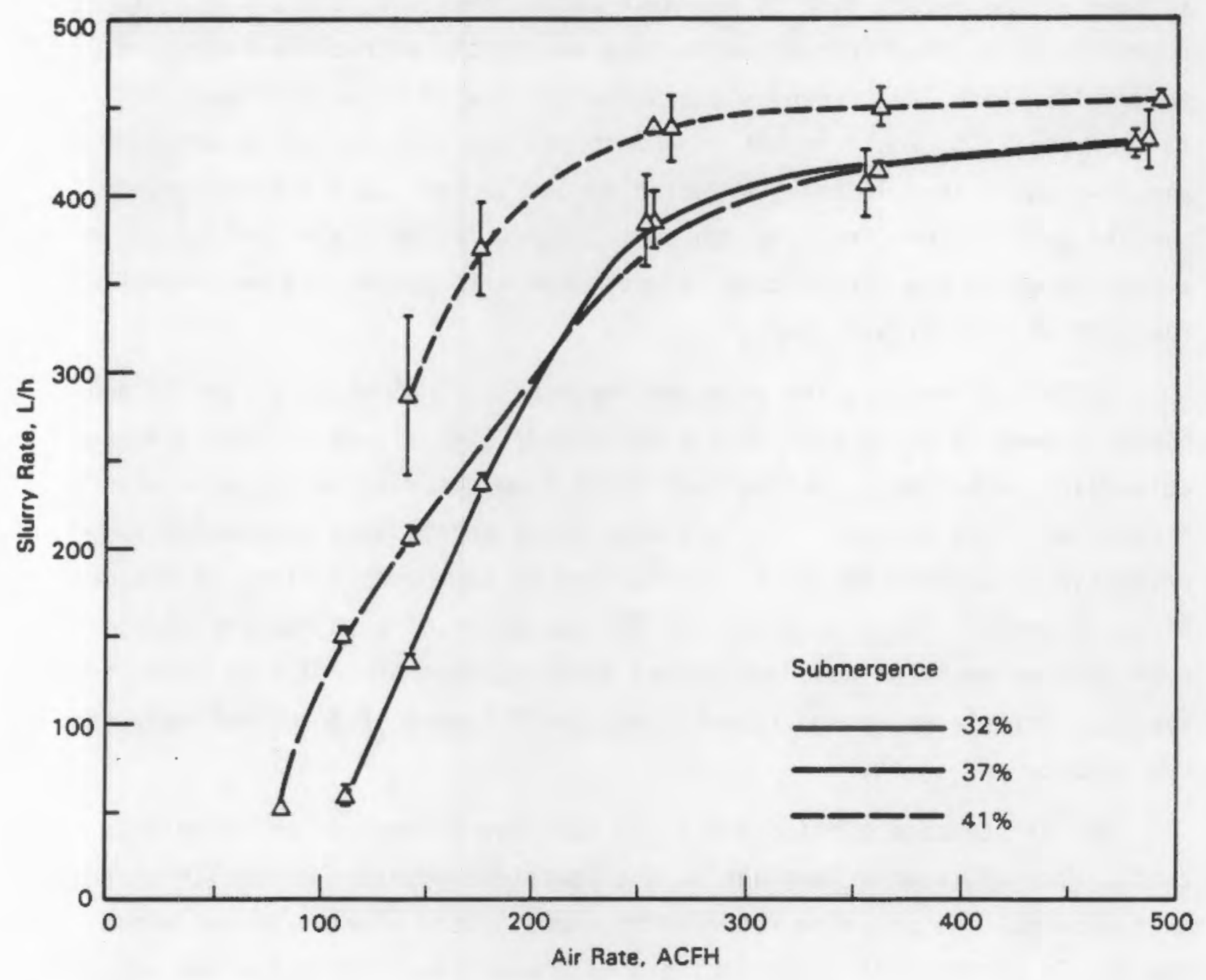

FIGURE 39. First-Stage Slurry Rate Versus Air Rate

Maximum lift rates of $\sim 450 \mathrm{~L} / \mathrm{h}$ were achieved at a maximum submergence of $41 \%$. In order to maintain first-stage lift rates about three times higher than second-stage lift rate requirements, first-stage rates of between 400 and $500 \mathrm{~L} / \mathrm{h}$ were required. The data shows that this criterion was met, even at the minimum submergence of $\mathrm{S}_{0}=32 \%$.

The slurry lift rate can be expected to increase significantly as the submergence approaches its maximum value of $80 \%$. Equipment constraints did not allow testing at $S_{0}$ greater than $41 \%$. Rates approaching $1,000 \mathrm{~L} / \mathrm{h}$ seem reasonable with the current pump. The possibility of flooding the headpot would seem unlikely based on available freeboard observed during testing and, of course, 
as long as the return line is not obstructed. However, for a 1-in. increase in liquid level in the first-stage headpot due to the weir characteristics of the return line port, the second-stage submergence will increase almost $2 \%$. Every $2 \%$ increase in $\mathrm{S}_{0}$ would result in a 5 to $10 \%$ increase in the capacity of the second-stage lift. If this variation in the second-stage lift is unacceptable, the air rate to the first leg can be adjusted. To maintain maximum and minimum slurry rates to the first-stage headpot, the lift air should be controlled as a function of tank liquid level.

Following testing, the pump was inspected. Evaluation of the internal piping showed it to be free of any buildup or significant scaling. No noticeable wear was evident. Ouring testing no problems were encountered with the first-stage lift system. The full-cone spray nozzle wash system was very effective in keeping the walls and ceiling of the headpots free of accumulation. A typical flush cycle (i.e., 2-s operation of each headpot nozzle in turn and the demister washdown spray) added approximately $1 \mathrm{~L}$ of water to the system. This is an insignificant quantity of liquid if done routinely once per day or once per shift.

The first-stage air footpiece did not plug throughout the long-term test. Usually, over a 24-h period the footpiece pressure gradually increased 1 to 3 psig. The pressure returned to normal after a short $150-\mathrm{mL}$ water flush. To prevent solids accumulation whenever the first stage was not operating, an air purge was maintained through the footpiece. Initially, a small purge rate of about 3 ACFH was used. However, the small bubbles that were apparently released up the lift line formed a froth which rose up the lift line and entered the headpot. The froth was quite stable and difficult to flush out of the line. As an alternative, a higher air purge rate of about 40 ACFH was used. This rate was slightly less than the required air to initiate slurry lifting. The higher air rate apparently caused enough turbulence and mixing in the lift line to destabilize any froth that might be generated. Due to constraints on equipment size, tank submergences higher than $41 \%$ were not possible. A maximum submergence of about $80 \%$ will be used in the actual full-scale system. It is not known if the minimum air required for lifting at $80 \%$ submergence will be so low that froth formation may occur during idling. This may, 
however, put constraints on the maximum tank slurry level that could be maintained during idling. Another solution may be to let slurry rise up into the footpiece and air supply line and periodically (many times per minute) apply an air pulse to the footpiece. Solids will be kept from settling by the forced movement of the liquid. This practice is sometimes used to prevent dip tubes, used to measure liquid head and weight factors in remote radioactive tanks, from plugging.

\subsubsection{Second-Stage Air-Lift Pump Performance}

The second-stage air-lift was operated for $1067 \mathrm{~h}$, pumping an estimated $124,726 \mathrm{~L}$ of slurry. One period of $782 \mathrm{~h}$ of continuous operation was achieved without any pump failure. The relationship of slurry lift rate and secondstage air rate is shown in Figure 40. Data was obtained at two different first-stage lift rates to determine the effect of varying the first-stage lift rate on the second-stage operation. The slurry lift rates were reproducible over the entire range of air rates. Most of the data was within $5 \%$ of the operating curves, which were fitted to the data. For most of the long-term operation the first-stage lift rate was operated at $\sim 325 \mathrm{~L} / \mathrm{h}$. Resulting second-stage lift rates of 35 to $175 \mathrm{~L} / \mathrm{h}$ were achieved. At the lower firststage lift rate of $225 \mathrm{~L} / \mathrm{h}$, second-stage lift rates of 40 to $165 \mathrm{~L} / \mathrm{h}$ were possible. Although the achievable lift rates were comparable at the two separate first-stage $1 \mathrm{ift}$ rates, as a function of air rate, the resultant slurry rates varied 10 to $15 \%$. This effect on second-stage operation by the first stage prohibits relying solely on the second-stage air rate to determine the secondstage lift rate. Only by grossly enlarging the first-stage recycle return line could this effect be minimized.

Typically, following footpiece water flushes, the indicated air flow to the footpiece would become unsteady. The unsteady air flow was especially prominent during operation at slurry rates less than $100 \mathrm{~L} / \mathrm{h}$ when the footpiece pressure was less than 2 psig. The surging tendency was thought to be due to 1) the short second-stage lift height of $56 \mathrm{in.}$ (i.e., the unsteady-state hydrostatic pressure head that existed during these periods) and 2) the surging 


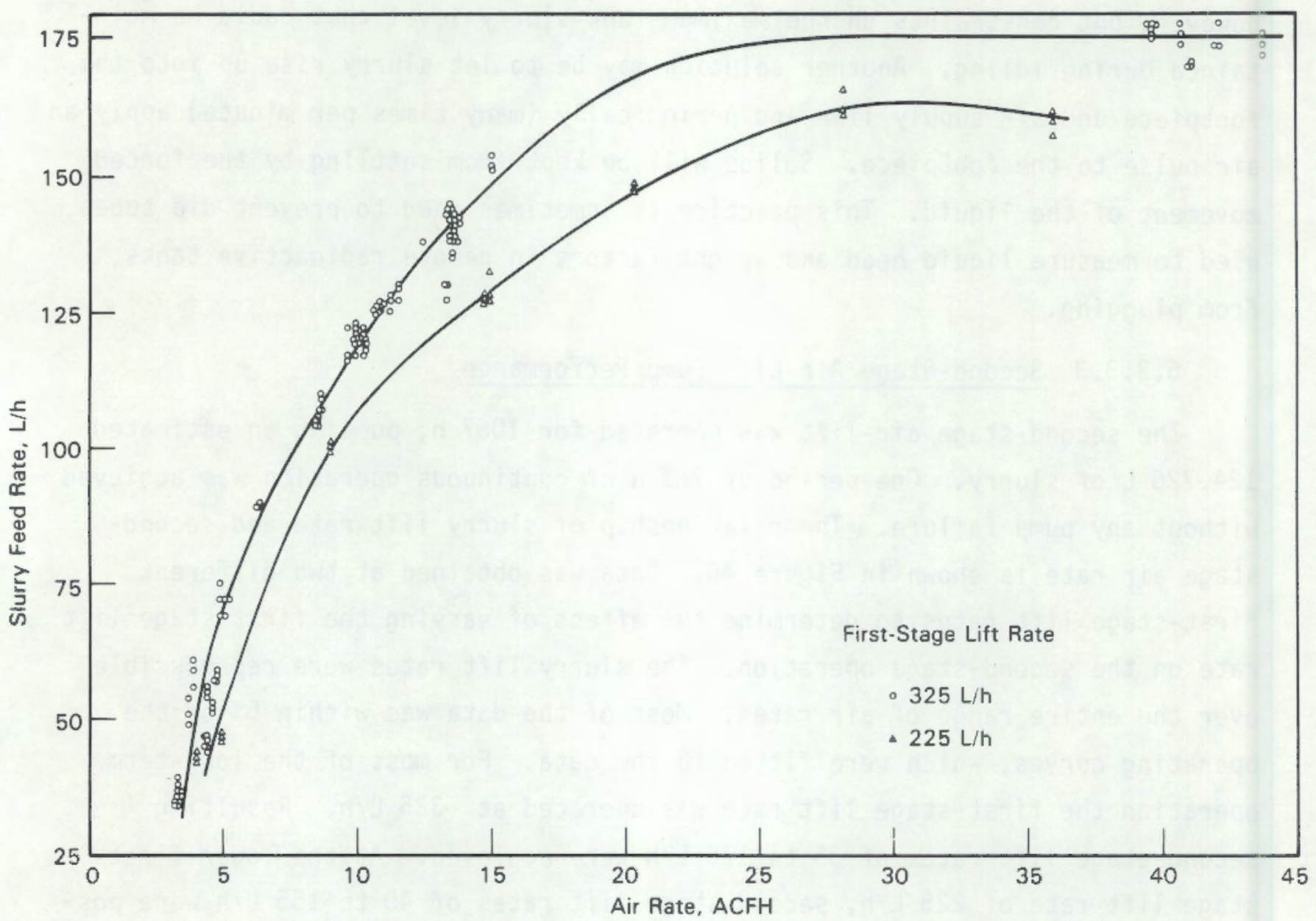

FIGURE 40. Second-Stage Slurry Rate Versus Air Rate at Two Different First-Stage Lift Rates

or slugflow characteristics of the slurry as it moved up the lift line. This resulted in a variable pressure at the orifice. The air flow usually stabilized after a period of 1 to $2 \mathrm{~h}$.

During testing, the $0.125-i n$-dia orifice footpiece was replaced with a 0.0625-in.-dia orifice footpiece to increase the pressure drop across the footpiece to study if this would stabilize the air flow. No loss in lift capacity was experienced, and the air flow stability was improved, as expected. However, some surging was still experienced at slurry rates below about $70 \mathrm{~L} / \mathrm{h}$. The indicated pressure and flow output by the second-stage air flow meter also became more erratic with time, indicating that the smaller orifice was 
frequently becoming partialiy plugged. The indicated footpiece pressure rose $200 \%$ to $400 \%$ above the initial pressure during these periods. Because of these negative results, the $0.125-i n$. dia orifice was placed back into service. The recommended minimum orifice size based on Eq. (2) was determined as follows. For a maximum air flow rate of 0.67 SCFM, a head pressure $\left(P_{2}\right)$ of 17.4 psia, and a maximum pressure difference of $5 \mathrm{psia}$, an orifice diameter of $0.0965 \mathrm{in}$. was recommended. This size footpiece diameter was $50 \%$ smaller than the original footpiece diameter of $0.125 \mathrm{in.,}$ a size based on initially higher anticipated air flow requirements. A 0.0938-in.-dia orifice was subsequently tested following the long-term testing. The surging tendency was reduced but not eliminated, and water flush requirements of the orifice were comparable to the larger 0.125 -in.-dia orifice.

Throughout the $45 \mathrm{~d}$ of operation, two interruptions were caused by solids dropout in the second-stage lift. The plugs occurred in the liquid supply line. The first line plug occurred after only $40 \mathrm{~h}$ of operation. Prior to plugging, the second stage was operated at rates less than $50 \mathrm{~L} / \mathrm{h}$. The plug originated in the U-tube of the liquid supply line. No large solid pieces were found. Therefore, the plug was attributed to the dropout of individual particles, particularly zeolite. At flow rates less than $50 \mathrm{~L} / \mathrm{h}$ the slurry velocity in the liquid supply line was on the order of $5 \mathrm{in./s}$. At the nominal rate of $135 \mathrm{~L} / \mathrm{h}$, the line velocity was $16 \mathrm{in.} / \mathrm{s}$. A maintenance procedure was instituted following the first line plug to prevent further plugs that might occur due to the gradual accumulation of settled particles in the low point of the supply line. The procedure called for the second-stage lift rate to be increased to its maximum level for a 5-min period each day. In doing this the maximum achievable slurry velocity of about $21 \mathrm{in.} / \mathrm{s}$ was reached. This was done to try and re-entrain any particles that may have settled in the U-tube section of the liquid supply line. This procedure proved, by the lack of any further plugging occasions, very successful. No further plugging of this section of line occurred for over $1000 \mathrm{~h}$. This procedure would have an insignificant impact on ceramic melter operation.

The second line plug occurred in the slurry return line from the secondstage headpot after $\sim 822 \mathrm{~h}$ of operation. Again no large particles were 
found. The plug occurred in a short relatively horizontal section of the line. Therefore, the plug was a result of a gradual accumulation of solids in the line. Since the line was not prototypical of the sharply slanting feed line that would exist in the production facility, the importance of this plug was discounted.

The final system interruption occurred after $1067 \mathrm{~h}$ of testing. The longterm testing was stopped following the occurrence of this plug. The plug was very similar to the first plug in location and makeup. No large particles wera found that may have caused plugging. In each case the plugs were easily removed by backflushing the supply line with 60 psig water.

Another daily preventive maintenance procedure that was used successfully was the daily flushing of the air footpieces. The flushing removed any scale that might have built up on the orifice causing the pressure at the footpiece to increase. Examinations of the footpiece showed that some slurry was leaking back through the orifice and depositing solids. It is believed the flushing helped to minimize this buildup. Each flush sequence added approximately $150 \mathrm{~mL}$ of water through each footpiece. This quantity is trivial in comparison to the slurry rates of the full-scale system. 


\subsection{REFERENCES}

Brouns, R. A., and M. S. Hanson. 1984. "The Nuclear Waste Glass Melter - An Update of Technical Progress." In Proceedings of Fuel Reprocessing and Waste Management Topical Meeting, pp. 101-115. American Nuclear Society, LaGrange Park, Illinois.

Chamberlain, H. V. 1957. Factors Affecting Capacity of Air Lifts. ID0-14398.

Chick, L. A., W. M. Bowen, R. 0. Lokken, G. W. Wald, L. R. Bunnell and D. M. Strachan. 1984. West Valley High-Level Nuclear Waste Glass Development: A Statistically Designed Mixture Study. PNL -4992, Pacific Northwest Laboratory, Richland, Washington.

Dabolt, R. J., and K. E. Plumer. 1980. Design of Air Lift Systems for Transfer and Measurement of Radioactive Liquids. AGNS-35900-3.2-77, AlliedGeneral Nuclear Services, Barnwell, South Carolina.

Hydraulic Institute. 1983. Hydraulic Institute Standards for Centrifugal, Rotary, and Reciprocating Pumps. 14 ed., p. 8.

Kearstey, G. W. T. 1956. Use of an Air Lift as a Metering Pump for Radioactive Solutions. ORNL-2175, Oak Ridge National Laboratory, Oak Ridge, Tennessee.

Perez, J. M., Jr. 1983. Design and Performance of Feed Delivery Systems for Simulated Radioactive Waste Slurries. PNL-4423, Pacific Northwest Laboratory, Richland, Washington.

Perry, R. H., and C. H. Chilton, eds, 1973. Chemical Engineers' Handbook. 5th ed. McGraw-Hill, Roca Baton, Florida.

Peterson, M. E., D. N. Berger, H. T. Blair and D. H. Siemens, 1985. "Adaptation of an Air-Displacement Slurry Pump for Remote Service." In Proceedings of ANS 1985 Winter Meeting, p. 575. American Nuclear Society, LaGrange Park, Illinois.

Stindt, W. H. 1971. "Pump Selection." Chem. Eng. 78:23,43. 


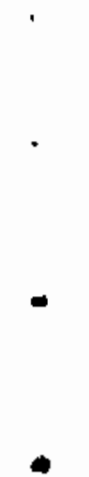


APPENDIX A

COMPOSITION AND PHYSICAL PROPERTIES OF SIMULATED SLURRIES 
IABLE A.1. Simulated Slurry Used During ADS Pump Test $\# 1$

\begin{tabular}{|c|c|}
\hline Compound & $\begin{array}{c}\text { Concentration } \\
(\mathrm{g} / \mathrm{L})\end{array}$ \\
\hline $\mathrm{AI}(\mathrm{OH})_{3}$ & 24.18 \\
\hline $\mathrm{Fe}(\mathrm{OH})_{3} \cdot \mathrm{H}_{2} \mathrm{O}$ & 56.70 \\
\hline $\mathrm{Cr}(\mathrm{OH})_{3}$ & 5.01 \\
\hline $\mathrm{Ni}(\mathrm{OH})_{2}$ & 2.24 \\
\hline $\mathrm{NaNO}_{3}$ & 69.89 \\
\hline $\mathrm{NaOH}$ & 25.36 \\
\hline $\mathrm{Na}_{4} \operatorname{EDTA}(\mathrm{a})$ & 1.66 \\
\hline $\mathrm{Sr}\left(\mathrm{NO}_{3}\right)_{2}$ & 1.49 \\
\hline $\mathrm{ZrO}_{2}$ & 4.10 \\
\hline $\mathrm{CsNO}_{3}$ & 2.34 \\
\hline $\mathrm{Ba}\left(\mathrm{NO}_{3}\right)_{2}$ & 3.21 \\
\hline Frit-131 (b) & 375.35 \\
\hline TOTAL & 571.53 \\
\hline
\end{tabular}

(a) Ethylenediaminetetracetic Acid Tetrasodium Salt.

(b) Frit-131 Composition (-200 mesh) shown below:

\begin{tabular}{|c|c|}
\hline Oxide & $\mathrm{Wt} \%$ \\
\hline $\mathrm{SiO}_{2}$ & 57.9 \\
\hline${ }^{B} 2_{2} \mathrm{O}_{3}$ & 14.7 \\
\hline $\mathrm{Na}_{2} \mathrm{O}$ & 17.7 \\
\hline $\operatorname{Li}_{2} \mathrm{O}$ & 5.7 \\
\hline $\mathrm{MgO}$ & 2.0 \\
\hline $\mathrm{TiO}_{2}$ & 1.0 \\
\hline $\mathrm{La}_{2} \mathrm{O}_{3}$ & 0.5 \\
\hline $\mathrm{Zr} \mathrm{O}_{2}$ & 0.5 \\
\hline
\end{tabular}


TABLE A.2. Physical Properties for Slurry. Used During ADS Pump Test \#1

\begin{tabular}{|c|c|c|c|c|}
\hline $\begin{array}{l}\text { Cumulative } \\
\text { Days of } \\
\text { Testing } \\
\end{array}$ & $\begin{array}{l}\text { Density } \\
(\mathrm{g} / \mathrm{m} 1) \\
\end{array}$ & $\begin{array}{l}\text { Total } \\
\text { Solids } \\
\text { Content } \\
(\mathrm{g} / \mathrm{L}) \\
\end{array}$ & $\begin{array}{c}\text { Total } \\
\text { Oxide } \\
\text { Content } \\
(\mathrm{g} / \mathrm{L}) \\
\end{array}$ & $\begin{array}{l}\text { Viscosity } \\
\text { (cp) }\end{array}$ \\
\hline 25 days & 1.37 & 556 & 419 & $5-11$ \\
\hline 40 days & 1.38 & 557 & 430 & 5 \\
\hline 70 days & 1.30 & 457 & 372 & -- \\
\hline 71 days & 1.29 & 439 & 356 & $\ldots$ \\
\hline
\end{tabular}

(a) Measured using a Brookfield ${ }^{\circledR}$ viscometer at room temperature.

(3) Brookfield Viscometer is manufactured by Brookfield Engineering Laboratories, Inc., Stoughton, Massachusetts. 
TABLE A.3. Simulated Slurry Used During ADS Pump Test $\# 5$ (using the modified ADS pump)

\begin{tabular}{|c|c|}
\hline Compound & $(\mathrm{g} / \mathrm{L})$ \\
\hline $\mathrm{Fe}(\mathrm{OH})_{3}$ & 63.4 \\
\hline $\mathrm{Al}(\mathrm{OH})_{3}$ & 27.0 \\
\hline $\mathrm{Na}_{2} \mathrm{SiO}_{3} \cdot 5 \mathrm{H}_{2} \mathrm{O}$ & 8.9 \\
\hline Didymium Carbonate & 7.0 \\
\hline $\mathrm{ZrO}\left(\mathrm{NO}_{3}\right)_{2} \cdot 2 \mathrm{H}_{2} \mathrm{O}$ & 6.8 \\
\hline $\mathrm{Cr}(\mathrm{OH})_{3}$ & 5.8 \\
\hline $\mathrm{NaOH}$ & 5.D \\
\hline $\mathrm{Na}_{2} \mathrm{MoO}_{4} \cdot 2 \mathrm{H}_{2} \mathrm{O}$ & 4.1 \\
\hline $\mathrm{Ni}(\mathrm{OH})_{2}$ & 2.4 \\
\hline $\mathrm{CsNO}_{3}$ & 2.4 \\
\hline $\mathrm{Ce}(\mathrm{OH})_{4}$ & 2.3 \\
\hline $\mathrm{Na}_{4}$ (EDTA) & 2.3 \\
\hline $\mathrm{MnCO}_{3}$ & 1.3 \\
\hline $\mathrm{CuSO}_{4}$ & 1.0 \\
\hline $\mathrm{SrCO}_{3}$ & 1.0 \\
\hline $\mathrm{BaCO}_{3}$ & 1.0 \\
\hline $\mathrm{Na}_{2} \mathrm{SO}_{4}$ & 0.9 \\
\hline $\mathrm{Mg}(\mathrm{OH})_{2}$ & 0.7 \\
\hline $\mathrm{CaCO}_{3}$ & 0.5 \\
\hline $\mathrm{SiO}_{2}(-325$ mesh $)$ & 201.0 \\
\hline $\mathrm{Ca}\left(\mathrm{NO}_{3}\right)_{2} \cdot 4 \mathrm{H}_{2} \mathrm{O}$ & 153.0 \\
\hline $\mathrm{NaNO}_{3}$ & 123.0 \\
\hline $\mathrm{LiNO}_{3}$ & 69.0 \\
\hline $\mathrm{Mg}\left(\mathrm{NO}_{3}\right)_{2} \cdot 6 \mathrm{H}_{2} \mathrm{O}$ & 18.0 \\
\hline TOTAL & $707.8 \mathrm{~g} / \mathrm{L}$ \\
\hline
\end{tabular}


TABLE A.4. Physical Properties for Slurry. Used During ADS Pump Test \#5 (using the modified ADS pump)

\begin{tabular}{|c|c|c|c|c|}
\hline $\begin{array}{l}\text { Cumulative } \\
\text { Days of } \\
\text { Testing } \\
\end{array}$ & $\begin{array}{l}\text { Density } \\
(\mathrm{kg} / \mathrm{L}) \\
\end{array}$ & $\begin{array}{l}\text { Total } \\
\text { Solids } \\
\text { Content } \\
(\mathrm{g} / \mathrm{L}) \\
\end{array}$ & $\begin{array}{c}\text { Total } \\
\text { Dxide } \\
\text { Content } \\
(\mathrm{g} / \mathrm{L}) \\
\end{array}$ & $\begin{array}{l}\text { Viscosity(a) } \\
\text { (Poise) }\end{array}$ \\
\hline 8 & 1.44 & 649 & 391 & 1.4 \\
\hline 18 & 1.40 & 625 & 380 & 1.1 \\
\hline 22 & 1.35 & 606 & 393 & 1.09 \\
\hline $33^{(b)}$ & 1.41 & (c) & 388 & (c) \\
\hline 43 & 1.43 & 662 & 402 & 1.37 \\
\hline 50 & 1.43 & 665 & 408 & 1.89 \\
\hline 57 & 1.44 & 671 & 403 & 2.00 \\
\hline
\end{tabular}

(a) Measured using Brookfield ${ }^{\text {(a) }}$ viscometer.

(b) New batch of slurry added.

(c) Not measured. 
TABLE A.5. Simulated Slurry Used During AOS Pump Test $\# 2$

\begin{tabular}{|c|c|}
\hline Compound & $\begin{array}{c}\text { Concentration } \\
(\mathrm{g} / \mathrm{L})\end{array}$ \\
\hline $\mathrm{HNO}_{3}(\mathrm{a})$ & 66.86 \\
\hline $\mathrm{Cr}\left(\mathrm{NO}_{3}\right)_{3} \cdot 9 \mathrm{H}_{2} \mathrm{O}$ & 7.98 \\
\hline $\mathrm{Al}\left(\mathrm{NO}_{3}\right)_{3} \cdot 9 \mathrm{H}_{2} \mathrm{O}$ & 388.04 \\
\hline $\mathrm{Fe}\left(\mathrm{NO}_{3}\right)_{3} \cdot 9 \mathrm{H}_{2} \mathrm{O}$ & 35.81 \\
\hline $\mathrm{Ni}\left(\mathrm{NO}_{3}\right)_{2} \cdot 6 \mathrm{H}_{2} \mathrm{O}$ & 2.63 \\
\hline $\mathrm{Cu}\left(\mathrm{NO}_{3}\right)_{3} \cdot 3 \mathrm{H}_{2} \mathrm{O}$ & 0.46 \\
\hline $\mathrm{Mg}\left(\mathrm{NO}_{3}\right)_{2} \cdot 6 \mathrm{H}_{2} \mathrm{O}$ & 15.70 \\
\hline $\mathrm{ZrO}\left(\mathrm{NO}_{3}\right)_{2} \cdot 2 \mathrm{H}_{2} \mathrm{O}$ & 1.98 \\
\hline $\mathrm{NaNO}_{3}$ & 67.16 \\
\hline $\mathrm{Mn}\left(\mathrm{NO}_{3}\right)_{2} \cdot 4 \mathrm{H}_{2} \mathrm{O}$ & 0.45 \\
\hline $\mathrm{Na}_{2} \mathrm{Si}_{3} \cdot 5 \mathrm{H}_{2} \mathrm{O}$ & 1.93 \\
\hline $\mathrm{Sr}\left(\mathrm{NO}_{3}\right)_{2}$ & 0.41 \\
\hline $\mathrm{Ba}\left(\mathrm{NO}_{3}\right)_{2}$ & 0.35 \\
\hline $\mathrm{Ca}\left(\mathrm{NO}_{3}\right)_{2} \cdot 4 \mathrm{H}_{2} \mathrm{O}$ & 0.35 \\
\hline $\mathrm{CsNO}_{3}$ & 0.60 \\
\hline $\mathrm{RuO}_{2}$ & 0.10 \\
\hline $\mathrm{RE}\left(\mathrm{NO}_{3}\right)_{3}(\mathrm{~b})$ & 4.15 \\
\hline $\mathrm{Na}_{2} \mathrm{MoO}_{4} \cdot 2 \mathrm{H}_{2} \mathrm{O}$ & 1.18 \\
\hline $\mathrm{SiO}_{2}(\mathrm{c})$ & 138.90 \\
\hline $\mathrm{Na}_{2} \mathrm{~B}_{4} \mathrm{O}_{7}$ & 48.99 \\
\hline $\mathrm{LiNO}_{3}$ & 77.52 \\
\hline TOTAL & $861.55 \mathrm{~g} / \mathrm{L}$ \\
\hline
\end{tabular}

(a) Nitric acid concentration to be 1 Molar.

(b) Rare earth nitrate mix, nominal oxide composition in percent:

$$
\begin{array}{ll}
\mathrm{CeO}_{2}-48 & \mathrm{Sm}_{2} \mathrm{O}_{3}-3 \\
\mathrm{La}_{2} \mathrm{O}_{3}-24 & \mathrm{Gd}_{2} \mathrm{O}_{3}-2 \\
\mathrm{Nd}_{2} \mathrm{O}_{3}-17 & \mathrm{Y}_{2} \mathrm{O}_{3}-0.2 \\
\mathrm{Pr}_{6} \mathrm{O}_{11}-5 & \text { Misc. }-0.8
\end{array}
$$

(c) Silica added as 83 wt\% sodiumstabilized, colloidal silica and $17 \%$ ground $(-325$ mesh) silica. 
TABLE A.6. Physical Properties of Slurry Used During ADS Pump Test \#2

\begin{tabular}{|c|c|c|c|}
\hline $\begin{array}{c}\text { Sample } \\
\text { Number of } \\
\text { Days Testing }\end{array}$ & $\begin{array}{l}\text { Density } \\
(\mathrm{g} / \mathrm{ml}) \\
\end{array}$ & $\begin{array}{c}\text { Total } \\
\text { Oxide } \\
\text { Content } \\
(\mathrm{g} / \mathrm{L}) \\
\end{array}$ & $\begin{array}{c}\text { Viscosity } \\
(\mathrm{cp}) \\
\end{array}$ \\
\hline 2 & 1.44 & 269 & 38 \\
\hline 15 & 1.47 & 289 & 33 \\
\hline 22 & 1.48 & 294 & 29 \\
\hline 28 & 1.51 & 350 & 35 \\
\hline 58 & 1.32 & 220 & 9 \\
\hline 66 & 1.35 & 230 & 14 \\
\hline
\end{tabular}

(a) Measured using Brookfield ${ }^{(1)}$ viscometer. 
TABLE A.7. Simulated Siurry Used During ADS Pump Test $\# 3$

\begin{tabular}{|c|c|}
\hline Compound & $\begin{array}{c}\text { Concentration } \\
(g / L)\end{array}$ \\
\hline $\mathrm{Fe}\left(\mathrm{NO}_{3}\right)_{3} \cdot 9 \mathrm{H}_{2} \mathrm{O}$ & 235.19 \\
\hline $\mathrm{NaNO}_{3}$ & 89.95 \\
\hline $\mathrm{HNO}_{3}(\mathrm{a})$ & 126.00 \\
\hline $\mathrm{ZrO}\left(\mathrm{NO}_{3}\right)_{2} \cdot 2 \mathrm{H}_{2} \mathrm{O}$ & 16.26 \\
\hline $\mathrm{Na}_{3} \mathrm{PO}_{4} \cdot 12 \mathrm{H}_{2} \mathrm{O}$ & 0.70 \\
\hline $\mathrm{H}_{3} \mathrm{PO}_{4}$ & 14.17 \\
\hline $\mathrm{Cr}\left(\mathrm{NO}_{3}\right)_{3} \cdot 9 \mathrm{H}_{2} \mathrm{O}$ & 14.94 \\
\hline $\mathrm{Nd}\left(\mathrm{NO}_{3}\right)_{3} \cdot 6 \mathrm{H}_{2} \mathrm{O}$ & 3.65 \\
\hline $\mathrm{Al}\left(\mathrm{NO}_{3}\right)_{3} \cdot 9 \mathrm{H}_{2} \mathrm{O}$ & 16.18 \\
\hline $\mathrm{Mn}\left(\mathrm{NO}_{3}\right)_{2} \cdot 4 \mathrm{H}_{2} \mathrm{O}$ & 6.35 \\
\hline $\mathrm{Ni}\left(\mathrm{NO}_{3}\right)_{2} \cdot 6 \mathrm{H}_{2} \mathrm{O}$ & 7.01 \\
\hline $\mathrm{Na}_{2} \mathrm{SO}_{4}$ & 6.20 \\
\hline $\mathrm{KNO}_{3}$ & 3.65 \\
\hline $\mathrm{CsNO}_{3}$ & 0.55 \\
\hline $\mathrm{RuO}_{2}$ & 0.16 \\
\hline $\mathrm{Sr}\left(\mathrm{NO}_{3}\right)_{2}$ & 0.27 \\
\hline $\mathrm{RE}\left(\mathrm{NO}_{3}\right)_{3}(\mathrm{~b})$ & 2.36 \\
\hline $\mathrm{Na}_{2} \mathrm{MoO}_{4} \cdot 2 \mathrm{H}_{2} \mathrm{O}$ & 0.12 \\
\hline $\mathrm{SiO}_{2}(-325$ mesh $)$ & 147.65 \\
\hline $\mathrm{Na}_{2} \mathrm{SiO}_{3} \cdot 5 \mathrm{H}_{2} \mathrm{O}$ & 2.29 \\
\hline $\mathrm{Na}_{2} \mathrm{~B}_{4} \mathrm{O}_{7}$ & 43.93 \\
\hline $\mathrm{LiNO}_{3}$ & 54.91 \\
\hline $\mathrm{Mg}\left(\mathrm{NO}_{3}\right)_{2} \cdot 6 \mathrm{H}_{2} \mathrm{O}$ & 27.35 \\
\hline $\mathrm{ZrO}\left(\mathrm{NO}_{3}\right)_{2} \cdot 6 \mathrm{H}_{2} \mathrm{O}$ & 2.17 \\
\hline $\mathrm{La}\left(\mathrm{NO}_{3}\right)_{3} \cdot 6 \mathrm{H}_{2} \mathrm{O}$ & 2.66 \\
\hline $\mathrm{TiO}_{2}$ & 2.00 \\
\hline TOTAL & $826.67 \mathrm{~g} / \mathrm{L}$ \\
\hline
\end{tabular}

(a) Nitric acid concentration to be 2 Molar.

(b) Rare earth nitrate mix, nominal oxide composition:

$$
\begin{array}{ll}
\mathrm{Ce}_{2}-48 \% & \mathrm{Sm}_{2} \mathrm{O}_{3}-3 \% \\
\mathrm{La}_{2} \mathrm{O}_{3}-24 \% & \mathrm{Gd}_{2} \mathrm{O}_{3}-2 \% \\
\mathrm{Nd}_{2} \mathrm{O}_{3}-17 \% & \mathrm{Y}_{2} \mathrm{O}_{3}-0.2 \% \\
\mathrm{Pr}_{6} \mathrm{O}_{11}-5 \% & \text { Misc. }-0.8 \%
\end{array}
$$


TABLE A.8. Simulated Slurry Used During ADS Pump Test \#4 and Air-Lift Test $\# 13$ (using the modified air-lift design)

\begin{tabular}{|c|c|}
\hline Compound & $(g / L)$ \\
\hline $\mathrm{Fe}\left(\mathrm{NO}_{3}\right)_{3} \cdot 9 \mathrm{H}_{2} \mathrm{O}$ & 157.0 \\
\hline $\mathrm{NaNO}_{3}$ & 8.9 \\
\hline Al $\left(\mathrm{NO}_{3}\right)_{3} \cdot 9 \mathrm{H}_{2} \mathrm{O}$ & 15.2 \\
\hline $\mathrm{Cr}\left(\mathrm{NO}_{3}\right)_{3} \cdot 9 \mathrm{H}_{2} \mathrm{O}$ & 13.1 \\
\hline $\mathrm{Ni}\left(\mathrm{NO}_{3}\right)_{2} \cdot 6 \mathrm{H}_{2} \mathrm{O}$ & 8.2 \\
\hline Didymium Carbonate & 5.6 \\
\hline $\mathrm{Nd}\left(\mathrm{NO}_{3}\right)_{2} \cdot 9 \mathrm{H}_{2} \mathrm{O}$ & 37.4 \\
\hline $\mathrm{KNO}_{3}$ & 0.6 \\
\hline $\mathrm{Mn}\left(\mathrm{NO}_{3}\right)_{2} \cdot 4 \mathrm{H}_{2} \mathrm{O}$ & 4.8 \\
\hline $\mathrm{ZrO}\left(\mathrm{NO}_{3}\right)_{2} \cdot 2 \mathrm{H}_{2} \mathrm{O}$ & 5.0 \\
\hline $\mathrm{NaCl}$ & 0.3 \\
\hline $\mathrm{Ba}\left(\mathrm{NO}_{3}\right)_{2}$ & 0.3 \\
\hline $\mathrm{FePO}_{4} \cdot 2 \mathrm{H}_{2} \mathrm{O}$ & 23.9 \\
\hline $\mathrm{Na}_{2} \mathrm{SO}_{4}$ & 4.9 \\
\hline $\mathrm{HNO}_{3}$ & 100.8 \\
\hline \multicolumn{2}{|l|}{ Zeolite (IE-95): } \\
\hline $\mathrm{SiO}_{2}$ & 46.9 \\
\hline $\mathrm{Al}_{2} \mathrm{O}_{3}$ & 12.6 \\
\hline $\mathrm{Na}_{2} \mathrm{O}$ & 2.6 \\
\hline $\mathrm{Fe}_{2} \mathrm{O}_{3}$ & 2.9 \\
\hline $\mathrm{CaO}$ & 2.9 \\
\hline Others & 2.0 \\
\hline $\mathrm{H}_{2} \mathrm{O}$ & 8.6 \\
\hline $\mathrm{SiO}_{2}(-325$ mesh $)$ & 103.7 \\
\hline $\mathrm{Na}_{2} \mathrm{~B}_{4} \mathrm{O}_{7} \cdot 10 \mathrm{H}_{2} \mathrm{O}$ & 127.7 \\
\hline $\mathrm{Ca}\left(\mathrm{NO}_{3}\right)_{2}$ & 20.9 \\
\hline $\mathrm{NaNO}_{3}$ & 69.7 \\
\hline TOTAL & $786.5 \mathrm{~g} / \mathrm{L}$ \\
\hline
\end{tabular}


TABLE A.9. Physical Properties of Slurry Used During ADS Pump Test \#4 and Air-Lift Test $\$ 13$ (using the modified air-lift design)

\begin{tabular}{|c|c|c|c|c|}
\hline $\begin{array}{l}\text { Cumulative } \\
\text { Days of } \\
\text { Testing } \\
\end{array}$ & $\begin{array}{l}\text { Density } \\
(\mathrm{kg} / \mathrm{L})\end{array}$ & $\begin{array}{l}\text { Total } \\
\text { Solids } \\
\text { Content } \\
(\mathrm{g} / \mathrm{L})\end{array}$ & $\begin{array}{c}\text { Total } \\
\text { Oxide } \\
\text { Content } \\
(\mathrm{g} / \mathrm{L}) \\
\end{array}$ & $\begin{array}{c}\text { Viscosity } \\
\text { (Poise) } \\
\end{array}$ \\
\hline 4 & (a) & (a) & (a) & $0.10^{(b)}$ \\
\hline 8 & 1.33 & 483 & 325 & (a) \\
\hline 15 & 1.34 & 467 & 311 & (a) \\
\hline 23 & (a) & (a) & (a) & $0.12^{(b)}$ \\
\hline 23 & 1.38 & 495 & 330 & (a) \\
\hline 29 & 1.37 & 486 & 301 & $0.19^{(b)}$ \\
\hline 36 & 1.37 & 526 & 344 & (a) \\
\hline 43 & 1.43 & 558 & 358 & (a) \\
\hline 43 & (a) & (a) & (a) & $0.15^{\text {(b) }}$ \\
\hline
\end{tabular}

(a) Not measured.

(b) Measured using a Brookfield ${ }^{\circledR}$ viscometer. 
TABLE A.10. Slurry Composition Used During Air-Lift Pump Tests \#1-8

\begin{tabular}{|c|c|}
\hline Compound & $\begin{array}{c}\text { Concentration } \\
(\mathrm{g} / \mathrm{L})\end{array}$ \\
\hline $\mathrm{Fe}(\mathrm{OH})_{3}$ & 73.7 \\
\hline $\mathrm{FePO}_{4} \cdot 2 \mathrm{H}_{2} \mathrm{O}$ & 48.7 \\
\hline $\operatorname{RE}\left(\mathrm{NO}_{3}\right)_{3}{ }^{(\mathrm{a})}$ & 50.8 \\
\hline $\mathrm{NaNO}_{3}$ & 27.5 \\
\hline $\mathrm{Cr}(\mathrm{OH})_{3}$ & 7.10 \\
\hline $\mathrm{MnCO}_{3}$ & 4.16 \\
\hline $\mathrm{Sr}\left(\mathrm{NO}_{3}\right)_{2}$ & 2.06 \\
\hline $\mathrm{CsNO}_{3}$ & 1.44 \\
\hline $\mathrm{Zr}\left(\mathrm{NO}_{3}\right)_{4}$ & 3.7 \\
\hline $\mathrm{Ni}(\mathrm{OH})_{2}$ & 2.93 \\
\hline A] $(\mathrm{OH})_{3}$ & 3.0 \\
\hline $\mathrm{Na}_{2} \mathrm{MoO}_{4} \cdot 2 \mathrm{H}_{2} \mathrm{O}$ & 2.52 \\
\hline $\mathrm{KNO}_{3}$ & 0.50 \\
\hline $\mathrm{Na}_{2} \mathrm{SO}_{4}$ & 3.0 \\
\hline $\mathrm{SiO}_{2}$ & 214.0 \\
\hline $\mathrm{Na}_{2} \mathrm{~B}_{4} \mathrm{O}_{7}$ & 62.1 \\
\hline $\mathrm{NaOH}$ & 42.1 \\
\hline $\mathrm{MgO}$ & 5.75 \\
\hline $\mathrm{TiO}_{2}$ & 2.9 \\
\hline $\mathrm{Zr}\left(\mathrm{NO}_{3}\right)_{4}$ & 4.1 \\
\hline $\mathrm{LiOH}$ & 26.7 \\
\hline TOTAL & 588.8 \\
\hline
\end{tabular}

(a) Rare earth nitrate mix (0.386 g oxide/g nitrate mix), nominal oxide composition:

$$
\begin{aligned}
& \mathrm{CeO}_{2}-48 \% \\
& \mathrm{Pr}_{6} \mathrm{O}_{11}-5 \% \\
& \mathrm{P}_{2} \mathrm{O}_{3}-0.2 \% \\
& \mathrm{La}_{2} \mathrm{O}_{3}-24 \% \\
& \mathrm{Sm}_{2} \mathrm{O}_{3}-3 \% \\
& \mathrm{Nd}_{2} \mathrm{O}_{3}-17 \% \\
& \mathrm{Gd}_{2} \mathrm{O}_{3}-2 \% \\
& \mathrm{Misc}-0.8 \%
\end{aligned}
$$


TABLE A.11. Slurry Composition Used During Air-Lift Pump Test \#9

\begin{tabular}{|c|c|}
\hline Compound & $\begin{array}{l}\text { Concentration } \\
(\mathrm{g} / \mathrm{L})\end{array}$ \\
\hline $\mathrm{Fe}(\mathrm{OH})_{3}$ & 73.7 \\
\hline $\mathrm{FePO}_{4} \cdot 2 \mathrm{H}_{2} \mathrm{O}$ & 48.7 \\
\hline $\mathrm{Nd}\left(\mathrm{NO}_{3}\right)_{3} \cdot 6 \mathrm{H}_{2} \mathrm{O}$ & 15.45 \\
\hline $\mathrm{Ce}\left(\mathrm{NO}_{3}\right)_{3} \cdot 6 \mathrm{H}_{2} \mathrm{O}$ & 40.73 \\
\hline $\mathrm{NaNO}_{3}$ & 27.5 \\
\hline $\mathrm{Cr}(\mathrm{OH})_{3}$ & 7.10 \\
\hline $\mathrm{MnCO}_{3}$ & 4.16 \\
\hline $\mathrm{Sr}\left(\mathrm{NO}_{3}\right)_{2}$ & 2.06 \\
\hline $\mathrm{CsNO}_{3}$ & 1.44 \\
\hline $\mathrm{Zr}\left(\mathrm{NO}_{3}\right)_{4}$ & 3.70 \\
\hline $\mathrm{Ni}(\mathrm{OH})_{2}$ & 2.93 \\
\hline $\mathrm{Al}(\mathrm{OH})_{3}$ & 3.00 \\
\hline $\mathrm{Na}_{2} \mathrm{MoO}_{4} \cdot 2 \mathrm{H}_{2} \mathrm{O}$ & 2.52 \\
\hline $\mathrm{KNO}_{3}$ & 0.50 \\
\hline $\mathrm{Na}_{2} \mathrm{SO}_{4}$ & 7.30 \\
\hline $\mathrm{SiO}_{2}$ & 214.0 \\
\hline $\mathrm{Na}_{2} \mathrm{~B}_{4} \mathrm{O}_{7}$ & 62.1 \\
\hline $\mathrm{NaOH}$ & 42.1 \\
\hline $\mathrm{LiOH}$ & 26.7 \\
\hline $\mathrm{Mg}(\mathrm{OH})_{2}$ & 8.2 \\
\hline $\mathrm{Zr}\left(\mathrm{NO}_{3}\right)_{4}$ & 4.1 \\
\hline $\mathrm{TiO}_{2}$ & 2.9 \\
\hline $\mathrm{La}_{2} \mathrm{O}_{3}$ & 1.5 \\
\hline TOTAL & $602 \mathrm{~g} / \mathrm{L}$ \\
\hline
\end{tabular}


TABLE A.12. Simulated Slurry Used During Air-Lift Pump Test \#10

\begin{tabular}{|c|c|}
\hline Compound & $(g / L)$ \\
\hline $\mathrm{Fe}\left(\mathrm{NO}_{3}\right)_{3} \cdot 9 \mathrm{H}_{2} \mathrm{O}$ & 235.19 \\
\hline $\mathrm{NaNO}_{3}$ & 89.95 \\
\hline $\mathrm{HNO}_{3}$ & 126.00 \\
\hline $\mathrm{ZrO}\left(\mathrm{NO}_{3}\right)_{2} \cdot 2 \mathrm{H}_{2} \mathrm{O}$ & 16.26 \\
\hline $\mathrm{Na}_{3} \mathrm{PO}_{4} \cdot 12 \mathrm{H}_{2} \mathrm{O}$ & 0.70 \\
\hline $\mathrm{H}_{3} \mathrm{PO}_{4}$ & 14.17 \\
\hline $\mathrm{Cr}\left(\mathrm{NO}_{3}\right)_{3} \cdot 9 \mathrm{H}_{2} \mathrm{O}$ & 14.94 \\
\hline $\mathrm{Nd}\left(\mathrm{NO}_{3}\right)_{3} \cdot 6 \mathrm{H}_{2} \mathrm{O}$ & 3.65 \\
\hline $\mathrm{Al}\left(\mathrm{NO}_{3}\right)_{3} \cdot 9 \mathrm{H}_{2} \mathrm{O}$ & 16.18 \\
\hline $\mathrm{Mn}\left(\mathrm{NO}_{3}\right)_{2} \cdot 4 \mathrm{H}_{2} \mathrm{O}$ & 6.35 \\
\hline $\mathrm{Ni}\left(\mathrm{NO}_{3}\right)_{2} \cdot 6 \mathrm{H}_{2} \mathrm{O}$ & 7.01 \\
\hline $\mathrm{Na}_{2} \mathrm{SO}_{4}$ & 6.20 \\
\hline $\mathrm{KNO}_{3}$ & 3.65 \\
\hline $\mathrm{CsNO}_{3}$ & 0.55 \\
\hline $\mathrm{Ru}_{2}$ & 0.16 \\
\hline $\mathrm{Sr}\left(\mathrm{NO}_{3}\right)_{2}$ & 0.27 \\
\hline $\mathrm{RE}\left(\mathrm{NO}_{3}\right)_{3}(\mathrm{a})$ & 2.36 \\
\hline $\mathrm{Na}_{2} \mathrm{MoO}_{4} \cdot 2 \mathrm{H}_{2} \mathrm{O}$ & 0.12 \\
\hline $\mathrm{SiO}_{2}(-325$ mesh $)$ & 147.65 \\
\hline $\mathrm{Na}_{2} \mathrm{SiO}_{3} \cdot 5 \mathrm{H}_{2} \mathrm{O}$ & 2.29 \\
\hline $\mathrm{Na}_{2} \mathrm{~B}_{4} \mathrm{O}_{7}$ & 43.93 \\
\hline $\mathrm{LiNO}_{3}$ & 54.91 \\
\hline $\mathrm{Mg}\left(\mathrm{NO}_{3}\right)_{2} \cdot 6 \mathrm{H}_{2} \mathrm{O}$ & 27.35 \\
\hline $\mathrm{ZrO}\left(\mathrm{NO}_{3}\right)_{2} \cdot 6 \mathrm{H}_{2} \mathrm{O}$ & 2.17 \\
\hline $\mathrm{La}\left(\mathrm{NO}_{3}\right)_{3} \cdot 6 \mathrm{H}_{2} \mathrm{O}$ & 2.66 \\
\hline $\mathrm{TiO}_{2}$ & 2.00 \\
\hline TOTAL & $826.67 \mathrm{~g} / \mathrm{L}$ \\
\hline
\end{tabular}

(a) Rare earth nitrate mix, nominal oxide composition:

$$
\begin{array}{ll}
\mathrm{CeO}_{2}-48 \% & \mathrm{Sm}_{2} \mathrm{O}_{3}-3 \% \\
\mathrm{La}_{2} \mathrm{O}_{3}-24 \% & \mathrm{Gd}_{2} \mathrm{O}_{3}-2 \% \\
\mathrm{Nd}_{2} \mathrm{O}_{3}-17 \% & \mathrm{Y}_{2} \mathrm{O}_{3}-0.2 \% \\
\mathrm{Pr}_{6} \mathrm{O}_{11}-5 \% & \text { Misc. }-0.8 \%
\end{array}
$$




\section{DISTRIBUTION}

No. of

Copies

OFFSITE

30 DOE Technical Information Center

R. D. Walton, Jr., DP-123

DOE Office of Defense Waste and Byproducts Management

GTN

Washington, D.C. 20545

J. A. Coleman, NE-25

DOE Office of Terminal Waste GTN

Disposal and Remedial Action

Washington, D.C. 20545

T. W. McIntosh, NE-25

DOE Office of Terminal Waste GTN

Disposal and Remedial Action

Washington, D.C. 20545

J. B. Zorn, NE-25

DOE Office of Terminal Waste

Disposal and Remedial Action GTN

Washington, D.C. 20545

W. H. Hannum

DOE West Valley Operations

Office

P.0. Box 191

West Valley, NY 14171

J. D. Hamric/J, B. Whitsett

DOE Idaho Operations Office

550 Second Street

Idaho Falls, ID 8340 I
No. of

Copies

R. Stein, RW-23

Engineering and Licensing Division

DOE Office of Civilian Radioactive Waste Management

Forrestal Building

Washington, D.C. 20585

L. Barrett, RW-33

Transportation and Waste

Systems Division

DOE Office of Civilian

Radioactive Waste Management

Forrestal Building

Washington, D.C. 20585

F. T. Fong

DDE San Francisco Operations

1333 Broadway

San Francisco, CA 94612

G. K. Oertel

DOE Savannah River Operations Office

P.0. Box A

Aiken, SC 29801

C. S. Abrams/J. H. Kittel

Argonne National Laboratory

9700 South Cass Avenue

Argonne, IL 60439

M. J. Steindler/L. E. Trevorrow Argonne National Laboratory 9700 South Cass Avenue.

Argonne, IL 60439

B. Rawles

Battelle Memorial Institute Project Management Division 505 King Avenue

Columbus, $\mathrm{OH} 43201$ 
No. of

Copies

F. Holzer

Lawrence Livermore National Laboratory

University of California

P.0. Box 808

Livermore, CA 94550

D. T. 0akley, MS 671

Los Alamos Scientific Laboratory

P.0. Box 1663

Los Alamos, NM 87544

T. H. Row/J. 0. Biomeke

Oak Ridge National Laboratory

P.0. Box X

Oak Ridge, TN 37830

H. F. Walter, NE-25

DOE Office of Terminal Waste Disposal and Remedial Action GTN

Washington, D.C. 20545

Technical Library

Sandia Laboratories

P.0. Box 5800

Albuquerque, NM 87185

B. R. Wheeler

Westinghouse Idaho Nuclear

Co., Inc.

P.0. Box 4000

Idaho Falls, ID 83401

M. D. Boersma

E. I. du Pont de Nemours Company

Savannah River Laboratory

Aiken, SC 29801

J. R. Glasscock

E. I. du Pont de Nemours Company

Savannah River Laboratory

Aiken, SC 29801
No, of

Copies

J. R. Knight

E. I. du Pont de Nemours Comoany

Savannah River Laboratory

Aiken, SC 29801

M. J. Plodinec

E. I. du Pont de Nemours Company

Savannah River Laboratory

Aiken, SC 29801

C. T. Randal 1

E. I. du Pont de Nemours Company

Savannah River Laboratory

Aiken, SC 29801

E. A. Jennrich

EG\&G Idaho

P.0. Box 1625

Idaho Falls, ID 83415

K. V. Gilbert/P. G. Hagen

Rockwell International

Rocky Flats Plant

P. 0 . Box 464

Golden, CO 80401

C. C. Chapman

West Valley Nuclear Services Company

P.0. Box 191

West Valley, NY 14171

J. C. Cwynar

West Valley Nuclear Services

Company

P.0. Box 191

West Valley, NY 14171

J. L. Knabenschuh

West Valley Nuclear Services

Company

P.0. Box 191

West Valley, NY 14171 
No. of

Copies

J. E. Krauss

West Valley Nuclear Services Company

P.0. Box 191

West Valley, NY 14171

J. M. Pope

West Valley Nuclear Services

Company

P.0. Box 191

West Valley, NY 14171

ONSITE

7 DOE Richland Operations Office

E. A. Bracken

G. J. Bracken

C. Collantes

M. J. Plahuta

M. W. Shupe

J. D. White

R. D. Izatt

6 Rockwell Hanford Operat ions

R. N. Gurley

J. M. Henderson

R. D. Prosser

K. R. Shah

J. L. Scott

File Copy

2 Westinghouse Hanford Company

R. E. Lerch

J. D. Watrous
No. of

Copies

42

C. R. Allen

H. T. Blair

W. F. Bonner

R. A. Brouns

H. C. Burkholder

J. R. Carrell

E. J. Eschbach

L. K. Holton

D. E. Knowlton

J. M. Latkovich

D. McCarthy

J. L. McElroy

A. H. McMakin

J. E. Mendel/M. D. Merz/

G. B. Mellinger

J. E. Minor

K. D. Muylstein

R. D. Nakoaka

J. M. Perez (5)

M. E. Peterson (10)

D. H. Siemens

J. L. Straalsund

R. L. Treat

Publishing Coordination (2)

Technical Information (5) 
4

, 